\title{
ADAPTING THE STRUCTURAL DESIGN ACTIONS STANDARD FOR THE SEISMIC DESIGN OF NEW INDUSTRIAL PLANT
}

\author{
G. H. Lindup ${ }^{1}$
}

\begin{abstract}
In the late 1970's it was recognised that the seismic provisions of then current NZS 4203:1976 did not readily apply to the types of structures normally used within the land based processing facilities of the "heavy industries" such as petrochemical and oil and gas processing plants impending under the "Think Big" regime.
\end{abstract}

Since the 1984 revision to NZS 4203, there have not been any publicly available New Zealand guidelines on how to interpret the earthquake provisions of the various versions of NZS 4203 (and now AS/NZS 1170) that would update the 1981 publication created by the Ministry of Works for the Ministry of Energy, "Seismic Design of Petrochemical Plants".

There are overseas publications that have considered the differences in the typical structural systems necessary to support the equipment and distributive systems needed to process industrial feedstock. How they behave seismically has been reviewed and recommendations made on the methods to be used to determine the design seismic actions. Such standards as ASCE 7 and FEMA 450 incorporate these in a specific manner relating to the design of industrial plant.

With the advent of new oil and gas processing plants in Taranaki, this paper takes the opportunity to review AS/NZS 1170 and adapt these overseas guidelines for the seismic design of new industrial plant in New Zealand. The background for these guidelines will be presented with examples of typical industrial structural systems and their seismic actions. This is with the aim of re-establishing a basis of seismic design for industrial plant within the framework of the new standards AS/NZS 1170.0 and NZS 1170.5 .

\footnotetext{
${ }^{1}$ Transfield Worley NZ Ltd, New Plymouth (Member)

glindup@transfieldworley.co.nz
} 


\section{WHY THE NEED TO ADAPT THE STRUCTURAL DESIGN ACTIONS STANDARD?}

New Zealand's past loadings standards and the new structural design actions standard, AS/NZS 1170, have been written with an emphasis on the requirements for new building and building-like structures (see Clause C1.1 of NZS 1170.5 Supp 1). They have been developed based on building orientated research and on the performance of buildings in service and during severe winds and earthquakes. With this focus on buildings, for those involved with the structural design of industrial plant in New Zealand, the use of loadings standards and the extent of the New Zealand Building Act's compliance requirements can become problematical as many of the structures involved do not resemble a building. Figure 1 shows a typical industrial plant item. Further examples have been included in Appendix A.

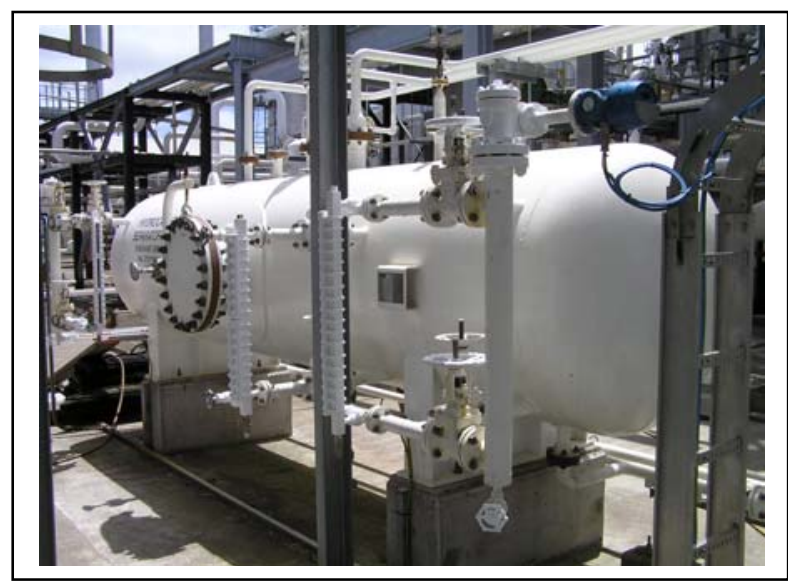

Figure 1. Horizontal pressure vessel on short pedestals

The structures within a typical industrial complex can have little redundancy in their structural load paths. There is little or no cladding, no internal partitions and few structural connections between members to produce the level of damping assumed to be present for buildings. They can be supporting equipment items weighing many times the weight of the support structure. The equipment may be pressure retaining and/or contain hazardous materials and thus their design is governed either by the Pressure Equipment, Cranes and Passenger Ropeways Regulations (PECPR) or the Hazardous Substances and New Organisms Act (HSNO). Hence there is an involvement by the industrial structural engineer in the affairs of mechanical engineers.

Pressure equipment is defined by the New Zealand Department of Labour's (DoL) Approved Code of Practice for Pressure Equipment (excluding boilers) (ACPPE) as including:

Compressors, fired heaters, gas turbines, hot water boilers, piping components, pressure fittings, pressure piping, pressure vessels, pumps, steam engines or steam turbines.

The standards used in the design of these items by mechanical engineers remain in the domain of working stress methods. The methodology of translating the ultimate earthquake base shear equations developed in the limit state based Loading Standard into an acceleration able to be used by a mechanical engineer for the design of their equipment or pressure piping has become uncertain as there is now no guidance given on this in the Loading Standard or its commentary. The New Zealand Building Code Clause B1 "Structures" Verification Method VM1 refers one to NZS 4203:1984 for items that are not designed by the limit state method. However, this reference has removed in the proposed changes to the Compliance Document for the New Zealand Building Code Clause B1 Structure released at the end of 2006.

The primary focus of the Standards NZS 4203:1992 and AS/NZS 1170 on buildings and their performance under wind and earthquake has lead, in the author's experience, to variance in the way the seismic aspects of these Standards are interpreted and applied to nonbuilding-like structures, pressure equipment and distributive systems typically found in industrial plant.

This paper is an attempt to integrate the recently completed set of Structural Design Actions standards setting out the minimum requirements for structural actions (AS/NZS 1170) with guidelines incorporated into overseas standards for the design of the nonbuilding-like structures commonly found in industrial and petrochemical plants.

\section{BACKGROUND}

The problems above and the need to get overseas structural and mechanical design engineers to be familiar with the 1976 version of NZS 4203 with its preference for strength design for the impending "Think Big" projects led to the commissioning by the Ministry of Energy and subsequent publishing in 1981 of the document "Seismic Design of Petrochemical Plants" (SDPP). NZS 4203 was subsequently revised in 1984 and in 1992 moving progressively to a limit state based approach to the design of new buildings. This has been continued with the newly published series of "Structural Design Actions" standards AS/NZS 1170 Parts 0, 1, 2 and 3 and NZS 1170.5 "Earthquake Actions - New Zealand".

Since 1981 there has been no New Zealand publication that has come to the author's attention that updates the "Seismic Design of Petrochemical Plants" with respect to the newer versions of NZS 4203 and now AS/NZS 1170. During the front end engineering and design (FEED) phase of recent oil and gas projects for Taranaki, the problems listed above were re-encountered. Time was taken to review how these and similar problems had been addressed by overseas standards and organisations.

The main source taken for the seismic design philosophy review was the guideline published by the American Society of Civil Engineers Task Committee on Seismic Evaluation and Design of Petrochemical Facilities. This 1997 publication, "Guidelines for Seismic Evaluation and Design of Petrochemical Plants" outlines specific seismic design approaches for the sorts of nonbuilding-like structures encountered in petrochemical plants. Although aimed at petrochemical plants, the philosophies are able to be used for other industrial plants that have nonbuilding-like structures. The ASCE guideline (1997) uses the Uniform Building Code (UBC) to illustrate the various aspects of the seismic design of structures that support equipment and the equipment themselves. 
The ASCE recommendations have been incorporated into other design codes commonly used for the design of industrial facilities in the United States of America such as ASCE 7-02 Section 9.14 "Nonbuilding Structures" and FEMA 450 Chapter 14 "Nonbuilding Structure Design Requirements".

In 2002, the American Lifelines Alliance (ALA) published their recommendations for the seismic design of new and seismic retrofitting of existing pressure piping. This included a proposed seismic design standard for the range of piping within the scope of the ASME B31 series of pressure piping codes. This document is an excellent reference document for the pipe stress design engineer involved in seismic design.

This paper takes the ASCE guidelines (1997), uses NZS 4203:1992, AS/NZS 1170.0, NZS 1170.5, FEMA 450, the ALA guidelines (2002) and relevant legislative requirements to develop design methods for the typical components of an industrial or petrochemical plant. Typical seismic coefficients have been determined in Appendix B to illustrate the design methods.

\section{RELEVANT LEGISLATION}

In general, all work on New Zealand soil for industrial plant is subject to the consents and approvals granted by the appropriate authority empowered under the following Acts/Regulations:

- $\quad$ Resource Management Act.

- New Zealand Building Code, a schedule to the Building Regulations made under the Building Act.

- $\quad$ Pressure Equipment, Cranes and Passenger Ropeways Regulations (PECPR) made under the Health and Safety in Employment (HSE) Act.

- Hazardous Substances and New Organisms (HSNO) Act.

The only exceptions to this will be where an item is exempt under the acts listed or an agreement to exempt an item from a jurisdiction has been obtained in the consents granted for the site.

Those items that come under the PECPR Regulations and the HSNO Act will also be subject to mechanical design considerations and the appropriate approvals and Design Verification. These requirements have been elaborated in approved code of practices (ACOP) or compliance guides written by either the Department of Labour for the HSE Act or the Environmental Risk Management Authority for the HSNO Act.

ACOPs are provided for in Section 20 of the HSE Act and are statements of preferred work practice and procedures and the use of their recommendations can be used as evidence of good practice. Thus they are similar to the Compliance Documents written by the Department of Building and Housing to provide guidance on how to comply with the New Zealand Building Code.

AS/NZS 1170 is not yet been included in any ACOPs or Verification Methods in the Building Code's Compliance
Documents. Hence its use until it has been, it can be used as an Alternative Compliance document to show compliance with the Building Code and the HSE Act.

\section{STRUCTURAL SYSTEMS}

\subsection{General}

Structures found in industrial and petrochemical facilities support the process, mechanical and electrical items that are located above ground. Hence, they are the primary means that ground shaking from an earthquake is introduced to these non-structural items. The way in which the structures respond to an earthquake then is the main influence on the level of shaking the non-structural items experience during a major earthquake. It is of benefit to now review how these structures can be classified and how this affects the analysis approach for earthquake actions as per the ASCE guidelines (1997).

\subsection{Building Code Provisions}

For the purposes of the NZ Building Code (NZBC), all structures are classified as being one of seven categories:

$\begin{array}{ll}\text { 1. } & \text { Housing } \\ \text { 2. } & \text { Communal Residential } \\ \text { 3. } & \text { Communal Non-residential } \\ \text { 4. } & \text { Commercial } \\ \text { 5. } & \text { Industrial } \\ \text { 6. } & \text { Outbuildings } \\ \text { 7. } & \text { Ancillary }\end{array}$

The first four categories will not typically be present within an industrial facility whereas within a plant's boundaries, all of the last three categories may be present. To avoid confusion, in this paper, any use of the words Industrial, Outbuilding or Ancillary with regard to the NZBC classification (items 5-7 in the above list) has been italicised.

\subsection{Types of Structures}

Industrial structures can be separated into two structural types:

1. Building structures.

2. Nonbuilding structures.

The "Nonbuilding structures" can be divided further into two sub-categories:

\subsection{Building-like structures.}

2.2 Nonbuilding-like structures.

Each structure should have its applicable NZBC category and structural type determined prior to detailed structural analysis being undertaken.

\subsection{Building Structures}

These are buildings that the NZBC and associated standards apply directly to without modification. Typically for industrial sites, these are administration buildings, buildings providing weather and/or hygienic protection to people who produce, repair or store goods, substations, maintenance buildings, shelters, compressor houses etc and normally are single storey structures. These structures will generally have a NZBC classification of either Industrial or Outbuilding and are not the subject of this paper. 


\subsection{Nonbuilding Structures}

Other than actual buildings, all structures within an industrial/petrochemical facility are typically nonbuilding structures. Some of these have structural systems that resemble those of buildings such as multi-storey modules or pipe racks. Hence, these types of structures are classified as building-like structures.

Other structures whose structural systems do not resemble buildings are classified as nonbuilding-like structures, for example circular storage tanks and horizontal pressure vessels.

These structures will generally have a NZBC classification of Ancillary. Photographs of some typical industrial nonbuilding structures have been included in Appendix A.

\subsubsection{Building-like Structures}

These are structures (generally unclad) that have Lateral Force Resisting Systems (LFRS) similar to those of buildings and their analysis can be undertaken as per Section 7. Examples of building-like structures found in typical industrial facilities include:

a) Multilevel moment resisting frames or braced frames supporting non-structural items such as stairs, ducts, hoppers and/or equipment such as heat exchangers, horizontal pressure vessels etc that individually weigh less than $20 \%$ of the structure's total weight.

b) Pipe racks with LFRS that are moment resisting frames (usually in the transverse direction) or braced frames (usually in the longitudinal direction).

c) Rectangular vertical furnaces or boilers.

\subsubsection{Nonbuilding-like Structures}

These structures can be subdivided into four subcategories:

1. Rigid structures with a natural period of vibration $T_{1}<$ 0.06 secs such as skids, pumps or compressors supported by ground slab foundations, or squat horizontal vessels supported on short stiff piers. A design seismic coefficient can be determined from Section 7.4 assuming system damping has little effect and a structural ductility factor $\mu=1.0$ or 1.25 depending on whether any limited ductility can be utilised.

2. Flat-bottomed tanks. These respond to earthquakes in an unique manner, refer to the NZSEE document "Seismic Design of Storage Tanks" (1986) and Whittaker and Jury (2000) for appropriate seismic analysis methods.

3. Combination structures. These support non-structural items (such as process related equipment or piping) whose weight exceeds $20 \%$ of the supporting structure's weight. Examples would include large horizontal pressure vessels, heat exchangers or fin-fan coolers supported above grade on a braced or moment resisting frames. The analysis method depends on whether the non-structural element is rigid or flexible. The supporting structure generally being building-like. Appropriate analysis methods are discussed below in Section 8. Example 3 in Appendix B illustrates one of the proposed design methods for these structures.

4. Others. Examples include skirt supported vertical vessels, spheres, guyed structures and vertical fired heaters supported on braced legs. These are generally either slender or vertically irregular and require a modal response spectrum analysis as discussed below in Section 7.5. Example 1 in Appendix B illustrates the proposed equivalent static analysis design method for a vertical skirt supported pressure vessel.

Self-supporting equipment items or rigid body structures at grade generally make up the majority of nonbuilding-like structures in an industrial plant. Example 4 in Appendix B illustrates the proposed design method for these structures.

\subsection{Parts and Components}

When a non-structural item's combined weight is less than $20 \%$ of the total weight of the structure, it shall be considered as a part or as a component (a sub-system in the ASCE terminology). The seismic forces shall be determined using Section 8 of NZS 1170.5 "Requirements for Parts and Components".

Examples of non-structural items classed as either a part or a component typically found in an industrial facility include:

a) Components such as pressure equipment; e.g. horizontal vessels, exchangers, piping, mechanical, electrical and other items; e.g. tubing, cable tray/ladders, lights, conduit, instruments, low pressure pumps and ductwork.

b) Parts such as access platforms and ladders.

Examples 2 and 5 in Appendix B illustrate the proposed design method for these structures. Example 2 covers the case where pressure piping is supported at elevations significantly above grade whereas Example 5 covers pressure piping supported sufficiently above grade to allow personnel access beneath the piping.

\section{APPLICABLE DESIGN STANDARDS}

Industrial structures are generally constructed using the same materials used elsewhere in the New Zealand construction industry and consequently the appropriate materials standards are used. There are other publications also used that assist in interpreting legislation or outline design methods for special structures e.g. storage tanks and those structures specifically excluded by AS/NZS 1170.5. These include but are not limited to the following:

1. AS/NZS 1170, Structural Design Actions.

2. NZS 3404, Steel Structures Standard.

3. NZS 3101, Concrete Structures Standard.

4. NZS 4230, Design of Reinforced Concrete Masonry Structures.

5. AS/NZS 4600, Cold-formed Steel Structures.

6. NZSEE Seismic Design of Storage Tanks.

7. API 650, Welded Storage Tanks for Oil Storage.

8. ASME Boiler and Pressure Vessel Code.

9. NZS PD 5500, Specification for Unfired Fusion Welded Pressure Vessels.

10. ASME B31.3, Code for Chemical Plant and Petroleum Refinery Piping.

11. ASME STS-1, Steel Stacks.

12. DoL Approved Code of Practice for Pressure Equipment (Excluding Boilers) (ACPPE).

13. AS/NZS 1200, Pressure Equipment.

14. AS 4343, Pressure Equipment - Hazard Levels. 
15. DoL Approved Code of Practice for the Design, Safe Operation, Maintenance and Servicing of Boilers.

16. NZS 4203:1992, General Structural Design and Design Loadings for Buildings.

A matrix of these documents for different structures within industrial facilities is given in Table 1.

\section{SEISMIC DESIGN PHILOSOPHY}

\subsection{General}

There are a number of issues to be considered prior to undertaking the detail design of industrial plant that are worth reviewing. Some of these relate in particular to the use of the set of AS/NZS 1170 standards and others to the observed and recorded behaviour of industrial structures and components during earthquakes.

\subsection{Design Life, Design Working Life, Durability Life or Intended Life?}

A project's Basis of Design document is the usual document that specifies the process design life for an industrial facility. That is the most probable time period for which the feedstock, be it natural gas, geothermal energy or forestry etc, will be available. For most petrochemical facilities this is typically taken as 25 years but it can be less as was the case for some small gas fields recently developed in Taranaki. For other facilities, the plant may be intended to be operated to some unknown long term date in the future.

\subsubsection{AS/NZS 1170.0 Requirements}

AS/NZS 1170.0 requires a Design Working Life (DWL) to be determined which is used to select the probability of exceedance of different actions such as wind, snow and earthquake. The definition given in AS/NZS 1170.0 for the DWL is:

Duration of the period during which a structure or structural element, when designed, is assumed to perform for its intended purpose with expected maintenance but without major structural repair being necessary.

\subsubsection{Building Act Requirements}

The owner or their agent has to obtain building consents from the appropriate territorial authority for non-exempt structures coming under the Building Act and the intended life of these is required to be nominated in the application for any building consent. For the purposes of compliance with the Building Act and the NZ Building Code, a structure is deemed to have an "indefinite life". However, if a structure is intended to have a use of less than 50 years, a specified intended life may be nominated in the application for its building consent.

At the end of a specified intended life, the territorial authority must be told by the owners at that time whether they propose to demolish, extend the life of the structure or change its use. Upgrading or refurbishment may be required if the structure is not to be demolished. So specifying a limited life may lead to a condition being attached to the building consent requiring alteration, removal or demolition at the end of the specified life. Consequently some plant owners do not want to have this limiting the use of their plant after the specified life would end and require the wind and earthquake forces to be determined using a DWL $=50$ years. Others consider this to be unwarranted pre-investment and require the minimum values to be used.

The durability requirements of the New Zealand Building Code set out minimum durability lives for all items making up a structure. For the primary systems that provide structural stability to the structure, the durability life must equal either the specified intended life (if this option is used) or 50 years. This is also applicable for non-structural components of a structure difficult to replace or whose failure would go undetected in both normal use and maintenance. Hence most new buildings would be designed having an AS/NZS 1170.0 DWL of 50 years.

Components moderately difficult to replace or whose failure would go undetected in normal use but be detected during normal maintenance must have a minimum durability life of 15 years. Those non-structural components of a structure easily replaced and whose failure would be detected in normal use must have a durability life of 5 years.

These non-structural components and secondary structural items are not normally designed using wind; earthquake or snow actions determined using a DWL equal to their durability lives of either 5 or 15 years. The DWL for their design actions is normally the same as that for the primary structure and that is set out in the building consent application as the intended life. Whether this is historical, a statutory requirement, a design office assumption that it is a statutory requirement or a decision to reduce the design effort is not certain; "it is the way it has always been done".

\subsubsection{HSE Act Requirements - Pressure Equipment}

Section 2.4.3 (3)(b) of DoL's ACPPE states that designers of new pressure equipment or alterations to existing pressure equipment shall state in the equipment's design documents the hazard level and the design life. The design life is to be also specified in the operating and maintenance instructions provided with the equipment to the owner.

Mechanical items that come under PECPR undergo regular inspections and their fitness for service is appraised. If fatigue, erosion or corrosion has occurred that reduces the capacity of the pressure containing envelope, the part is replaced or the item is down-rated to suit its new capacity. There is no requirement in the ACPPE for the mechanical design life to be equated with either the intended life, the DWL of the supporting structure (the ACPPE being written before AS/NZS 1170 was issued) or the durability life of the supporting structure's components. The only requirements being for the mechanical design life to be as per the applicable mechanical design code and that the seismic coefficient shall be determined in accordance with AS/NZS 1200 .

The design seismic coefficient set out in AS/NZS 1200 is the maximum of that derived from NZS 4203:1992 or the value given in AS/NZS 1200 Appendix I, Table I1. The minimum seismic coefficients given in AS/NZS 1200 Table I1 appear to be based on NZS 4203:1992 but as AS/NZS 1200 has no associated commentary, there is no explanation as to how the minimum coefficients were derived. There is an apparent inconsistency in that the Table I1 minimum coefficients only increase by $50 \%$ ( 0.4 to 0.6$)$ for an increase of $100 \%$ in the NZS 4203:1992 zone factor Z (0.6 to 1.2). 
Table 1. Standards used in the design of industrial structures

\begin{tabular}{|c|c|c|c|c|c|c|c|c|c|c|c|c|c|}
\hline Facility & $\begin{array}{c}\text { NZS } \\
4203^{(1)}\end{array}$ & $\begin{array}{c}\text { AS/ } \\
\text { NZS } \\
1170\end{array}$ & $\begin{array}{c}\mathrm{AS} \\
4343\end{array}$ & $\begin{array}{l}\text { NZS } \\
1200\end{array}$ & $\begin{array}{l}\text { NZS } \\
3404\end{array}$ & $\begin{array}{l}\text { NZS } \\
3101\end{array}$ & $\begin{array}{l}\text { NZS } \\
4230\end{array}$ & $\begin{array}{c}\text { API } \\
650+ \\
\text { SDPP }\end{array}$ & $\begin{array}{c}\text { SDS } \\
\mathrm{T}^{(2)}\end{array}$ & $\begin{array}{c}\text { OSH } \\
\text { ACOPs }\end{array}$ & $\begin{array}{c}\text { ASME } \\
\text { BPV } \\
\text { NZS PD } \\
5500 \\
\end{array}$ & $\begin{array}{c}\text { ASME } \\
\text { B31.3 }\end{array}$ & $\begin{array}{l}\text { ASME } \\
\text { STS-1 }\end{array}$ \\
\hline $\begin{array}{c}\text { Steel } \\
\text { structures }\end{array}$ & $\sqrt{ }$ & $\sqrt{ }$ & & & $\sqrt{ }$ & & & & & & & & \\
\hline $\begin{array}{l}\text { Concrete } \\
\text { structures }\end{array}$ & $\sqrt{ }$ & $\sqrt{ }$ & & & & $\sqrt{ }$ & & & & & & & \\
\hline $\begin{array}{l}\text { Masonry } \\
\text { structures }\end{array}$ & $\sqrt{ }$ & $\sqrt{ }$ & & & & & $\sqrt{ }$ & & & & & & \\
\hline $\begin{array}{c}\text { Storage } \\
\text { tanks }\end{array}$ & $\sqrt{ }$ & & & & & & & $\sqrt{ }$ & $\sqrt{ }$ & $\sqrt{ }$ & & & \\
\hline Boilers & $\sqrt{ }$ & $\sqrt{ }$ & $\sqrt{ }$ & & $\sqrt{ }$ & & & & & $\sqrt{ }$ & $\sqrt{ }$ & & \\
\hline $\begin{array}{c}\text { Pressure } \\
\text { vessels }\end{array}$ & $\sqrt{ }$ & $\sqrt{ }$ & $\sqrt{ }$ & $\sqrt{ }$ & $\sqrt{ }$ & & & & & $\sqrt{ }$ & & & \\
\hline $\begin{array}{c}\text { Pressure } \\
\text { piping }\end{array}$ & $\sqrt{ }$ & $\sqrt{ }$ & $\sqrt{ }$ & $\sqrt{ }$ & & & & & & $\sqrt{ }$ & & $\sqrt{ }$ & \\
\hline $\begin{array}{c}\text { Guyed } \\
\text { Structures }\end{array}$ & $\sqrt{ }$ & $\sqrt{ }$ & $\sqrt{ }$ & $\sqrt{ }$ & & & & & & $\sqrt{ }$ & & $\sqrt{(3)}$ & $\sqrt{ }$ \\
\hline
\end{tabular}

Notes:

1. Code only applies until the Building Controls division of the Department Building and Housing updates the Building Code and the Engineering Safety Unit of the Department of Labour updates their various codes of practice.

2. $\quad \mathrm{SDST}=$ Seismic Design of Storage Tanks, NZSEE, December 1986 plus Whittaker \& Jury (2000).

3. For flare stacks, pressure vents and other PECPR related items.

\subsubsection{HSE Act Requirements - Boilers}

Section 1.11.1 of DoL's ACOP for boilers sets out the minimum seismic requirements for these equipment items. The table of minimum seismic coefficients based on the NZS 4203 Zone Factor Z is repeated from Appendix I of AS/NZS 1200. However, water tube package boilers have a minimum coefficient of 0.6 no matter what Zone Factor $\mathrm{Z}$ applies for the site. The design seismic coefficient then is the maximum of that derived from NZS 4203:1992 or the value given in Section 1.11 .1 of the ACOP.

\subsubsection{Summary}

Before AS/NZS 1170 was issued, mechanical engineers accepted minimum seismic coefficients based on NZS 4203:1992 that has as a default assumption that all items have a 50 year design life. However, it has been difficult in the author's experience for pressure equipment design engineers to agree to a DWL as per AS/NZS 1170.0 for pressure equipment's seismic force determinations to be the same as that of the structure that supports or encloses them. There is a tendency to equate the mechanical design life with the concept of durability life and use this as the DWL when determining design earthquake actions for mechanical items and pressure equipment in an attempt to keep the seismic design forces down.

The equivalent in the building industry would be those items that have a minimum durability life of 15 years (e.g. nonstructural wall cladding) being designed for earthquake forces determined from Section 8 of NZS 1170.5 using a DWL of 15 years, giving for an Importance Level 2 structure, a design ULS earthquake return period of 250 years compared with 500 years for the building's main earthquake resisting structural system assuming it was to have an indefinite life.
This is to be avoided if at all possible as it leads to seismic design force interface complications within the structure as to what item is designed for what DWL. For example, a recent project in Taranaki for a plant with a nominated field life of 25 years, the foundations, hold down bolts and structural supports were sized using a DWL of 50 years while the pressure equipment was sized for earthquakes determined using a DWL equal to 25 years and the intended life set out in the building consent application for non-exempt structures was for an indefinite life.

\subsubsection{Recommendations}

For the industrial plant design engineer, the term "design life" has multiple meanings. The above legislation requires the applicable parts of a plant to have a design life, intended life and a durability life set during its design phase by various disciplines. It is preferable for there to be a consistent approach to be established at the start of the project to the choice of the DWL for use with the AS/NZS 1170 set of standards. This would be for each major plant item, structure, part and components.

The DWL along with the chosen Importance Level sets the required return periods for wind and earthquake forces for the design ultimate and serviceability limit states. Thus it has a major affect on the required strength, displacements and foundation sizing requirements. Table 2 below gives a recommended approach based on the proposed length of time that the plant will be operating. 
Table 2. Recommended Design Working Lives for Earthquake Load Level Determinations

\begin{tabular}{|c|c|c|}
\hline $\begin{array}{c}\text { Process Design } \\
\text { Life or Period of } \\
\text { Feedstock } \\
\text { Availability }\end{array}$ & $\begin{array}{c}\text { Mechanical } \\
\text { Design Life for } \\
\text { PECPR Items }\end{array}$ & $\begin{array}{c}\text { Design Working } \\
\text { Life/Intended } \\
\text { Life for Building } \\
\text { Act Compliance }\end{array}$ \\
\hline$\leq 15$ years & 15 years & 15 years \\
\hline$\leq 25$ years & 25 years & 25 years $^{(1)}$ \\
\hline$>25$ years & 25 years & $50+$ years $^{(2)}$ \\
\hline
\end{tabular}

Notes:

1. The owner should agree to the specific intended life for the items covered by the Building Act.

2. All items to be designed for the earthquake with a return period determined using a DWL $=50$ years.

3. If the design life required by the appropriate mechanical design standard is greater, this shall apply.

\subsection{Pressure Equipment Hazard Levels}

The hazard level of pressure equipment is usually determined by the mechanical design engineer using the Australian standard AS 4343. The nature of the contained substance, various operating parameters, diameter or volume and other variables combine to set a hazard level that can range from A (high hazard) to E (negligible hazard).

The hazard level given to each pressure equipment item is used by the industrial structural engineer usually in discussion with a safety and risk engineer to determine the nature of the hazard if there were leaks following a major earthquake event. The number of items with a Hazard Level of A or B then can be used to determine whether the appropriate Importance Level(s) should be set at a value greater than 2 , the value for a normal facility.

\subsection{Importance Levels}

Tables 3.1 and 3.2 of AS/NZS 1170.0:2002 are used to determine what Importance Level applies for each component or structure or the plant as a whole. A decision should be made early on in the design process whether each structure or item in the plant is to have a separate Importance
Level applied or whether a single Importance Level shall apply for the whole site. Large plants may have enough separation to allow blocks of plant to have a common Importance Level.

Table 3 shows a comparison between SDPP Table 2.2, NZS 4203:1992 Table 2.3.1, the ASCE Guidelines (1997) Table 2.1 and AS/NZS 1170.0 Table 3.2 in how each document endeavours to categorise the importance of a range of structures and components. NZS 4203:1992 and AS/NZS 1170 have five different classifications whereas the more specialised SDPP and the ASCE guidelines (1997) have only four different classifications.

A mainstream hydrocarbon gas conditioning facility upstream of the main gas distribution network usually have some items, if not the whole plant, classed as having an Importance Level of 4 unless the plant is a minor network supplier and/or is in a remote area. Most downstream industrial facilities would have an Importance Level of 2 or 3. However, the example of a fire in a Takaka dairy factory in June 2005 that caused the evacuation of the Takaka township shows that careful consideration of the contained materials within the plant is necessary. Importance Level 4 covers facilities containing hazardous materials capable of causing hazardous conditions that extend beyond the plant which was the case in the Takaka fire.

The Importance Levels set should be decided in conjunction with the plant's owner and/or operator using a risk based approach in conjunction with Safety and Risk engineers. The chosen Importance Level determines from Table 3.3, AS/NZS 1170.0:2002 the applicable return periods for the Ultimate Limit State and Serviceability Limit States and from Clause 2.1.3, AS/NZS 1170.0:2002 how many serviceability states are required to be considered.

Examples 1 and 2 in Appendix B illustrates the effects of setting the Importance Level $=4$. Examples 3 to 5 in Appendix B illustrates the proposed design method for the more common Importance Level $=2$ structures.

Table 4. Recommended lower bound structural damping levels for vital items as a \% of critical damping

\begin{tabular}{|l|c|c|c|c|}
\hline \multirow{2}{*}{} & \multicolumn{3}{|c|}{ Values for $\xi$ when T $\geq 0.2$ sec } \\
\cline { 2 - 5 } & $\begin{array}{c}\text { SLS1 } \\
\text { Eqke }\end{array}$ & $\begin{array}{c}\text { SLS2 } \\
\text { Eqke }\end{array}$ & \multicolumn{2}{c|}{$\begin{array}{c}\text { ULS } \\
\text { Earthquake }\end{array}$} \\
\hline & & & $\mu_{\text {uls }} \leq 1.25$ & $\mu_{\text {uls }} \geq 2.0$ \\
\hline Reinforced Concrete & $1.0 \%$ & $4.0 \%$ & $7.0 \%$ & $5.0 \%$ \\
\hline Reinforced Masonry & $1.0 \%$ & $4.0 \%$ & $7.0 \%$ & $5.0 \%$ \\
\hline Prestressed Concrete & $0.5 \%$ & $3.0 \%$ & $5.0 \%$ & $5.0 \%$ \\
\hline $\begin{array}{l}\text { Unclad steel welded or bolted with } \\
\text { friction connections }\end{array}$ & $0.5 \%$ & $1.0 \%$ & $2.0 \%$ & $5.0 \%$ \\
\hline $\begin{array}{l}\text { Unclad Steel with bearing type } \\
\text { bolted connections }\end{array}$ & $1.0 \%$ & $2.0 \%$ & $5.0 \%$ & $5.0 \%$ \\
\hline $\begin{array}{l}\text { Pressure vessels, heat exchangers, } \\
\text { pumps and valves }\end{array}$ & $0.5 \%$ & $2.0 \%$ & $3.0 \%$ & $5.0 \%$ \\
\hline $\begin{array}{l}\text { Electrical cabinets, panels, motor } \\
\text { control centres }\end{array}$ & $0.5 \%$ & $2.0 \%$ & $3.0 \%$ & $5.0 \%$ \\
\hline
\end{tabular}

Notes: 1. Use ULS values only if the significant stresses due to load combinations that include the ULS earthquake are at least $80 \%$ of the applicable design standard's stress limits. 


\subsection{Strength Considerations}

\subsubsection{Items coming under Building Act}

Unless requirements that are more stringent are imposed by the process design, the performance of all structures should meet the requirements of AS/NZS 1170:2002. That is all structures shall be designed to have:

- $\quad$ Adequate strength, stability, ductility and stiffness under seismic effects to satisfy the Ultimate Limit State (ULS) such that for an ULS earthquake, the structural system does not collapse.

- For structures or items given an Importance Level $=4$ or 5 from Table 3.2 of AS/NZS 1170.0:2002, adequate strength, stability and stiffness under seismic effects to satisfy the serviceability limit state SLS2 such that for an SLS2 earthquake, the structure/item remains operational.

- $\quad$ Adequate strength and stiffness under seismic effects to satisfy the serviceability limit state SLS1 such that for an SLS1 earthquake, the structure/item does not require repair.

It should be emphasised to owners that the purpose of code levels of design is to prevent loss of life and not to prevent damage to property. If the owners want to prevent earthquake damage to their plant it is likely that a longer return period design earthquake will need to be designed for. An estimate of the maximum credible earthquake can be part the scope of any site specific seismic hazard study. Once this is known, the owner along with the design team can decide on the approach to this level of earthquake.

\subsubsection{Items coming under PECPR Regulations}

Pressure equipment items are designed in accordance with the working stress codes listed in Schedule $\mathrm{C}$ of the ACPPE. These codes are concerned largely with pressure containment and strength and do not address issues such as ductility, collapse, ultimate or serviceability limit states.

The New Zealand seismic design requirements for pressure equipment are set out in AS/NZS 1200 Appendix I. The design seismic coefficient derived from the AS/NZS 1200 Appendix I requirements is the maximum of that derived from NZS 4203:1992 or the value given in AS/NZS 1200 Table I1. The values given in Table I1 are dependent on the NZS 4203:1992 zone factor Z thus do not reflect the current seismic hazard map of New Zealand as shown in Figures 3.3 and 3.4 of NZS 1170.5. However, the ACPPE allows for the use of lower seismic coefficient values if a site-specific seismic hazard study has been undertaken.

It has been the author's experience that for sites without a site-specific hazard study, Mechanical Design Verifiers and Approved Pressure Vessel Inspectors will accept seismic coefficients derived from NZS 1170.5 as an alternative allowed for in Section 3.2.3 of the ACPPE provided the coefficients are not less than those given in Table I1 of AS/NZS 1200. For sites with a site-specific hazard study, they will accept lower seismic coefficients than those given in Table I1 with the coefficient being determined from NZS 1170.5 in conjunction with the results from the site-specific hazard study.

Taking the intent of the ACPPE, all pressure equipment items shall be designed to have:
- Adequate strength and stability, under seismic effects to satisfy the pressure containment limit state such that for an ULS return period earthquake, leak tightness and position retention are maintained.

- For items given an Importance Level $=4$ or 5 from Table 3.2 of AS/NZS 1170.0:2002 adequate strength and stability, under seismic effects to satisfy the functionality limit state such that for an ULS return period earthquake, the item or system remains operational.

\subsection{Limit State Objectives}

The objectives of the ultimate limit state for an ULS return period earthquake are:

- To avoid collapse of the structural system.

- To avoid personnel injury and loss of life.

- To minimise damage to equipment.

- To avoid collapse or loss of support of parts of structures classified as P.1, P.2, P.3 or P.4 in Table 8.1 of NZS 1170.5.

- To maintain vital services.

The objectives of the serviceability limit state SLS2 for the appropriate return period earthquake are:

- The structural system to maintain operational continuity.

- To avoid collapse or loss of support of parts of structures classified as P.5 in Table 8.1 of NZS 1170.5.

The objectives of the serviceability limit state SLS1 for the appropriate return period earthquake are:

- The structural system and non-structural components to not require repair.

- To avoid collapse or loss of support of parts of structures classified as either P.6 or P.7 in Table 8.1 of NZS 1170.5 .

The objectives of the general serviceability limit state are as follows:

- To avoid disruption to all services.

- To avoid inelastic behaviour and non-vibrational damage.

- To ensure deformations and vibrations are within acceptable limits for occupational comfort, process operations and material fatigue.

\subsection{Performance Objectives}

The structural performance objectives for buildings are set out in Clause 3.2 of AS/NZS 1170.0. These can be translated into the industrial situation to cover:

- Structural Integrity.

- Containment.

- Functionality.

\subsubsection{Structural Integrity}

Structures and components should not collapse or otherwise fail under the design loads determined for the site from 
AS/NZS 1170 or any site specific seismic hazard studies. In general, maintaining structural integrity does not mean maintaining the functionality of the structure unless the set Importance Level requires this. Typically owners are not aware that this is the case and there is a perception that once designed for earthquakes, a structure will always be functional. It is something engineers should take upon themselves to educate the general public and asset owners in particular what level of earthquake protection is being provided by designing structures in accordance with the NZ Building Code.

Strength, ductility and deformation limits are the main considerations to ensure that the structural integrity performance requirements are met.

\subsubsection{Containment}

Structures and components containing hazardous materials should be designed so they do not permit significant releases into the environment during and after a major earthquake or wind event. Ensuring containment requires considerations of strength, deformation limits and structural and mechanical details of elements with respect to potential leak paths.

\subsubsection{Functionality}

Structures and components that are needed to be operating after a major earthquake should be designed to maintain their designated function during and after such events. These systems such as emergency depressurising systems, flare lines, flare stacks, electrical supply systems, communication towers and fire fighting systems require attention to strength, ductility, deformation limits, stress levels, structural details, seismic interaction and protection of essential systems and components from falling or collapsing objects.

\subsection{Ductility Considerations 6.8.1 ULS Ductility Factors}

Ductility is a vital requirement for structures to resist seismic loadings even for nominally ductile structures. The ductility limits chosen for each structure and its accompanying deformations and limit state, if not available from the appropriate material design standard, should not exceed the requirements set out below. Ductility limits may also be demonstrated through independent testing.

The measure of a structure's ductility in response to seismic events is indicated by the value of its "Structural Displacement Ductility Factor", $\mu$. This is an assessment of the overall ability of the structure to sustain cyclic inelastic displacements. NZS 1170.5 Clauses 2.2.1 to 2.2.4 give the allowable ranges of the ULS Structural Displacement Ductility Factor for four different types of structures responding to earthquakes:

- $\quad$ Brittle or elastic structures, $\mu_{\mathrm{uls}}=1.0$.

- Nominally ductile structures, $1<\mu_{\mathrm{uls}} \leq 1.25$.

- Structures with limited ductility have a $\mu_{\mathrm{uls}}$ in the range of $1.25<\mu_{\mathrm{uls}}<3$.

- Ductile structures have a $\mu_{\mathrm{uls}}$ in the range of $1.25<\mu_{\mathrm{uls}}$ $\leq 6$.

Careful consideration of the structural systems resisting seismic forces should be undertaken using the appropriate material design standard before assigning the ULS Structural
Displacement Ductility Factor. This is especially the case when designing nonbuilding-like structures, see Section 4.5.2 above. Also the value chosen has a bearing on whether capacity design is required or is an option (NZS 1170.5 Section 5.6). Capacity design has generally an additional amount of design effort needed to verify the structure and has a bearing on what methods are used to design verify the structure (NZS 1170.5 Clause 5.3.1).

\subsubsection{SLS1 and SLS2 ductility factors}

Clause 4.3.2 of NZS 1170.5 sets out the allowable limits for the values for $\mu$ for the two possible serviceability limit states:

$$
\begin{array}{lll}
\text { - } & \text { SLS1 } & 1<\mu_{\mathrm{sls} 1} \leq 1.25 \\
\text { - } & \text { SLS2 } & 1<\mu_{\mathrm{sls} 2} \leq 2.0
\end{array}
$$

If either the equivalent static or the modal response spectrum method of analysis is to be used for either a SLS1 or SLS2 analysis, a value for $\mu$ needs to be assigned. Equation 5.2(4) of NZS 1170.5 that sets out the serviceability limit state horizontal modal response spectrum has incorrectly left out the use of the factor $k_{\mu}$ and this error should be corrected in the next amendment to NZS 1170.5.

The higher the ULS Structural Displacement Ductility Factor used, the higher the value of a SLS1 or SLS2 Structural Displacement Ductility Factor may be justified within the limits given above.

\subsection{Analysis Methods}

The equivalent static method of analysis (ESA) for seismic effects generally is appropriate; however, dynamic analysis of irregular or slender structures may be required. The designer should use judgement in deciding whether a dynamic analysis is appropriate. NZS 1170.5 Clause 6.1.3.1 outlines the limitations to the ESA method for buildings and building-like structures. Structures within petrochemical facilities are often inter-linked by platforms, large diameter piping etc and a modal response spectrum analysis (MRSA) of the total system may be more appropriate. The Clause 6.1.3.1 limitations on the appropriateness of the ESA method can also be used for nonbuilding-like structures.

\subsection{Acceptance Criteria}

Generally, for structures, limit state methods shall be used in establishing acceptance criteria. The method that all limit states are shown to be complied with shall be as per Section 7 of AS/NZS 1170.0:2002.

Components that are designed to mechanical codes such as piping, pressure vessels etc generally use allowable or working stress methods to establish acceptance criteria. Hence, the structural engineer needs to provide to the mechanical engineer seismic accelerations and displacements that can be accommodated within the mechanical acceptance criteria. This requires consideration of the structural supporting system for the component and how it would behave under severe shaking.

\subsection{Review of Components}

Each system and its components shall be assessed to determine their susceptibility to strong ground shaking. Many systems and components are seismically rugged but those that are part of hazardous or essential elements shall be considered closely. 
Non-structural components shall be reviewed to ensure that their performance meets the objectives above in Sections 6.6 and 6.7. The review may comprise consideration of records of experience, vendor data provided, analysis, testing or any combination of these.

\subsection{Seismic Interaction between Components}

Process, mechanical and piping design requirements and the desire to minimise plot space encourages placing components close together. This creates the potential for damaging interaction of structures and components during an earthquake, especially in skid mounted systems. It is essential that the structural engineer reviews proposed layouts and addresses any concerns about interaction between plant items.

Impact and differential displacement generally have adverse effects on the performance of sensitive systems and components. Separation of such items from others is a basic design principle. If not practical, then seismic interaction should be accounted for in the analysis and design.

Examples of potential structure and component interaction are:

- Tall vertical vessels with platforms or pipe in close proximity to each other.

- Vessels with shared working platforms.

- Interconnecting pipe and pipe ways.

- Distributive systems that connect structures that have different LFRS or foundations. For example, piping is often routed vertically from a high elevation on a pipe rack into flanges or nozzles of turbines, pumps, vessels etc at grade. Large differential displacements of the supports for these pipes during an earthquake may cause leaks at the flanges leading onto possible fire and/or explosions.

Maximum horizontal deflections do not occur at the same instant as the earthquake induced peak accelerations. Also peak horizontal displacements for separate structures may not occur at the same instant. Hence when reviewing the physical interaction between adjacent structures, the NZS 1170.5 Section 7.4.1.2 requirement that no contact is made between adjacent structures with both deflecting at their design horizontal displacements can be reviewed as to how likely this is to occur.

This review could comprise a check on the fundamental periods of the two adjacent structures and if substantially different, the clear gap provided could be reduced to at least the square root of the sum of the squares of the design horizontal displacements rather than a straight summation of the two design horizontal displacements.

Good practice to avoid or minimise physical interaction involves:

- Set out all structures as regular structures whenever possible.

- $\quad$ Provide adequate space between components (also helps for maintenance activities).

- Check the maximum displacements and ensure there is enough room between the structures and components supported off them.
- Provide in conjunction with the pipe stress engineer, support and restraint configurations for pipes to minimise transfer of load across flanges and couplings and to prevent pipes falling off their supports.

- Provide in conjunction with the pipe stress engineer, piping systems more flexible to mitigate the coupling effects of large diameter pipes spanning between structures.

- Minimising the ULS inter-storey deflections to levels substantially less than the $2.5 \%$ allowed in Section 7 of NZS 1170.5.

\subsection{Redundancy within Structures}

Experience of earthquakes indicates that the more load paths that are provided in a structure (i.e. greater redundancy) the better its seismic performance. Industrial and petrochemical facilities tend to consist of structures that lack redundancy thus consideration should be given to providing redundant structural systems to the maximum extent practical. If sufficient redundancy is unable to be provided, the chosen structural performance factor $\mathrm{S}_{\mathrm{p}}$, should reflect this.

\subsection{P-Delta Effects}

When a structure is displaced laterally, the P-Delta actions reduce the resistance of the structure to further displacement in the same direction. For ductile structures, this becomes important in the ultimate limit state, as each time the inelastic range is entered, there is a tendency for the displacement to increase and it may be possible for sway mechanisms to form. If a sway mechanism is developed during an earthquake, the structure may collapse if the earthquake is of sufficient duration.

P-Delta effects in a structure increase with:

- An increase in ductility demand on the structure.

- The duration of the severe ground motions.

- The inverse of the fundamental period of the structure.

An assessment of the need to allow for P-Delta effects should be made as per Clause 6.5.2 of NZS 1170.5.

\subsection{Horizontal Torsion Effects}

NZS 1170.5 Clauses 5.3.2 and 6.3.5 set out the recommended minimum requirements for torsion load effects in buildings. These requirements are in terms of a minimum eccentricity required between the applied seismic forces and the centre of mass. The $0.1 \mathrm{~b}$ eccentricity is intended to allow for variations in structural properties, the distribution of mass, participation of non-structural elements and the effect of ground rotation about the vertical axis. Rigid diaphragms are required to transfer these eccentricities to the LFRS.

However, in industrial and petrochemical facilities, the mass location for most structures can be determined with reasonable accuracy and rigid diaphragms are usually not present. For these structures, the torsion effects are minimal. However, if the mass distribution cannot be determined with accuracy or the structure has a rigid diaphragm, an allowance should be made for accidental torsion.

For nonbuilding-like structures, the allowance for accidental torsion if required shall be by assuming the centre of mass is shifted in each horizontal direction from its calculated value 
by a distance equal to $5 \%$ of the structure's dimension perpendicular to the earthquake direction being considered.

\subsection{Directions of Earthquake Forces}

For ductile structures, NZS 1170.5 allows that the independent design for each of the principal LFRS will provide adequate resistance for earthquakes acting in any direction; see Clause 5.3.1.1 of NZS 1170.5. Therefore, for ductile structures the design seismic forces may be assumed to act non-concurrently with the exception of the corner columns and foundations that are part of the LFRS in both horizontal directions, see Clause C5.3.1 in NZS 1170.5-Supp 1.

For nonbuilding structures in industrial facilities, the requirement that earthquake forces are to be considered to come from any direction should be carefully evaluated. The Clause 5.3.1 of NZS 1170.5 requirement that orthogonal effects be considered shall be satisfied by designing elements using the applicable method outlined in either Clause 5.3.1.1 for ductile structures or Clause 5.3.1.2 of NZS 1170.5 for nominally ductile or brittle structures.

There is no requirement in Section 8 of NZS 1170.5 for parts and components to be analysed for $F_{\text {ph }}$ acting concurrently as per Clause 5.3.1 of NZS 1170.5. There is a requirement for parts sensitive to vertical accelerations to be designed for vertical actions $\mathrm{F}_{\mathrm{pv}}$ as per Eqn 8.5(2) of NZS 1170.5 concurrent with the horizontal actions from Eqn 8.5(1) of NZS 1170.5. FEMA 450 Clause 6.2.6 specifically requires no horizontal concurrency, $F_{\mathrm{ph}}$ being applied in two orthogonal directions independently but requires a concurrent vertical seismic action equal to $20 \%$ of the peak ESA elastic site hazard spectrum.

Therefore it is recommended that $F_{\mathrm{ph}}$ be applied in two orthogonal directions independently and parts sensitive to vertical accelerations shall be designed for concurrent vertical actions $F_{\mathrm{pv}}$.

\subsection{System Damping}

What the appropriate system damping values should be requires consideration for each structure to be analysed. The spectra curves given in Table 3.1 of NZS 1170.5 have been created using the structural damping value $=5 \%$ of critical damping for all modes of vibration on the basis that $5 \%$ is applicable for most buildings for the level of accuracy that a seismic analysis can claim. That the curves represent the 5\% damping case is not specifically stated in the standard or its commentary, NZS 1170.5 Supp 1 but that this has been confirmed in correspondence with Standards New Zealand.

A significant number of the building-like and nonbuildinglike structures and the components supported off them that make up industrial plant are either welded steel pressure retaining items required to remain elastic or nominally ductile with few or no bolted joints and are not clad. Hence the assumption that $5 \%$ damping will exist during a major earthquake needs to be examined carefully for these and other industrial structures.

Also specific requirements by clients may prevail. For instance, the type of vertical vessel analysed in Example 1 in Appendix B, if installed at the New Zealand Refining Company's refinery at Marsden Point would be analysed assuming $1 \%$ damping for the ULS. For vertical skirt supported vessels and horizontal vessels supported on saddles, damping ratios for elastic fully welded structures are typically used.

The level of damping applying is strain dependant, and the strain levels experienced under the various SLS and ULS return period earthquakes will differ. This effect is shown in the recent report by the Brookhaven National Laboratory (2006) for the U.S. Nuclear Regulatory Commission (USNRC), NUREG/CR-6919. NUREG/CR-6919 (2006) in Table 2 has lower recommended levels of damping for the case when an earthquake causes stresses that are $80 \%$ or less than the applicable design standard's stress limits than for the case when the structural response to the design earthquake will be close to the applicable design standard stress limits.

Damping also has less effect on rigid structures. Standards such as FEMA 450 reduce the effect of damping in the short period range so that at $\mathrm{T}=0.0 \mathrm{secs}$ the scaling factor $\mathrm{C}_{\mathrm{f}}(\xi)=$ 1.0 for all values of $\xi$.

In addition, where the particular material standard indicates that the applicable damping values are not equal to $5 \%$ of critical; appropriate scale factors $\mathrm{C}_{\mathrm{f}}(\xi)$ should be applied to the seismic response spectrum to determine the design forces. For example, for steel structures, NZS 3404:1997 Clause 12.2.9 recommends ULS damping values and a method for determining the damping scaling factor for standard steel structures. For the unclad steel structures that are normally used for modular industrial construction, $2 \% \leq \xi \leq 7 \%$ and $\mathrm{C}_{\mathrm{f}}(\xi)$ varies between 1.333 and 0.895 respectively. However, the NZS 3404 Clause 12.2.9 values for $C_{\mathrm{f}}(\xi)$ do not decrease for short periods.

NUREG/CR-6919 (2006) has recommended damping values for structures, piping, electrical distribution systems, HVAC items, mechanical and electrical components. For piping subsystems, NUREG/CR-6919 (2006) recommends damping values in the range $3 \%$ to $4 \%$ for SLS2 and ULS level responses. Some pipe stressing software programs have a default damping value of $3 \%$ for their MRSA analyses. However, ALA (2002) recommends that for both ESA and MRSA, piping design is undertaken using 5\% damped spectra.

As a structural system responds to seismic loading in an increasingly inelastic manner $(\mu \geq 2)$, the level of damping becomes less significant in determining the ultimate structural response. Hence, different levels of damping should be considered for the ULS, SLS1 and SLS2 earthquakes. For the ULS, if the damping levels are overestimated in the design, during an ULS return period earthquake, the structure will start to yield earlier than expected and the damping effects are likely to increase to a level approximately that assumed in the design. The overall effect is not likely to be that different from the original design assumptions.

Because the damping for each individual system will vary, the level of damping to be used in the design for the ULS, SLS1 and SLS2 limit states should be determined as part of the initial process when assessing seismic performance. Lower bound values for damping should be considered for critical items, refer to Table 4 for recommended values. Higher values of $\xi$ may be used if justifiable or if premature yielding can be tolerated. 
Table 3. Comparison of Structure Classifications

\begin{tabular}{|c|c|c|c|c|c|}
\hline $\begin{array}{l}\text { SDPP } \\
\text { Seismic } \\
\text { Classification }\end{array}$ & $\begin{array}{l}\text { NZS } \\
\text { 4203:1992 } \\
\text { Structure } \\
\text { Classification }\end{array}$ & $\begin{array}{l}\text { ASCE Usage } \\
\text { Categories }\end{array}$ & $\begin{array}{l}\text { AS } 4343 \\
\text { Hazard } \\
\text { Level }\end{array}$ & \begin{tabular}{l|} 
AS/NZS \\
1170.0 \\
Importance \\
Levels \\
\end{tabular} & Description of structure or its intended role \\
\hline- & - & - & A & 5 & 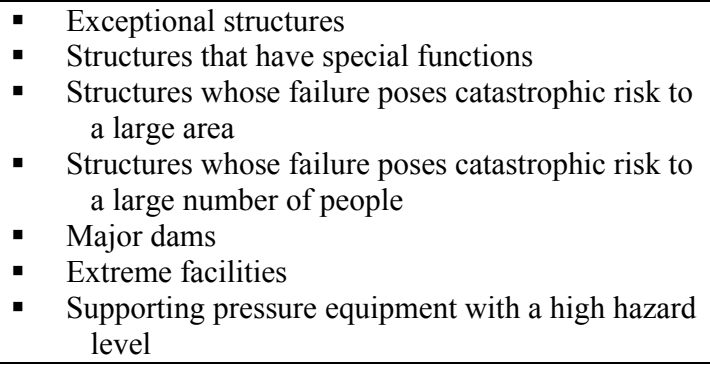 \\
\hline A & I & Essential & A \& B & 4 & $\begin{array}{l}\text { - } \quad \text { Preservation of life } \\
\text { - } \quad \text { Cevere impact on society } \\
\text { - } \quad \text { Components critical to safe plant shutdown } \\
\text { hazard beyond plant } \\
\text { - } \quad \text { In plants of national importance, components that } \\
\text { cannot be readily repaired, replaced or by-passed } \\
\text { - } \quad \text { Post disaster functions or dangerous activities } \\
\text { - } \quad \text { forities or emergency supplies or backup facilities } \\
\text { Facilities containing hazardous materials capable } \\
\text { of causing hazardous conditions that extend } \\
\text { beyond plant } \\
\text { - Supporting pressure equipment with a high or } \\
\text { average hazard level }\end{array}$ \\
\hline \multirow[t]{2}{*}{ B } & II & Hazardous & B & 3 & $\begin{array}{l}\text { - } \quad \text { Contain people in crowds } \\
\text { - } \quad \text { Components failure represents a severe hazard } \\
\text { within plant } \\
\text { - } \quad \text { Major structures affecting crowds } \\
\text { - } \quad \text { Fablic utilities not designated as post-disaster } \\
\text { hazardous materials capable of causing } \\
\text { hazardous conditions that do not extend beyond } \\
\text { plant } \\
\text { - Supporting pressure equipment with an average } \\
\text { hazard level }\end{array}$ \\
\hline & III & Special & & & $\begin{array}{l}\text { - } \quad \text { Public buildings with contents of high value } \\
\text { - } \quad \text { Components that cannot be readily repaired, } \\
\text { replaced or by-passed } \\
\text { - } \quad \text { Major structures affecting crowds }\end{array}$ \\
\hline $\mathrm{C}$ & IV & Normal & $\mathrm{C}, \mathrm{D} \& \mathrm{E}$ & 2 & $\begin{array}{l}\text { - } \quad \text { Normal structures } \\
\text { - } \quad \text { ritical components that can be readily repaired, } \\
\text { replaced or by-passed } \\
\quad \text { Supporting pressure equipment with a low, extra } \\
\quad \text { low or negligible hazard level }\end{array}$ \\
\hline $\mathrm{D}$ & $\mathrm{V}$ & - & - & 1 & $\begin{array}{l}\text { - } \quad \text { Secondary nature } \\
\text { - } \quad \text { fomponents other than Class I-IV above whose } \\
\text { failure represents a minimal safety hazard } \\
\text { - } \begin{array}{c}\text { Minor structures whose failure is not likely to } \\
\text { endanger human life }\end{array}\end{array}$ \\
\hline
\end{tabular}

The recommendations of the NZSEE Study Group on Earthquake Risk Buildings (2005) gives a method for modifying the $5 \%$ damped spectra for other values of damping. Their equation has been given below.

It is recommended that for structures that need to be analysed using damping values different to $5 \%$ that the following adjustment factor $C_{\mathrm{f}}(\xi)$ is used:
For $\mathrm{T} \geq 0.2 \mathrm{sec}: \quad \mathrm{C}_{\mathrm{f}}(\xi)=[7 /(2+\xi)]^{0.5}$

For $\mathrm{T} \leq 0.06 \mathrm{sec}: \quad \mathrm{C}_{\mathrm{f}}(\xi)=1.0$

For $0.06<\mathrm{T}<0.2 \mathrm{sec}$, linearly interpolate between the above values. 


\subsection{Soil-Structure Interaction}

Soil-structure interaction (SSI) refers to the dynamic interaction effects between a structure and the underlying soil during an earthquake. SSI effects are pronounced for heavy items founded on soft or medium soil such as large diameter storage tanks. In general SSI effects can be ignored for light surface founded structures or structures founded on stiff or rock material.

Methods for considering SSI effects are available in FEMA 450 and "Seismic Design of Storage Tanks" (NZSEE 1986). Generally, values for the shear wave velocities for the underlying soil are required to ascertain soil stiffness as part of these procedures.

SSI effects can result in potential amplification or deamplification of the structure's response depending on the site-specific conditions and the combined dynamic characteristics of the structure and soil. As a rule when SSI effects are significant, the period of the system increases and there is a reduction in the structural response to an earthquake, unless there is resonance between the structure and the soil. In addition, parts or components that are flexible may have an increased response and their detailing needs specific attention. The additional response of the soil plus building tends to increase the lateral and rocking displacements thus, deflection related actions need consideration.

\subsection{Working Stress Methods}

The hazard curves calculated using Equation 3.1(1) in NZS 1170.5 , give the predicted earthquake accelerations for various return periods at any location within New Zealand. These can be presumed to be independent of the analysis method used to determine the earthquake resistance of items experiencing the earthquake.

In the Ultimate Limit State, as a generalisation, the "ultimate strength" of members within a structure is equated to the actual gravity plus earthquake loading. In the "Working Stress" design method (WSD), a load factor is applied to the seismic loadings to reduce the loadings to a level appropriate for allowable stresses including their overstress allowance. In early versions of NZS 4203, this factor was 0.8 . AS 1170.4 and ALA (2002) use 1/1.4 (= 0.71) and both FEMA 450 and ASCE 7-02 use 0.7 as this factor. AS/NZS 1170.3 uses $1 / 1.5(=0.67)$ to convert ULS wind forces to those to be used with WSD design codes.

Different scaling factors may be required for different actions as the factor depends on the ratio of the allowable stress (increased for load cases that include wind or earthquake) and the ultimate stress. The commentary section of ASCE 702 , Section C9.0 states that the 0.7 figure is a compromise for the various materials the standard ASCE 7-02 would be used for. Table C9-1 of ASCE 7-02 shows which ratios of dead load to earthquake load and live load to earthquake load give arise to situations where WSD analysis using the 0.7 scaling factor would give a section whose capacity would be less than what would be required if done by limit state design.

ASCE 7-02, Section C9.0 also indicates that the usual 1/3 allowable stress increase given in some steel design standards for earthquake loads is not valid in some situations and that a WSD earthquake actions scaling figure of 0.8 is more appropriate.

This qualification for the $1 / 3$ allowable stress increase has implications for the design of pressure equipment and piping as this stress increase is often used in the standards for the seismic and storm wind design of these items. The $1 / 3$ allowable stress increase has disappeared from the basic load combination checks for steel structures in various overseas building standards, such as ASCE 7-02 and the International Building Code.

The designer who intends to use this allowable stress increase needs to check that alternate basic load combinations have been used to derive the combined actions that are compatible with the use of the $1 / 3$ allowable stress increase and that the increase is justified by structural behaviour caused by rate or duration of load.

Hence, for the purposes of this document, the "Working Stress" method of design as applied to the types of structures designed to WSD standards shall be based on:

1. Design actions being calculated assuming linear elastic behaviour without any redistribution. That is, the maximum value for $\mu$ or $\mu_{\mathrm{p}}=1.25$.

2. Permissible stresses within the limits of the approved WSD design standards such as the ASME B31 codes for pressure piping or for pressure vessels, NZS PD 5500 or approved equivalents.

3. The nominal earthquake loads as derived from AS/NZS 1170:2002 and this document but as modified as follows:

- Multiplied by 0.80 for ULS earthquake loads with a $1 / 3$ allowable stress increase if permitted by the material design standard.

- Multiplied by 1.0 for earthquake loads derived for the serviceability limit states SLS2 and SLS1 with no overstress allowance.

- Incorporating load factors of 1.0 for other load components with load factors equal to or greater than 1.0 .

- Incorporating load factors of 0.70 for other load components with load factors less than 1.0, when considering stability.

Higher values for $\mu$ or $\mu_{\mathrm{p}}$ indicate that substantial yielding is anticipated and a working stress analysis is not appropriate. ALA (2002) presents in Chapter 7 several advanced analysis techniques for piping systems that go into the plastic range of the stress-strain relationship. These would allow a pipe stress engineer to undertake a more complex limit state analysis approach for pressure piping that is anticipated to yield under ULS design actions with a $\mu$ or $\mu_{\mathrm{p}} \geq 2.0$. This could be useful for the analysis of existing lines that cannot be strengthened or seismically restrained easily in a retrofit situation or where new pressure piping lines are tied into existing older piping systems.

\subsection{Seismic Displacements}

Section 7 of NZS 1170.5 "Earthquake Induced Deflections" sets out the requirements for the consideration of the seismically induced displacements for buildings both for total displacements and for design inter-storey displacements. ASCE (1997) indicates that it is not necessary to meet the ULS inter-storey deflection limits for nonbuilding structures. The ULS inter-storey deflection limits are set in Clause 7.5.1 of NZS 170.5 as being $2.5 \%$ of the corresponding storey height. However, ASCE recommends that if this drift limit is 
exceeded, P-Delta effects and the effects on any component containing hazardous or flammable material should be considered.

The ULS horizontal seismic displacements are taken as the larger of the values determined from NZS 1170.5 Clause 7.2.1.1(a) or (b). Figure C7.1 in the Commentary to NZS 1170.5 attempts to show the methodology outlined in Clause 7.2.1.1(b) for a structure where sidesway mechanisms are not suppressed by the application of capacity design. However, not the entire diagram was printed and the Figure C7.1 should be the same as that shown in the Commentary to NZS 4203:1992, Figure C4.7.1.

The Commentary Clause C7.2.1.1 does not outline whether the deflection profile (1) showing the elastic deflections was determined from a ESA or MRSA, how the ESA deflection scaling factor $\mathrm{k}_{\mathrm{d}}$ obtained from Clause 6.2.3 should be accounted for if an ESA is used or how the scaling factor for P-Delta effects using Method A of Clause 6.5.4 should be applied if that was the chosen method for accounting for PDelta effects. Hence the Fig C7.1 and the Commentary Clauses C7.2 and C7.3 are guidelines only and not comprehensive.

If required, the design inter-storey deflections between adjacent levels can be determined from Clause 7.3. The ULS inter-storey deflections involve the use of the drift modification factor $\mathrm{k}_{\mathrm{dm}}$ obtained from Table 7.1. For category 1 and 2 steel concentrically braced frames (CBF) designed in accordance with Clause 12.12 of NZS 3404, there is a further deflection factor set out in Clause 12.12.5.2(h) of NZS 3404 that is required to be considered for both total and inter-storey deflections.

For detailed guidance on how ULS deflections can be determined, Section 19.2 of HERA report R4-76 (1995) can be adapted for use with NZS 1170.5. The procedure set out in Section 19.2 of R4-76 is for CBF structures but can be adapted for use with any structure not just CBF's in lieu of guidance from the Commentary to NZS 1170.5. Example 1 given in Appendix B includes the derivation of the ULS horizontal displacements plus the inter-storey drifts based on the HERA (1995) approach.

\subsection{Seismic Anchor Motion for Distributive Systems}

ALA (2002) recommends in Section 4.1.4 "Seismic Anchor Motion" that pressure equipment items should be designed for both the inertia effects due to the supporting structure moving under earthquake and the differential motion between support attachment points or "seismic anchor motion" (SAM). This is usually only relevant for distributive systems such as piping and ducting networks as they most frequently are supported off a number of different structures along their route. NZS 1170.5 indirectly includes this effect by the inclusion of the requirement in Clause 8.5.3 to account for inter-storey deflection induced actions calculated in accordance with Clause 7.3 where parts are attached to the primary structure on more than one level. However, no guidance is given as to how to combine these deflection induced effects with the inertia effects.

SAM is accounted for by inputting the seismic displacements at the support attachments or equipment nozzles as separate analyses or load cases in the analysis of the distributive system. For a distributive system that is either supported off many levels of an individual structure or off different structures, the various deflection profiles resulting from the possible inter-storey movements need to be used in the analyses.

The resulting stresses in the system are combined with the stresses due to inertia by the square root of the sum of the squares method. This assumes that the maximum deflections do not occur at the same instant as the maximum inertia accelerations.

In the ALA proposed seismic standard for the ASME B31 pressure piping standards, this is shown in ALA Equation S304-1:

$$
\left(\mathrm{M}_{\mathrm{i}}^{2}+\mathrm{M}_{\mathrm{a}}^{2}\right)^{0.5} * \mathrm{i} / \mathrm{Z}<\mathrm{S}_{\mathrm{s}}
$$

Where:

$\mathrm{M}_{\mathrm{i}}=$ Moments due to earthquake inertia

$\mathrm{M}_{\mathrm{a}}=$ Moments due to earthquake displacement of supports or SAM

$\mathrm{i}=$ Applicable stress intensification factor from the B31 standards

$\mathrm{Z}=$ Pipe elastic section modulus

$\mathrm{S}_{\mathrm{s}}=$ Allowable stress from the appropriate B31 standard

The use of the elastic section modulus and allowable stresses in this equation further illustrate that this a working stress approach and that the use of $\mu$ or $\mu_{\mathrm{p}}>1.25$ is inappropriate.

Examples 2 and 5 in Appendix $\mathrm{B}$ show the sequence for deriving both the $\mathrm{M}_{\mathrm{i}}$ and $\mathrm{M}_{\mathrm{a}}$ effects based on the ALA approach.

\subsection{Summary of Input Data}

Important data to be determined before detailed structural design starts for industrial structures includes:

- $\quad$ NZ Building Code building category

- Structural Type; building or nonbuilding structure, part or component

- Intended Life

- Design Working Life

- Importance Level

- Applicable design standards

- Analysis method

- Site subsoil class

- Damping levels for design earthquakes

\section{EARTHQUAKE ANALYSIS}

\subsection{Selection of Analysis Method}

Two options for seismic analyses are commonly used:

a) Equivalent Static Analysis (ESA).

b) Modal Response Spectrum Analysis (MRSA).

For the majority of cases, the ESA method is appropriate for industrial structures, but its limitations as per Clause 6.1.3.1 of NZS 1170.5 should be investigated and a MRSA used when appropriate.

Numerical integration time history analyses (NITHA) either linear or non-linear as per Section 6.4 of NZS 1170.5 are not often undertaken in a design office situation. Typically it would be the analysis and design of important and unusual structures that would warrant the expense of this method. 
The lack of readily available earthquake records suitable for each of the site subsoil classes and those with and without the forward directivity effects associated with near fault motions means that NITHA will remain associated only with projects that can afford this work being subcontracted to specialists.

\subsection{Site Elastic Hazard Spectrum C(T)}

If a site specific seismic hazard study has not been undertaken, the values for the 5\% damped elastic site spectrum $\mathrm{C}(\mathrm{T})$ shall determined from Clause 3.1.1 of NZS 1170.5 for the various return periods required for each applicable limit state.

$$
\mathrm{C}(\mathrm{T})=\mathrm{C}_{\mathrm{h}}(\mathrm{T}) \mathrm{Z} \mathrm{R} \mathrm{N}\left(\mathrm{T}_{1}, \mathrm{D}\right) \quad \text { Eqn 3.1(1) }
$$

Where:

$C_{h}(T)=$ Spectral shape factor for chosen Site Subsoil Class, see Clause 3.1.2 of NZS 1170.5.

$\mathrm{Z}=$ Hazard Factor for the chosen site, see Clause 3.1.4 of NZS 1170.5.

$\mathrm{R}=$ Return Period Factor for the chosen Importance Level and earthquake return period, see Clause 3.1.5 of NZS 1170.5 .

$\mathrm{N}\left(\mathrm{T}_{1}, \mathrm{D}\right)=$ Near-fault factor for the chosen site, see Clause 3.1.6 of NZS 1170.5.

Site specific hazard studies should either:

- $\quad$ Provide curves similar to those developed by Eqn 3.1(1) and shown in Figures 3.1 and 3.2 with return periods that match those in Table 3.3 AS/NZS 1170.0; or

- Provide a more refined estimate for $Z$, the hazard factor determined in NZS 1170.5 Clause 3.1.4.

Site specific hazard studies should also consider all local faults not just those listed in Table 3.8 of NZS 1170.5.

NZS 1170.5 provides five different generalised hazard spectra. These are typical for five different site subsoil classes, Subsoil Classes A, B, C, D and E. The level of earthquake shaking experienced by a structure at a site depends on the soil layers beneath the site. An assessment of the site's subsoil class is needed to determine the design earthquake.

\subsubsection{Site Subsoil Class}

The criteria for determining whether a site has a Subsoil Class of A, B, C, D or E shall be as per Clause 3.1.3 of NZS 1170.5. Any geotechnical investigations for the site shall consider the soil underlying strata and should make a recommendation as to the site's Subsoil Class.

\subsubsection{Generalised Hazard Spectra $C_{h}(T)$}

Once the site's Subsoil class has been determined, Table 3.2 of NZS 1170.5 shall be used for the generalised 5\% damped hazard spectra $\mathrm{C}_{\mathrm{h}}(\mathrm{T})$.

\subsubsection{Hazard Factor $Z$}

Table 3.5 of NZS 1170.5 shall be used to determine the appropriate hazard factor unless the location is not listed, then $\mathrm{Z}$ shall be interpreted from Figures 3.3 or 3.4 of NZS 1170.5 as well as the figures for adjacent locations listed in NZS 1170.5 Table 3.5.

\subsubsection{Return Period Factor $R$}

The return period for the serviceability states SLS2 and SLS1 and for the ultimate limit state ULS, shall be determined from Table 3.7 of NZS 1170.5 for the return periods determined from Table 3.1 of AS/NZS 1170.0 for the chosen Importance Level.

\subsubsection{Near-fault Factor $N\left(T_{1}, D\right)$}

Long period structures $\left(T_{1}>1.5\right.$ secs $)$ experience greater accelerations than previously expected when located within 20 kilometres of the epicentre of an earthquake. Clause 3.1.6 of NZS 1170.5 shall be used to determine the near-fault factor $N\left(T_{1}, D\right)$ that endeavours to cater for this effect.

Table 3.5 of NZS 1170.5 lists for each major New Zealand location whether they are within $20 \mathrm{~km}$ of the 15 most active fault lines within New Zealand. The list of major faults that require consideration of a near-fault factor are listed in Table 3.8 of NZS 1170.5 and these are shown graphically in Figure 3.5 of NZS 1170.5 .

\subsection{Design Earthquake Actions}

The general equation for seismic forces adapts the 5\% damped elastic hazard curves to allow for the assumed level of ductility, building performance, actual damping and PDelta effects. This is shown in NZS 1170.5 equations 5.2(1), 5.2(3) and 5.2(4). These can be further modified to suit industrial structures:

Where:

$$
\mathrm{C}_{\mathrm{d}}(\mathrm{T})=\mathrm{C}(\mathrm{T}) * \mathrm{~S}_{\mathrm{p}} / \mathrm{k}_{\mu} * \mathrm{C}_{\mathrm{f}}(\xi) * \mathrm{~K}
$$

$\mathrm{C}_{\mathrm{d}}(\mathrm{T})$ Design action coefficient for the appropriate limit state.

C(T) Site elastic hazard spectrum.

$\mathrm{S}_{\mathrm{p}} \quad$ Structural Performance factor for the appropriate limit state.

$\mathrm{k}_{\mu} \quad$ Inelastic Spectrum Scaling Factor for the appropriate limit state and soil class.

$\mathrm{C}_{\mathrm{f}}(\xi)$ Damping Factor $=1.0$ unless the structural damping is not equal to $5 \%$ of critical damping for the appropriate limit state.

K Scaling factor that accounts for a variety of ULS effects that may need to be considered such as PDelta effects, steel braced frame seismic load modifiers, modal response spectrum method ULS scaling factor $k$ etc. For SLS1 and SLS2, $\mathrm{K}=1.0$.

\subsubsection{System Damping Factor $C_{f}(\xi)$}

Appropriate structural damping values shall be selected for the analysis of the structural system as the spectra curves given in Table 3.1 of NZS 1170.5 have been created using the structural damping value $=5 \%$ of critical damping for all modes of vibration.

The damping factor then is determined as per 6.17 above. The factor $\mathrm{C}_{\mathrm{f}}(\xi)$ for periods $>0.2$ secs has been given in Table 5 for different values of $\xi$. 
Table 5. $C_{\mathbf{f}}(\xi)$ values for different levels of damping for $T_{1} \geq 0.2$ secs

$\begin{array}{cc}\begin{array}{c}\text { \%o of Critical } \\ \text { Damping }(\xi)\end{array} & \mathbf{C}_{\mathbf{f}}(\xi) \\ 0.5 & 1.67 \\ 1.0 & 1.53 \\ 2.0 & 1.32 \\ 3.0 & 1.18 \\ 5.0 & 1.00 \\ 10.0 & 0.76 \\ 15.0 & 0.64\end{array}$

7.3.2 P-Delta Scaling Factor $\boldsymbol{k}_{1}$ or $\boldsymbol{k}_{3}$

The scaling factor obtained by using method A of Clause 6.5.4.1 of NZS 1170.5 to account for P-Delta effects requires the least amount of analysis work. However, for higher structural ductility factors, the factor significantly increases the applied seismic forces and using the more computationally heavy method B of Clause 6.5.4.2 may be more economic. Depending on the value of $\mathrm{T}_{1}$ and the site subsoil class, the factor may be different for an ESA $\left(\mathrm{k}_{1}\right)$ or for a MRSA $\left(k_{3}\right)$.

For example, a structure with $\mathrm{T}_{1}=0.2$ secs, 500 year return period ULS earthquake, $Z=0.30$, Soil Class $=C, 5 \%$ damping, the P-Delta scaling factors vary according to $\mu$ as follows:

Table 6. Typical P-Delta scaling factors using method A

\begin{tabular}{|c|c|c|c|}
\hline \multirow[b]{2}{*}{$\mu$} & \multirow[b]{2}{*}{$\mathbf{k}_{\mathrm{p}}$} & \multicolumn{2}{|c|}{ k Scaling Factor } \\
\hline & & $\operatorname{ESA}\left(\mathbf{k}_{1}\right)$ & $\operatorname{MRSA}\left(k_{3}\right)$ \\
\hline 1 & 0.0150 & 1.021 & 1.017 \\
\hline 1.25 & 0.0169 & 1.029 & 1.024 \\
\hline 2 & 0.0225 & 1.071 & 1.057 \\
\hline 3 & 0.0300 & 1.130 & 1.104 \\
\hline 4 & 0.0300 & 1.164 & 1.132 \\
\hline 5 & 0.0300 & 1.199 & 1.160 \\
\hline 6 & 0.0300 & 1.233 & 1.188 \\
\hline
\end{tabular}

If P-Delta effects are required to be considered the following is recommended:

\subsubsection{Equivalent Static Analysis}

The method A as set out in Clause 6.5.4.1 of NZS 1170.5 shall be used to increase the applicable seismic forces and displacements using the P-Delta scaling factor $\mathrm{k}_{1}$.

\subsubsection{Modal Response Spectrum Analysis}

These are usually undertaken by computer software packages. Most modern software programmes allow either small or large displacement options to be used in the analysis. Small displacement theory does not directly allow for P-Delta effects and should only be used for serviceability limit state analyses. If the large displacement option accounts directly for P-Delta effects by updating the displacement matrix and member stiffness, the P-Delta scaling factor $\mathrm{k}_{3}=1.0$. If not and if P-Delta effects need to be considered, the input spectrum shall be increased by the scaling factor $\mathrm{k}_{3}$ determined from Clause 6.5.4.1 of NZS 1170.5 .

\subsubsection{Structural Performance Factor $\boldsymbol{S}_{\boldsymbol{p}}$}

NZS 4203:1992 as well as NZS 1170.5 uses the structural performance factor $S_{p}$ together with a displacement ductility factor to reduce the elastic seismic loads to obtain the design loads on a structure. The structural performance factor reflects:

- That the calculated loads correspond to peak accelerations that happen only for a limited time and therefore have limited time to inflict significant damage.

- The construction material's inherent ductility.

- The total structural capacity is stronger than predicted through redundancy and non-structural elements.

- The energy dissipation of the structure is typically higher than assumed through damping from nonstructural elements and the foundation.

- The limit state being considered.

- The designer's ability to provide detailing consistent with ductile behaviour.

$S_{p}$ values need to be determined for buildings, building-like structures and for the main structural support systems for nonbuilding-like structures for each limit state. Rigid nonstructural elements of combination structures, parts and components are supported elements and are designed for forces derived from Section 8 of NZS 1170.5 and do not need to be given an $S_{p}$ value.

The value for the $S_{p}$ factor in NZS 1170.5 varies from 0.7 to 1.0 depending on the chosen structural ductility factor $\mu$ for the limit state under consideration. For industrial structures there is less redundancy than for general buildings, they also can contain less non-structural items that give the structure greater damping and strength during a strong earthquake.

For steel or steel/concrete composite items, NZS 3404 C12.2.2 indicates that unless these items have been designed in accordance with NZS 3404 and they contain brittle elements that would not respond in a ductile fashion to an earthquake, the $S_{p}$ factor should equal 1.0. Whittaker and Jury (2000) recommend for storage tanks $S_{p}=1$.

Jury (2004) indicates that the choice of the $S_{p}$ factor is a matter of judgement as often the performance of actual structures is greater than that predicted by analysis but especially for those structures that are outside of the immediate application of the loadings standard, a conservative approach should be adopted. Until there is data available on the seismic performance of the type of structure in question under strong earthquake motions, the designer of industrial structures needs to consider carefully whether the NZS 1170.5 default $S_{p}$ values can apply to the structure being designed or whether more a conservative value should apply.

The $S_{p}$ values below are recommended unless the relevant material standard specifies a greater value for the material or form of LFRS: 
Table 7. Recommended Structural Performance Factors $\underline{\mathbf{S}}_{\mathbf{p}} \quad \underline{\text { Item }}$

0.70 Steel, concrete, masonry and timber structures designed according to the relevant NZ limit state standards where $\mu \geq$ 2.0.

0.925 - Steel, concrete, masonry and timber structures designed according to the relevant NZ limit state standards where $\mu=$ 1.25 .

- $\quad$ Pressure vessels and piping where $\mu=1.25$ and limited ductility can be tolerated.

1.00 - Steel, concrete, masonry and timber structures designed according to the relevant NZ standards where $\mu=1.0$.

- Tanks, pressure vessels and piping where $\mu$ $=1.0$.

- Items for which NZ material standards are not used.

- When considering lateral stability against sliding or toppling of a whole structure.

\subsubsection{Inelastic Spectrum Scaling Factor $\boldsymbol{k}_{\mu}$}

The inelastic lateral load design actions are obtained by factoring the elastic actions by $1 / k_{\mu}$. The factor represents the change in the dynamic response of the structure undertaking plastic deformations. The factor is calculated differently for Soil Class E; see NZS 1170.5 Supp 1 Clause C5.2.1.1 for an explanation as to why this is the case. To evaluate requires an estimate of the structure's fundamental period of translation vibration, $T_{1}$ for the limit state in question.

ASCE (1997) Table 4.4 recommends generally lower values for the UBC response modification factor $R_{w}$ for industrial structures than that recommended in the UBC for general buildings. $\mathrm{R}_{\mathrm{w}}$ performs a similar function in the UBC base shear equation (UBC Equation 28-1) to the NZS 1170.5 factor $k_{\mu}$. Lower values of $R_{w}$ and $k_{\mu}$ represent a recommended response that is more elastic, more suitable for a structure that inherently does not possess good seismic resistance and/or greater than predicted strength or damping.

Table 8 lists recommended values for $\mu$ for typical industrial structures.

Table 8. Recommended Maximum Structural Ductility Factors

\begin{tabular}{|c|c|c|c|}
\hline Description & $\begin{array}{c}\text { Structural } \\
\text { Steel }\end{array}$ & $\begin{array}{c}\text { Reinforced } \\
\text { Concrete }\end{array}$ & $\begin{array}{c}\text { Pre-stressed } \\
\text { Concrete }\end{array}$ \\
\hline $\begin{array}{l}\text { 1. } \begin{array}{l}\text { Concrete or steel } \\
\text { tanks on ground }\end{array}\end{array}$ & \multicolumn{3}{|c|}{ As per Whittaker and Jury (2000) } \\
\hline $\begin{array}{ll}\text { 2. } & \text { Chimneys or stacks } \\
\text { cantilevered piers or } \\
\text { columns }^{(1)(6)}\end{array}$ & $3^{(4)}$ & 3 & 3 \\
\hline $\begin{array}{l}\text { 3. } \begin{array}{l}\text { Guyed chimneys or } \\
\text { stacks }^{(4)(6)}\end{array}\end{array}$ & 3 & - & - \\
\hline $\begin{array}{ll}4 . & \text { Interconnecting pipe } \\
\text { work supported } \\
\text { above grade }\end{array}$ & \multicolumn{3}{|c|}{ To be treated as a subsystem } \\
\hline $\begin{array}{l}\text { Interconnecting pipe } \\
\text { work supported at } \\
\text { grade by rigid } \\
\text { supports }^{(2)(6)}\end{array}$ & 1.25 & - & - \\
\hline $\begin{array}{ll}6 . & \text { Low pedestal } \\
\text { supports for pipe } \\
\text { work }\end{array}$ & 1.25 & 1.25 & - \\
\hline $\begin{array}{l}\text { 7. A ductile skirt } \\
\text { supporting a vertical } \\
\text { vessel }^{(4)(6)}\end{array}$ & 3 & - & - \\
\hline $\begin{array}{ll}\text { 8. } & \text { Vessels with hold } \\
\text { down bolts designed } \\
\text { for yielding under } \\
\text { the design } \\
\text { earthquake }^{(3)(6)}\end{array}$ & 3 & - & - \\
\hline $\begin{array}{ll}\text { 9. } & \begin{array}{l}\text { Horizontally } \\
\text { mounted pressure } \\
\text { equipment }^{(5)}(6)\end{array}\end{array}$ & \multicolumn{3}{|c|}{$\begin{array}{c}\text { To be treated as a subsystem or a combination } \\
\text { structure }\end{array}$} \\
\hline
\end{tabular}

Notes to Table 8:

1. Slender process columns, chimneys or stacks greater than 15 metres high shall be subject to dynamic analysis.

2. For Item 4 , in situations where very little damage can be tolerated or inadequate ductile capacity is available, the part structural ductility factor $\mu_{\mathrm{p}}$ shall be taken as 1.25 otherwise as per Table C8.2 of NZS 1170.5-Supp 1. 
3. For Item 8 , a higher value of $\mu$ may be used, subject to ratification by rational analysis that shall include a time history analysis of a detailed analytical model of the system.

4. $\quad \mu$ values for skirt and shell to comply with Table 12.5 of NZS 3404 .

5. For structures supporting equipment whose weight exceeds $20 \%$ of the supporting structures, the required $\mu$ depends on whether the equipment item is rigid or not, see Table 11.

6. Pressure envelope to remain within pressure design code allowable stresses.

\subsubsection{Soil Classes A, B, C \& D}

To allow for the behaviour of inelastic structures with fundamental periods less than 0.7 secs, this factor is adjusted.

$\mathrm{k}_{\mu}=\mu$

$\mathrm{k}_{\mu}=\left[(\mu-1) * \mathrm{~T}_{1} / 0.7\right]+1$

For $\mathrm{T}_{1} \geq 0.7 \mathrm{secs}$

For $\mathrm{T}_{1}<0.7 \mathrm{secs}$

Provided for the purposes of calculating $\mathrm{k}_{\mu}, \mathrm{T}_{1}$ shall not be taken less than 0.4 secs, see Clause 5.2.1.1 of NZS 1170.5.

Table 9. Soil Classes A, B, C \& D, values of inelastic spectrum scaling factor $k_{\mu}$

$\begin{array}{lllll}\mu & \begin{array}{l}\mathbf{T}_{\mathbf{1}}=\mathbf{0 . 4} \\ \text { secs }\end{array} & \begin{array}{l}\mathbf{T}_{\mathbf{1}}=\mathbf{0 . 5} \\ \text { secs }\end{array} & \begin{array}{l}\mathbf{T}_{\mathbf{1}}=\mathbf{0 . 6} \\ \text { secs }\end{array} & \begin{array}{l}\mathbf{T}_{\mathbf{1}} \geq \mathbf{0 . 7} \\ \text { secs }\end{array} \\ 1.0 & 1.00 & 1.0 & 1.0 & 1.0 \\ 1.25 & 1.14 & 1.18 & 1.21 & 1.25 \\ 2.0 & 1.57 & 1.71 & 1.86 & 2.0 \\ 3.0 & 2.14 & 2.43 & 2.71 & 3.0 \\ 4.0 & 2.71 & 3.14 & 3.57 & 4.0 \\ 5.0 & 3.29 & 3.86 & 4.43 & 5.0 \\ 6.0 & 3.86 & 4.57 & 5.29 & 6.0\end{array}$

\subsubsection{Soil Class $E$}

To allow for the behaviour of inelastic structures with fundamental periods less than $1.0 \mathrm{secs}$, this factor is adjusted.

$$
\begin{array}{ll}
\mathrm{k}_{\mu}=\mu & \text { For } \mathrm{T}_{1} \geq 1 \mathrm{sec} \text { or } \mu<1.5 \\
\mathrm{k}_{\mu}=\left[(\mu-1.5)^{*} \mathrm{~T}_{1}\right]+1.5 & \text { For } \mathrm{T}_{1}<1 \mathrm{sec} \text { and } \mu \geq 1.5
\end{array}
$$

Provided for the purposes of calculating $\mathrm{k}_{\mu}, \mathrm{T}_{1}$ shall not be taken less than 0.4 secs, see Clause 5.2.1.1 of NZS 1170.5.

Table 10. Soil Class E, values of inelastic spectrum scaling factor $\mathbf{k}_{\mu}$

$\begin{array}{lllll}\boldsymbol{\mu} & \begin{array}{l}\mathbf{T}_{\mathbf{1}}=\mathbf{0 . 4} \\ \text { secs }\end{array} & \begin{array}{l}\mathbf{T}_{\mathbf{1}}=\mathbf{0 . 6} \\ \text { secs }\end{array} & \begin{array}{l}\mathbf{T}_{\mathbf{1}}=\mathbf{0 . 8} \\ \text { secs }\end{array} & \begin{array}{l}\mathbf{T}_{\mathbf{1}} \geq \mathbf{1 . 0} \\ \text { secs }\end{array} \\ 1.0 & 1.00 & 1.00 & 1.00 & 1.0 \\ 1.25 & 1.25 & 1.25 & 1.25 & 1.25 \\ 2.0 & 1.70 & 1.80 & 1.90 & 2.0 \\ 3.0 & 2.10 & 2.40 & 2.70 & 3.0 \\ 4.0 & 2.50 & 3.00 & 3.50 & 4.0 \\ 5.0 & 2.90 & 3.60 & 4.30 & 5.0 \\ 6.0 & 3.30 & 4.20 & 5.10 & 6.0\end{array}$

\subsection{Equivalent Static Analysis Method}

\subsubsection{Ultimate Limit State Horizontal Design Actions}

The main ULS equation is set out using Equations 3.1(1) and 5.2(1) of NZS 1170.5; this is modified for the general situation as follows:

$$
\begin{aligned}
\mathrm{C}_{\mathrm{d}}\left(\mathrm{T}_{1}\right) & =\mathrm{C}\left(\mathrm{T}_{1}\right) * \mathrm{~S}_{\mathrm{p}} / \mathrm{k}_{\mu} * \mathrm{C}_{\mathrm{f}}(\xi) * \mathrm{~K} \\
& =\mathrm{C}_{\mathrm{h}}\left(\mathrm{T}_{1}\right) \mathrm{R} \mathrm{Z} \mathrm{N}\left(\mathrm{T}_{1}, \mathrm{D}\right) * \mathrm{~S}_{\mathrm{p}} / \mathrm{k}_{\mu} * \mathrm{C}_{\mathrm{f}}(\xi) * \mathrm{~K}
\end{aligned}
$$

$\mathrm{C}_{h}\left(\mathrm{~T}_{1}\right) \mathrm{Z} \mathrm{R} \mathrm{N}\left(\mathrm{T}_{1}, \mathrm{D}\right)$ represents the ordinate of the site's hazard spectra outlined above for the fundamental translational period of vibration $T_{1}$ for the chosen ULS return period earthquake.

$\mathrm{S}_{\mathrm{p}} \quad$ ULS Structural Performance factor.

$\mathrm{k}_{\mu} \quad$ ULS Ductility Factor set out in Clause 5.2.1.1 of NZS 1170.5 and requires an estimated of the structure's ULS fundamental period of translation vibration, $\mathrm{T}_{1}$. See Clause 5.2.1.1 of NZS 1170.5.

$\mathrm{C}_{\mathrm{f}}(\xi)$ ULS Damping Factor $=1.0$ unless the structural damping is not equal to $5 \%$ of critical damping.

K ULS scaling factor that accounts for a variety of effects that may need to be considered. Generally:

$=\mathrm{k}_{1} * \mathrm{k}_{2}$

$\mathrm{k}_{1} \quad$ ESA P-Delta scaling factor if P-Delta effects are required to be considered, see the approximate method as set out in Clause 6.5.4 Method A of NZS 1170.5 .

$\mathrm{k}_{2} \quad$ Material code earthquake actions modifier factor. Other factors can modify the basic seismic acceleration coefficient and these are set out in the relevant material codes. For example, in the Steel Structures Standard NZS 3404, there is the additional scaling factor $\mathrm{C}_{s}$ :

$\mathrm{C}_{s} \quad$ Steel Concentrically Braced Frame (CBF) seismic load modifier for CBF's with bracing effective in tension and compression. Refer to NZS 3404 Clause 12.12.3:

$1.0 \leq \mathrm{C}_{s} \leq 2.1$. As $\mu$ increases, so does the value of $\mathrm{C}_{\mathrm{s}}$.

\subsubsection{Serviceability Limit State Horizontal Actions}

The main SLS equation is taken from NZS 1170.5 Clause 5.2.1.2 that refers to Equations 3.1(1) and 5.2(1) of NZS 1170.5 ; this is modified for the general situation as follows:

$$
\mathrm{C}_{\mathrm{d}}\left(\mathrm{T}_{1}\right)=\mathrm{C}\left(\mathrm{T}_{1}\right) * \mathrm{~S}_{\mathrm{p}} / \mathrm{k}_{\mu} * \mathrm{C}_{\mathrm{f}}(\xi)
$$

Where:

$\mathrm{C}\left(\mathrm{T}_{1}\right)=$ the ordinate of the site's elastic hazard spectra outlined above for the fundamental translational period of vibration $T_{1}$ for the chosen SLS1/SLS2 return period earthquake. $\mathrm{T}_{1}$ for SLS1/SLS2 can be different to that for the ULS. The structure is generally stiffer for lower amplitude effects and this effect is shown in Clause C4.1.2.2 of NZS 1170.5 Supp 1.

$\mathrm{S}_{\mathrm{p}} \quad$ SLS1/SLS2 Structural Performance factor. 
$\mathrm{k}_{\mu}=\mathrm{SLS} 1 / \mathrm{SLS} 2$ Ductility Factor calculated using the chosen ductility factor for the SLS1/SLS2 limit state. This factor requires an estimated of the structure's fundamental period of translation vibration, $\mathrm{T}_{1}$ appropriate for the chosen serviceability limit state. See Clause 5.2.1.1 of NZS 1170.5.

$\mathrm{C}_{\mathrm{f}}(\xi)$ SLS1/SLS2 Damping Factor $=1.0$ unless the structural damping is not equal to $5 \%$ of critical damping for the particular serviceability limit state.

\subsubsection{Ultimate Limit State Vertical Design Actions}

The main ULS equation is set out in Equations 3.2(1) and 5.4(1) of NZS 1170.5:

$$
\begin{aligned}
\mathrm{C}_{\mathrm{vd}}\left(\mathrm{T}_{\mathrm{v}}\right) & =\mathrm{C}_{\mathrm{v}}\left(\mathrm{T}_{\mathrm{v}}\right) * \mathrm{~S}_{\mathrm{p}} * \mathrm{C}_{\mathrm{f}}(\xi) \\
& =0.7 \mathrm{C}_{\mathrm{h}}\left(\mathrm{T}_{\mathrm{v}}\right) \mathrm{R} \mathrm{Z} \mathrm{N}\left(\mathrm{T}_{\mathrm{v}}, \mathrm{D}\right) * \mathrm{~S}_{\mathrm{p}} * \mathrm{C}_{\mathrm{f}}(\xi)
\end{aligned}
$$

Where:

$C_{h}\left(T_{v}\right) Z R N\left(T_{v}, D\right)$ represents the ordinate of the site's hazard spectra outlined above for the fundamental vertical period of vibration $T_{v}$ for the chosen ULS return period earthquake.

$\mathrm{T}_{\mathrm{v}} \quad$ The fundamental vertical period of the structure or element under consideration.

$\mathrm{S}_{\mathrm{p}} \quad$ ULS Structural Performance factor.

$\mathrm{C}_{\mathrm{f}}(\xi)$ ULS Damping Factor $=1.0$ unless the structural damping is not equal to $5 \%$ of critical damping.

Clause 5.4.1 NZS 1170.5 sets $T_{v}=0.0$ secs for buildings. For industrial structures, the mass distribution may be such that significant masses for nonbuilding items may be not set over columns and a $\mathrm{T}_{\mathrm{v}}>0.0$ secs may be more appropriate.

\subsubsection{Serviceability Limit State Vertical Actions}

The main ULS equation is set out in Equations 3.2(1) and 5.4(1) of NZS 1170.5:

$\mathrm{C}_{\mathrm{vd}}\left(\mathrm{T}_{1}\right)=\mathrm{C}_{\mathrm{v}}\left(\mathrm{T}_{\mathrm{v}}\right) * \mathrm{~S}_{\mathrm{p}} * \mathrm{C}_{\mathrm{f}}(\xi)$

$\mathrm{C}_{\mathrm{vd}}\left(\mathrm{T}_{1}\right)=0.7 \mathrm{C}_{\mathrm{h}}\left(\mathrm{T}_{\mathrm{v}}\right) \mathrm{R} \mathrm{Z} \mathrm{N}\left(\mathrm{T}_{\mathrm{v}}, \mathrm{D}\right) * \mathrm{~S}_{\mathrm{p}} * \mathrm{C}_{\mathrm{f}}(\xi)$

Where:

$C_{h}\left(T_{v}\right) Z R N\left(T_{v}, D\right)$ represents the ordinate of the site's elastic hazard spectra outlined above for the fundamental vertical period of vibration $T_{1}$ for the chosen SLS return period earthquake.

$\mathrm{T}_{\mathrm{v}} \quad$ The fundamental vertical period of the structure or element under consideration.

Other terms are as above.

$\mathrm{S}_{\mathrm{p}} \quad$ SLS1 and/or SLS2 Structural Performance factor.

$\mathrm{C}_{\mathrm{f}}(\xi) \quad$ SLS1 and/or SLS2 Damping Factor $=1.0$ unless the structural damping is not equal to $5 \%$ of critical damping.

\subsection{Modal Response Spectrum Analysis Method (MRSA)}

\subsubsection{Ultimate Limit State Equation for Horizontal Design} Actions

The main ULS equation is set out in Equations 3.1(1) and 5.2(3) of NZS 1170.5:

$\mathrm{C}_{\mathrm{d}}(\mathrm{T})=\mathrm{C}(\mathrm{T}) * \mathrm{~S}_{\mathrm{p}} / \mathrm{k}_{\mu} * \mathrm{C}_{\mathrm{f}}(\xi) * \mathrm{~K}$
$=\mathrm{C}_{\mathrm{h}}(\mathrm{T}) \mathrm{R} \mathrm{Z} \mathrm{N}\left(\mathrm{T}_{1}, \mathrm{D}\right) * \mathrm{~S}_{\mathrm{p}} / \mathrm{k}_{\mu} * \mathrm{C}_{\mathrm{f}}(\xi) * \mathrm{~K}$

$\mathrm{C}_{h}(\mathrm{~T}) \mathrm{Z} \mathrm{R} \mathrm{N}\left(\mathrm{T}_{1}, \mathrm{D}\right)$ represents the site's elastic hazard spectra outlined above for the chosen ULS return period earthquake.

$\mathrm{S}_{\mathrm{p}} \quad$ ULS Structural Performance factor.

$\mathrm{k}_{\mu} \quad$ Ductility Factor set out in Clause 5.2.1.2 of NZS 1170.5 and requires an estimated of the structure's fundamental period of translation vibration, $\mathrm{T}_{1}$. See Clause 5.2.1.1 of NZS 1170.5.

$\mathrm{C}_{\mathrm{f}}(\xi) \quad$ ULS Damping Factor $=1.0$ unless the structural damping is not equal to $5 \%$ of critical damping.

K ULS scaling factor that accounts for a variety of effects that may need to be considered. Generally:

$=\mathrm{k}_{3} * \mathrm{k}_{4} * \mathrm{k}_{5}$

$\mathrm{k}_{3} \quad$ MRSA P-Delta scaling factor if P-Delta effects are required to be considered, see the approximate method as set out in Clause 6.5.4.1 Method A of NZS 1170.5 .

$\mathrm{k}_{4} \quad$ MRSA effects scaling factor $k$ if base shear comparisons with ESA base shear are required to be considered, see Clause 5.2.2.2 of NZS 1170.5.

$\mathrm{k}_{5} \quad$ Material code earthquake actions modifier factor. Other factors can modify the basic seismic acceleration coefficient and these are set out in the relevant material codes. For example, in the Steel Structures Standard NZS 3404, there is the additional scaling factor Cs:

$\mathrm{C}_{\mathrm{s}} \quad$ Steel Concentrically Braced Frame (CBF) seismic load modifier for CBF's with bracing effective in tension and compression. Refer to NZS 3404 Clause 12.12.3:

$1.0 \leq \mathrm{C}_{\mathrm{s}} \leq 2.1$. As $\mu$ increases, so does the value of $\mathrm{C}_{\mathrm{s}}$.

\subsubsection{Serviceability Limit State Equation for Horizontal Design Actions}

The main SLS equation is given in the corrected version of Equation 5.2(4) of NZS 1170.5. This can be written as:

$\mathrm{C}_{\mathrm{d}}(\mathrm{T})=\mathrm{C}(\mathrm{T}) * \mathrm{~S}_{\mathrm{p}} / \mathrm{k}_{\mu} * \mathrm{C}_{\mathrm{f}}(\xi)$

Where:

$\mathrm{C}(\mathrm{T})=$ the site's elastic hazard spectra outlined above for the chosen SLS return period earthquake.

$\mathrm{S}_{\mathrm{p}} \quad$ SLS1 and/or SLS2 Structural Performance factor.

$\mathrm{k}_{\mu}=$ SLS1/SLS2 Ductility Factor calculated using the chosen ductility factor for the SLS1/SLS2 limit state.

$\mathrm{C}_{\mathrm{f}}(\xi) \quad \mathrm{SLS} 1$ and/or SLS2 Damping Factor $=1.0$ unless the structural damping is not equal to $5 \%$ of critical damping.

\subsubsection{Limit State Equations for Vertical Design Actions}

The main ULS and SLS equations are set out in Equations 3.2(1) and 5.4(1) of NZS 1170.5. If required to be considered, for both limit states, the vertical design spectra shall be taken as $70 \%$ of the horizontal spectra set out above with $\mathrm{k}_{\mu}=1.0$ for the ULS. 


\section{GUIDELINES FOR EARTHQUAKE ANALYSIS OF COMBINATION STRUCTURES}

\subsection{General}

Combination structures are nonbuilding-like structural systems that support nonbuilding items that weigh $20 \%$ or more than the weight of the structural support, see Section 4.5.2 above. They generally will have difficulty meeting the horizontal and/or vertical regularity requirements of Section 4.5 of NZS 1170.5. Thus depending on the overall height and the fundamental period of the combined system, the equivalent static analysis method may not be applicable. See Clause 6.1.3.1 of NZS 1170.5. Photographs A.5 and A.6 in Appendix A show some typical industrial combination structures.

Where the examples in Appendix B relate to the guidelines for the seismic design of combination structures, these are highlighted during this section.

$$
\begin{aligned}
& W_{\mathrm{p}} \quad=\text { Weight of nonbuilding item } \\
& T_{\mathrm{p}} \quad=\text { Fundamental horizontal period of nonbuilding } \\
& \text { item } \\
& W_{\mathrm{s}} \quad=\text { Weight of support structure } \\
& \mu_{\mathrm{p}} \quad=\text { Structural Ductility Factor for nonbuilding item } \\
& \mu_{\mathrm{s}} \quad=\text { Structural Ductility Factor for support structure } \\
& S_{\mathrm{pe}} \quad=\text { Structural Performance Factor for nonbuilding } \\
& \text { item } \\
& S_{\mathrm{ps}} \quad=\text { Structural Performance Factor for support } \\
& \text { structure } \\
& \mathrm{C}_{\mathrm{f}}(\xi)_{\mathrm{p}} \quad=\text { Damping Factor for nonbuilding item } \\
& \mathrm{C}_{\mathrm{f}}(\xi)_{\mathrm{s}} \quad=\text { Damping Factor for support structure } \\
& k_{\mu} \quad=\text { Inelastic Spectrum Scaling Factor } \\
& R_{\mathrm{p}} \quad=\text { Part Risk Factor for nonbuilding item } \\
& C_{\mathrm{ph}} \quad=\text { Part Horizontal Response Factor for nonbuilding }
\end{aligned}
$$

\subsection{Method of Analysis}

Section 4.4.3 and Appendix 4.B of the ASCE guidelines (1997) outlines their recommended analysis approach. The method of analysis differs depending on whether the nonbuilding item is flexible ( $\left.T_{\mathrm{p}}>0.06 \mathrm{secs}\right)$ or not $\left(T_{\mathrm{p}} \leq 0.06\right.$ secs). The two approaches are outline in more detail below.

One aspect of the ASCE approach that has not been universally adopted is where ASCE recommends that the design value for the structural ductility factor for the analysis of the supporting structure is the minimum of that for the nonbuilding item or the supporting structure, i.e. $\mu=\left[\mu_{\mathrm{p}}\right.$, $\left.\mu_{\mathrm{s}}\right]_{\min }$. FEMA 450 Clause 14.1.5 differs in that for rigid nonbuilding items, $\left(T_{\mathrm{p}} \leq 0.06 \mathrm{secs}\right)$ the combined system is designed using the structural ductility factor for the supporting structure, i.e. $\mu=\mu_{\mathrm{s}}$. For flexible nonbuilding items, FEMA 450 restricts $\mu$ to being $\leq 3.0$. The FEMA 450 approach is less conservative for the design of the supporting structure especially for those that are supporting critical items that are designed by working stress methods and may not be able to exhibit any great levels of ductility.

For those structures that are supporting pressure equipment covered by PECPR, the minimum seismic coefficients set out in NZS 1200 Appendix I often govern. Unless the site has a specific seismic hazard study, the effect of the NZS 1200 Appendix I minimum values usually limits $\mu$ to a value of
1.25. This effect is illustrated in Examples 3 and 5 in Appendix B.

Table 11 gives the two design cases, Case 1 and Case 2 and details how the seismic coefficients shall be derived for the ULS. Case 2 can always be used in lieu of undertaking a Case 1 analysis.

\subsubsection{Rigid Nonbuilding Items - Case 1}

The actions on the supporting structure are determined using the procedures outlined above in Sections 7.4 or 7.5 with the overall heights adjusted for the masses of the rigid nonbuilding items.

The actions on the nonbuilding item are determined using the procedures outlined below in Section 9. These are based on Section 8 of NZS 1170.5 for parts and components. The ductility of the supporting structure has no input into the derived horizontal earthquake actions for the nonbuilding item. The chosen value for $\mu_{\mathrm{p}}$ does have an effect on the magnitude of $F_{\mathrm{ph}}$ and the designer needs to assess what is the maximum value that can be given to the structural ductility factor for the nonbuilding item.

Suggested values for the part structural ductility factor have been given in Table C8.2 of NZS 1170.5 Supp 1. Note 4 to this table states that the designer needs to consider when the nonbuilding item can start to sustain damage and whether continuity of operation is required after a ULS event. C8.6 of NZS 1170.5 Supp 1 states:

In many instances, especially with mechanical services plant, the design of the part is based on non-structural considerations, and proportioning is such that yielding is unlikely and $\mu_{p}$ should be taken as 1.0.

It is unrealistic for a designer of a supported nonbuilding item designed by working stress methods to assume a $\mu_{\mathrm{p}}>$ 1.25 , determine $F_{\mathrm{ph}}$ then multiply this by 0.8 to obtain a working stress level of earthquake design force, design the nonbuilding item to the allowable working stress code limits and assume that the item will be in working order or undamaged after a significant seismic event.

The values for $\mu_{\mathrm{p}}$ in Table C8.2 reflect the ability of the item to carry load in the post-elastic phase of their horizontal force induced stress/strain relationship. Thus yielding and permanent deformations have occurred and if this situation cannot be countenanced, $\mu_{\mathrm{p}} \leq 1.25$. This is the apparent problem with the ALA (2002) approach where the component response modification factor $\mathrm{R}_{\mathrm{p}}$ that performs a similar function to $S_{\mathrm{p}} / \mathrm{k}_{\mu}$ and is used in determining the seismic input can be set as high as 3.5. Yet the ALA Equation S304-1 shown in Section 6.21 above is an elastic design equation.

The actions on the anchorages for rigid nonbuilding item are determined using the procedures outlined in Clause 8.7 of NZS 1170.5. Generally anchorages are needed to restrain the item from sliding. 
Table 11. Analysis Methods for Combination Structures

\begin{tabular}{|c|c|c|}
\hline Description & Case 1 & Case 2 \\
\hline Period of supported nonbuilding item & $T_{\mathrm{p}} \leq 0.06 \mathrm{secs}$ & $T_{\mathrm{p}}>0.06 \mathrm{secs}$ \\
\hline $\begin{array}{l}\text { Fundamental horizontal period of } \\
\text { system }\end{array}$ & $\mathrm{T}_{1}$ determined for combined system & $\mathrm{T}_{1}$ determined for combined system \\
\hline Structural ductility factor & $\mu=\mu_{\mathrm{s}}$ & $\mu=\left[\mu_{\mathrm{p}}, \mu_{\mathrm{s}}\right]_{\min }$ and $\mu \leq 3$ \\
\hline Structural performance factor & $\mathrm{S}_{\mathrm{p}}=\mathrm{S}_{\mathrm{ps}}$ & $\mathrm{S}_{\mathrm{p}}=\left[\mathrm{S}_{\mathrm{pe}}, \mathrm{S}_{\mathrm{ps}}\right]_{\max }$ \\
\hline System damping & $\mathrm{C}_{\mathrm{f}}(\xi)=\mathrm{C}_{\mathrm{f}}(\xi)_{\mathrm{s}}$ & $\mathrm{C}_{\mathrm{f}}(\xi)=\left[\mathrm{C}_{\mathrm{f}}(\xi)_{\mathrm{p}}, \mathrm{C}_{\mathrm{f}}(\xi)_{\mathrm{s}}\right]_{\max }$ \\
\hline Seismic Weight & $\mathrm{W}_{\mathrm{t}}=\mathrm{W}_{\mathrm{p}}+\mathrm{W}_{\mathrm{s}}$ & $\mathrm{W}_{\mathrm{t}}=\mathrm{W}_{\mathrm{p}}+\mathrm{W}_{\mathrm{s}}$ \\
\hline Heights to seismic masses & $\begin{array}{l}\text { Heights to masses adjusted for mass of } \\
\text { nonbuilding item }\end{array}$ & $\begin{array}{l}\text { Floor heights include those to masses of } \\
\text { nonbuilding items }\end{array}$ \\
\hline ULS Inelastic Spectrum Scaling factor & $\begin{array}{l}\mathrm{k}_{\mu} \text { determined for } \mathrm{T}_{1} \text { based on the site } \\
\text { soil class and fundamental period (with } \\
\mathrm{T}_{1} \text { taken not less than } 0.4 \text { secs) }\end{array}$ & $\begin{array}{l}\mathrm{k}_{\mu} \text { determined for } \mathrm{T}_{1} \text { based on the site } \\
\text { soil class and fundamental period (with } \\
\mathrm{T}_{1} \text { taken not less than } 0.4 \text { secs) }\end{array}$ \\
\hline Horizontal design action coefficient & $\mathrm{C}_{\mathrm{d}}\left(\mathrm{T}_{1}\right)$ based on system's period & $\begin{array}{l}\mathrm{C}_{\mathrm{d}}\left(\mathrm{T}_{1}\right) \text { based on period of combined } \\
\text { system }\end{array}$ \\
\hline Base Shear & $\begin{array}{l}\mathrm{V}=\mathrm{C}_{\mathrm{d}}\left(\mathrm{T}_{1}\right) \mathrm{W}_{\mathrm{t}} \\
\text { For structures supporting pressure } \\
\text { equipment; } \mathrm{C}_{d}\left(\mathrm{~T}_{1}\right) \geq \text { applicable value } \\
\text { from Table } \mathrm{I} 1 \text { of NZS } 1200\end{array}$ & $\begin{array}{l}\mathrm{V}=\mathrm{C}_{\mathrm{d}}\left(\mathrm{T}_{1}\right) \mathrm{W}_{\mathrm{t}} \\
\text { For structures including modelled } \\
\text { pressure equipment; } \mathrm{C}_{\mathrm{d}}\left(\mathrm{T}_{1}\right) \geq \text { applicable } \\
\text { value from Table I1 of NZS } 1200\end{array}$ \\
\hline Support structure's member forces & $\begin{array}{l}\text { Determined from model by either } \\
\text { equivalent static analysis or modal } \\
\text { response spectrum analysis }\end{array}$ & $\begin{array}{l}\text { Determined from combined model by } \\
\text { either equivalent static analysis or } \\
\text { modal response spectrum analysis }\end{array}$ \\
\hline Nonbuilding item's member forces & $\begin{array}{l}\text { Forces on nonbuilding item } F_{\mathrm{ph}} \\
\text { determined from Section } 8 \text { of NZS } \\
1170.5 \text { using } T_{\mathrm{p}}, \mu_{\mathrm{p}}, R_{\mathrm{p}}, C_{\mathrm{ph}} \text { and } \mathrm{C}_{\mathrm{f}}(\xi)_{\mathrm{s}} \\
\text { applied through the centre of gravity of } \\
\text { the nonbuilding item. } \\
\text { WSD design forces }=0.8 F_{\mathrm{ph}} \text { with } F_{\mathrm{ph}} \\
\text { obtained using } \mu_{\mathrm{p}} \leq 1.25\end{array}$ & $\begin{array}{l}\text { WSD design forces obtained from } \\
\text { combined model analysed using } \mu \leq \\
1.25\end{array}$ \\
\hline $\begin{array}{l}\text { Nonbuilding item's anchorages design } \\
\text { forces }\end{array}$ & $\begin{array}{l}\text { Forces on nonbuilding item's } \\
\text { anchorages are determined from Section } \\
8.7 \text { of NZS } 1170.5 \text { using } \mu_{\mathrm{p}}=1.25, T_{\mathrm{p}} \text {, } \\
R_{\mathrm{p}}, C_{\mathrm{ph}} \text { and } \mathrm{C}_{\mathrm{f}}(\xi)_{\mathrm{s}} \text { applied through the } \\
\text { centre of gravity of the nonbuilding item }\end{array}$ & $\begin{array}{l}\text { Determined from combined model by } \\
\text { either equivalent static analysis or } \\
\text { modal response spectrum analysis using } \\
\text { a design philosophy consistent with } \\
\text { Section 12.9.1 of NZS } 3404 \text {. }\end{array}$ \\
\hline
\end{tabular}

\subsubsection{Flexible Nonbuilding Items - Case 2}

The nonbuilding item is included in the analysis model as specific structural members and the masses of the nonbuilding items are kept separate from the rest of the supporting structure. The actions on the combined structure are determined using the procedures outlined above in Sections 7.4 or 7.5 with the overall heights including those to the masses of the flexible nonbuilding items. The actions on the nonbuilding item are determined also using the combined model.

The design actions on the anchorages for the flexible nonbuilding item should be determined using a connection design philosophy similar to that set out in Clause 12.9.1 of NZS 3404. This philosophy ensures that the connection between the supporting structure and the nonbuilding item is not the weakest link whose premature failure would invalidate the analysis assumptions.

To derive any benefit in providing a ductile support structure with a $\mu>3$ for a combination structure to reduce the earthquake forces on nonbuilding items, a special study involving non-linear time history analyses would be necessary as per Clause C8.8 NZS 1170.5:Supp 1.

\subsection{Example 3 Discussion}

The example is for 3 rigid pressure vessels supported 5 metres above ground in the Blenheim area so the calculation is an example of a Case 1 analysis. The weight of the 3 pressure vessels being over 2.5 times the weight of the supporting reinforced concrete structure.

NZS 3101 permits a maximum structural ductility factor of 6 for a moment resisting frame but as no site specific seismic hazard study is available, the NZS 1200 Appendix I minimum seismic coefficient of 0.6 applies for the pressure vessels (for the WSD case), their supporting structure and their foundation using limit state design. The example shows that the use of $\mu_{\text {uls }} \geq 2$ develops a $C_{d}\left(T_{1}\right)_{\text {uls }}<0.60$ for the supporting structure. Hence a nominally ductile structure with $\mu_{\text {uls }}=1.25$ complies with the DoL ACPPE with the least amount of analysis work. 
To design the reinforced concrete structure as a ductile structure with $\mu_{\mathrm{uls}}=6$, a seismic hazard study would be required. This would permit a MRSA or an ESA to be done and the use of seismic coefficients less than those set in NZS 1200 Appendix I.

If the vessels were flexible instead of being rigid, to design the reinforced concrete structure as a ductile structure with $\mu_{\mathrm{uls}}=6$, a nonlinear NITHA special study would be required as per Clause 6.4 of NZS 1170.5. To progress a simpler design approach and to design the reinforced concrete structure either as a ductile structure with $\mu_{\mathrm{uls}}=3$, the maximum recommended by FEMA 450 without a special study, or as a structure of limited ductility with $\mu_{\text {uls }}=2$, the seismic hazard study would be required. This would permit a MRSA or an ESA to be done and the use of seismic coefficients less than those set in NZS 1200 Appendix I.

The total ULS displacements were checked in accordance with Section 6.20 above to double check whether P-Delta effects should have been incorporated.

The parts analysis for the seismic forces on the vessels has assumed that although the vessels have wall thickness of 90 $\mathrm{mm}$, there will be some inherent ductility available through their connections to the concrete structure, their shape and material of construction, so $\mu_{\mathrm{p}}$ was taken as 1.25 . If the vessels were operating at very cold temperatures or were made from steel with limited notch ductility, a $\mu_{\mathrm{p}}=1$ would be more appropriate.

Because the vessels were supported by a slab and not placed directly over the supporting columns, the fundamental vertical period of the structure, $\mathrm{T}_{\mathrm{v}}$ was taken for the example as being greater than 0.0 secs. This gave a ULS $\mathrm{F}_{\mathrm{pv}}=$ $\pm 0.69 \mathrm{~W}_{\mathrm{p}}$ that would reduce to $\pm 0.26 \mathrm{~W}_{\mathrm{p}}$ if $\mathrm{T}_{\mathrm{v}}=0.0 \mathrm{secs}$.

The Part Category was taken as P.1 to give a ULS seismic load for the vessels. The notes to Table 8.1 in NZS 1170.5 have to be interpreted for industrial plant utilising the intent that critical, hazardous or heavy items supported above grade need to perform for the ULS or SLS2 limit states. All other non-critical nonbuilding items only need to perform satisfactorily in the serviceability limit state SLS1.

\section{GUIDELINES FOR EARTHQUAKE ANALYSIS OF PARTS AND COMPONENTS}

\subsection{General}

The derivation of the applicable seismic forces is undertaken as per Section 8 of NZS 1170.5, "Requirements for Parts and Components" including any deflection induced forces as per NZS 1170.5 Clause 8.5.3 and Section 6.21 above.

There is no exclusion in Section 8 in its use when the supporting structure is required to be analysed by a method other than ESA as per Clause 6.1.3.1 of NZS 1170.5. It is possible to use the results from a MRSA substituted into Equation 8.2(1) of NZS 1170.5 as an alternative to the estimated floor accelerations, the product $C(0) * C_{\mathrm{Hi}}$ although there are no specific guidelines given in the standard compared to that given in FEMA 450 and ASCE-07.

Where the examples in Appendix B relate to the guidelines for the seismic design of parts and components, these are highlighted during this section.

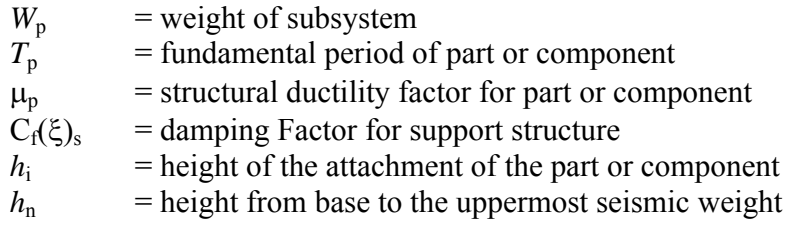

\subsection{Floor Height Coefficient $C_{\mathrm{Hi}}$}

The use of the three equations to determine the value of the floor height coefficient, $C_{\mathrm{Hi}}$ in Clause 8.3 of NZS 1170.5 can be confusing. The use of equation 8.3(3) $\left(C_{\mathrm{Hi}}=3.0\right)$ when for $h_{\mathrm{n}}<12 \mathrm{~m}$ is not specifically excluded but for items attached to the top of low level structures appears unduly onerous. Clarity and serving the apparent intent of Clause 8.3 would be achieved if NZS 1170.5 equation 8.3(3) was written:

$$
C_{\mathrm{Hi}}=3.0 \text { for } h_{\mathrm{i}} \geq 0.2 h_{\mathrm{n}} \text { and } h_{\mathrm{n}} \geq 12 \mathrm{~m} \quad \text { Eqn 8.3(3) }
$$

\subsection{Damping}

When the supporting structure is analysed using a system damping $\xi<5 \%$, for the design of parts or components attached to such a structure, the designer needs to consider whether the design action on the part or component need to be adjusted for the likely greater response occurring in the supporting structure. The damping scaling factor $\mathrm{C}_{\mathrm{f}}(\xi)_{\mathrm{s}}$ from Section 6.17 above can be added into the NZS 1170.5 Equation 8.5(1) as shown below to account for the greater response:

$$
F_{\mathrm{ph}}=C_{\mathrm{p}}\left(T_{\mathrm{p}}\right) C_{\mathrm{ph}} R_{\mathrm{p}} \mathrm{C}_{\mathrm{f}}(\xi)_{\mathrm{s}} W_{\mathrm{p}} \leq 3.6 W_{\mathrm{p}}
$$

\subsection{Method of Analysis}

\subsubsection{When Supporting Structure is Analysed using ESA}

Table 12 gives the design case for the ULS/SLS2/SLS1 limit states and details how the seismic coefficients shall be derived. In general, the method of calculating the response for the part or component is not dependent on whether the part or component is rigid or flexible. The value for the period of the part, $T_{\mathrm{p}}$ only affects the value for the part spectral shape coefficient, $C_{\mathrm{i}}\left(T_{\mathrm{p}}\right)$.

The results for the horizontal design earthquake actions on a part or component as per a NZS 1170.5 Section 8 analysis is also not dependent on the chosen or actual structural ductility factor, $\mu_{\mathrm{s}}$ of the supporting structure. The only way to reduce the design action $F_{\mathrm{ph}}$ is to increase the $\mu_{\mathrm{p}}$, the structural ductility factor for the part or component. For items designed using working stress methods, such as pressure retaining systems, this is often not desirable or within the bounds of the design analysis and a $\mu_{p}=1.25$ is the maximum level of structural ductility.

\subsubsection{When Supporting Structure is Analysed using MRSA}

FEMA 450 Eqn 6.2-2 outlines how the attachment point accelerations determined from a MRSA can be used to determine $F_{\mathrm{ph}}$. When FEMA 450 Eqn $6.2-2$ is compared to the equations in Section 8 of NZS 1170.5, it can be seen that the acceleration $\mathrm{a}_{\mathrm{i}}$ at Level i determined from a MRSA can be substituted for $C(0) * C_{\mathrm{Hi}}$ within NZS 1170.5 Eqn 8.2(1) to determine $C_{\mathrm{p}}\left(T_{\mathrm{p}}\right)$. The MRSA shall be undertaken as per 7.5 above assuming $\mu=1 . C_{\mathrm{p}}\left(T_{\mathrm{p}}\right)$ then can be substituted into NZS 1170.5 Eqn $8.5(1)$ to determine the horizontal design action $F_{\text {ph }}$. 
Depending on the software used to do the MRSA, $a_{i}$ may be part of the output generated or it may have to be calculated from the deflected shape by established methods of dynamic analysis.

Table 12. Inertia Force Analysis Method for Parts and Components

\begin{tabular}{|c|c|}
\hline Description & Case 3 \\
\hline Period of part or component & $T_{\mathrm{p}}=$ any value \\
\hline ULS Part Category & P.1 through to P.4 \\
\hline SLS2 Part Category & P.5 For Importance Level 4 or 5 items only \\
\hline SLS1 Part Category & P.6 or P.7 \\
\hline Structural ductility factor & $\mu=\mu_{\mathrm{p}}$ \\
\hline System damping & $\mathrm{C}_{\mathrm{f}}(\xi)=\mathrm{C}_{\mathrm{f}}(\xi)_{\mathrm{s}}$ \\
\hline $\begin{array}{l}\text { Site Hazard Coefficient for } \\
\mathrm{T}=0 \text { secs, } C(0)\end{array}$ & Sections 3.1 and 8.2 \\
\hline Floor Height Coefficient $\mathrm{C}_{\mathrm{Hi}}$ & Section 8.3 \\
\hline Part Spectral Shape Coefficient $\mathrm{C}_{\mathrm{i}}\left(T_{\mathrm{p}}\right)$ & Section 8.4 \\
\hline Design Response Coefficient $C_{\mathrm{p}}\left(T_{\mathrm{p}}\right)$ & $\begin{array}{l}\text { Equation 8.2(1) } \\
C_{\mathrm{p}}\left(T_{\mathrm{p}}\right)=C(0) C_{\mathrm{Hi}} C_{\mathrm{i}}\left(T_{\mathrm{p}}\right)\end{array}$ \\
\hline Part Risk Factor $R_{\mathrm{p}}$ & Table 8.1 \\
\hline Part Response Factor $C_{\mathrm{ph}}$ & Table 8.2 \\
\hline Horizontal Design Action $F_{\mathrm{ph}}$ & $\begin{array}{l}\text { Equation 8.5(1): } \\
F_{\mathrm{ph}}=C_{\mathrm{p}}\left(T_{\mathrm{p}}\right) C_{\mathrm{ph}} R_{\mathrm{p}} \mathrm{C}_{\mathrm{f}}(\xi)_{\mathrm{s}} W_{\mathrm{p}} \leq 3.6 W_{\mathrm{p}} \\
\text { Item checked for } F_{\mathrm{ph}} \text { acting in two principal directions separately. } \\
\text { Internal forces and moments }=\mathrm{M}_{i x} \text { and } \mathrm{M}_{i y} \text {. }\end{array}$ \\
\hline $\begin{array}{l}\text { WSD design force on part or component }= \\
0.8 F_{\mathrm{ph}}\end{array}$ & $\begin{array}{l}F_{\mathrm{ph}} \text { calculated as above with } \mu_{\mathrm{p}} \leq 1.25 \\
\text { Item checked for } 0.8 F_{\mathrm{ph}} \text { acting in two principal directions separately. } \\
\text { For pressure equipment components, } 0.8 F_{\mathrm{ph}} \geq \text { appropriate value from } \\
\text { Table I1 NZS 1200. Internal forces and moments }=0.8 \mathrm{M}_{i x} \text { and } 0.8 \mathrm{M}_{i y} \text {. }\end{array}$ \\
\hline $\begin{array}{l}\text { For item supported on same structure but at } \\
\text { different levels, inter-storey deflections } \delta_{\text {is }}\end{array}$ & Section 7.3 \\
\hline $\begin{array}{l}\text { For item supported on different structures, } \\
\text { design horizontal deflections } \delta_{h}\end{array}$ & $\begin{array}{l}\text { Section } 7.2 \\
\text { Item analysed for ULS/SLS2/SLS1 deflection cases with the item's } \\
\text { imposed deflections in two principal directions analysed separately. } \\
\text { Internal forces and moments }=\mathrm{M}_{\delta x} \text { and } \mathrm{M}_{\delta y} \text {. }\end{array}$ \\
\hline $\begin{array}{l}\text { Internal limit state horizontal design actions } \\
\mathrm{M}_{h x u} \text { and } \mathrm{M}_{h y u}\end{array}$ & $\begin{array}{l}\mathrm{M}_{h x u}=\left(\mathrm{M}_{i x}{ }^{2}+\mathrm{M}_{\delta x}{ }^{2}\right)^{0.5} \text { and } \\
\mathrm{M}_{h y u}=\left(\mathrm{M}_{i y}{ }^{2}+\mathrm{M}_{\delta y}{ }^{2}\right)^{0.5}\end{array}$ \\
\hline $\begin{array}{l}\text { Internal WSD horizontal design actions } \mathrm{M}_{h x w} \\
\text { and } \mathrm{M}_{h y w}\end{array}$ & $\begin{array}{l}\mathrm{M}_{\mathrm{hxw}}=\left[\left(0.8 \mathrm{M}_{i x}\right)^{2}+\mathrm{M}_{\delta x}{ }^{2}\right]^{0.5} \text { and } \\
\mathrm{M}_{\mathrm{hyw}}=\left[\left(0.8 \mathrm{M}_{i y}\right)^{2}+\mathrm{M}_{\delta y}^{2}\right]^{0.5}\end{array}$ \\
\hline Vertical limit state design action $\mathrm{F}_{p v}$ & $\begin{array}{l}\text { Equation } 8.5(2) \\
\mathrm{F}_{\mathrm{pv}}=C_{\mathrm{vd}} C_{\mathrm{pv}} R_{\mathrm{p}} W_{\mathrm{p}} \leq 2.5 W_{\mathrm{p}} \\
\text { Internal forces and moments }=\mathrm{M}_{i v}\end{array}$ \\
\hline WSD vertical design action $=0.8 \mathrm{~F}_{p v}$ & $\begin{array}{l}\mathrm{F}_{\mathrm{pv}} \text { calculated as above with } \mu_{\mathrm{p}}=1.0 \\
\text { Internal forces and moments }=0.8 \mathrm{M}_{i v}\end{array}$ \\
\hline Total limit state design actions & $\begin{array}{l}\mathrm{M}_{h x u}+\mathrm{M}_{i v} \text { and } \\
\mathrm{M}_{h y u}+\mathrm{M}_{i v}\end{array}$ \\
\hline Total WSD design actions & $\begin{array}{l}\mathrm{M}_{h x w}+0.8 \mathrm{M}_{i v} \text { and } \\
\mathrm{M}_{h y w}+0.8 \mathrm{M}_{i v}\end{array}$ \\
\hline $\begin{array}{l}\text { Anchorages design force for part or } \\
\text { component }\end{array}$ & Forces on anchorages are determined from Section 8.7 using $\mu_{\mathrm{p}}=1.25$ \\
\hline
\end{tabular}




\subsection{Examples 2 and 5 Discussion}

\subsubsection{Importance Levels}

For the piping in Example 2, the importance level of 4 given to the piping is derived from the pressure piping hazard level being classed as B as per AS 4343 and that some form of operational continuity is required during and immediately after a major earthquake. The design working life has been taken as being the same as the vessel it is attached to. A case could be made for having the design working life set at a shorter duration if the plant owner has a maintenance policy of replacing such critical items on a regular basis e.g. 25 years.

\subsubsection{SLS2 Design Case}

For the SLS2 case, the chosen displacement ductility factor for the piping of 1.0 as per Clause 8.6 of NZS 1170.5 combined with the required return period for the SLS2 case of 500 years, results in a severe loading condition for the piping. The SLS2 case would need to be investigated by the pipe stress engineer as it could be the critical design loading in Example 2 especially if the over-stress allowance of $1 / 3$ is forgone as recommended. The SLS2 inter-storey deflections would have to be determined as per Clauses 7.3.2 and 7.2.2 of NZS 1170.5 so that the design actions due to seismic anchor motion for the SLS2 case could be analysed.

\subsubsection{Deflection Induced Actions or SAM}

NZS 1170.5 Clause 8.5.3 states that for items supported on more than one level, the deflection induced actions are determined from Clause 7.3. As the pipe in Example 2 is passing up largely the full height of the vessel, the calculated inter-storey deflections are then summed up the full height to determine the worst case deflection scenario for the pipe support attachment points. The deflections at the attachment points in the two principal directions would need to be fed into the pipe stress analysis as separate loading cases to determine the SAM related actions.

\subsubsection{Inertia Actions on Piping}

In Example 2, the elevated locations of the supports ensure that the design horizontal accelerations are well above the minimums required by ACPPE. In Example 5, the lower elevation of the pipe support, shorter design working life and lower zero period spectral shape factor $C_{h}(T)$ give a ULS spectral ordinate of the part of 0.92 compared with the Example 2 value of 2.59 for the upper supports.

For Example 5, the design horizontal WSD acceleration of $0.74 \mathrm{~g}$ for the pressure piping is greater than that required by ACPPE of $0.60 \mathrm{~g}$. Using the $0.74 \mathrm{~g}$, the ULS case along with an over-stress allowance of $1 / 3$ may not be critical and a check should be made into the SLS1 case with its no damage requirements. The SLS1 unscaled design acceleration of $0.31 \mathrm{~g}$ lead to a higher estimate of $1 \%$ damping for the system damping rather than the minimum recommended of $0.5 \%$. With this assumption, the SLS1 design acceleration $=0.47 \mathrm{~g}$.

\subsubsection{Combining Earthquake Actions}

In both examples, the horizontal inertia effects have been combined with the horizontal earthquake induced deflection effects on the piping by the square root of the sum of the squares as per the ALA (2000) recommendations. Whereas the vertical effects have been combined in a vectorial fashion as $70 \%$ of the peak vertical acceleration is taken as occurring with the peak horizontal acceleration as per Clause 3.2 of NZS 1170.5 .

\subsubsection{Pipe Support Design}

In Example 5, the option to design the pipe supports as a limited ductility structure with $\mu=3$ is investigated. This was found to have a number of implications for the choice as a limited ductility structure:

- The earthquake design actions can be applied separately without concurrency being considered.

- The minimum value for the structural performance factor $S_{\mathrm{p}}$ was taken as 0.7 even though the support is a single vertical cantilever structure with no redundancy.

- The ULS damping was taken as $5 \%$ of critical assuming that some yielding would occur. This would need to be checked when the final section size and capacity ratio found. The steel design material standard's section stability requirements for ductile members, even though lightly loaded, often force the use of compact steel sections that are in the end not highly stressed, yielding may not occur even under the $\mathrm{E}_{\max }$ case and the effective damping may be less than $5 \%$.

- The ULS seismic design coefficient for the support of 0.29 is less than that permitted by the ACPPE and NZS 1200 Appendix I. The minimum required $=0.60$ and this would be used for the design of the steel support.

- The seismic coefficient required to yield the member at its maximum possible yield strength would be much greater than the maximum likely elastic response.

- To design the foundation for bearing and the HD bolts an elastic seismic coefficient $=0.88$ is required. This is greater than the minimum required by the ACPPE of 0.60 .

- To design the foundation for stability, a seismic coefficient of 0.96 is required.

The design option to analyse the pipe support as a nominally ductile structure with $\mu=1.25$ had the following notable points:

- For a $\mu=1.25$ design, the earthquake directions of action are as per NZS 1170.5 Clause 5.3.1.2, 100\% on one axis simultaneously with $30 \%$ along the perpendicular axis.

- The unscaled 5\% damped design accelerations were for the ULS $=0.71 \mathrm{~g}$ and for SLS1 $=0.21 \mathrm{~g}$. Thus the assumed levels of damping for the design case were taken to be higher than the minimums recommended in Table 4.

- To design the foundation for bearing and stability and the HD bolts, an elastic seismic coefficient $=$ 1.16 is required. This is greater than the minimum required by the ACPPE of 0.60 .

\section{LOADS AND LOAD COMBINATIONS}

\subsection{General}

Load combinations including seismic and wind forces shall be assessed in terms of AS/NZS 1170.0 Clauses 4.2.1 and 4.2.2 for the ultimate limit states of stability and strength respectively and Clause 4.3 for serviceability limit states. 
Structures and foundations should be designed for the most critical effects resulting from the combination of all applicable loads that may reasonably occur simultaneously. This shall include all the load combinations stipulated in Sections 4.2, 4.3 and 4.4 of AS/NZS 1170.0.

Suggested load combinations including seismic and wind forces have been given below.

\subsection{Loads for Industrial \& Petrochemical Plants}

In industrial and petrochemical facilities, different types of loadings affect the design of members and structures than those normally considered in building standards. All applicable loads shall be reviewed and their supports designed for their effects. These loads typically include:

1. $\mathrm{G}=$ Dead Load. Is the total weight of materials forming the permanent part of a structure including structural framing, platforms, walls, fixed equipment, vessels, piping, insulation and fireproofing.

2. $\mathrm{DV}=$ Vessel Operating Load. Is the weight of any liquids, gas or solids within a vessel and any attached equipment and piping during normal operations.

3. DP $=$ Piping Operating Load. Is the weight of any liquids, gas or solids within piping or in-line equipment during normal operations plus internal pressure effects.

4. $\mathrm{Q}=$ Live Load. Is the weight of all movable loads such as personnel, tools, stored material, movable partitions, cranes and hoists, maintenance loads, impact, surge forces, vibration and horizontal forces from moving equipment. The design loads shall be maximum loads likely to result from the intended use and shall not be less than those given in AS/NZS 1170.1.

5. $\mathrm{E}=$ Earthquake Load. Is the inertia and differential movement effect due to the design earthquake for the chosen limit state.

6. $\mathrm{W}=$ Wind Load. Is the wind force acting on the structure or members. For the determination of wind loads, refer to AS/NZS 1170.3.

7. $\mathrm{TF}=$ Support Friction Loads. These are caused by the sliding of pipes or by the sliding of either horizontal vessels or heat exchangers on their supports in response to thermal expansion. In lieu of results from detailed pipe stressing, the thermal friction force can be approximated as being $10 \%$ of the vertical pipe dead plus operating loads being supported. When there are three or fewer pipes, use $30 \%$ of the vertical pipe dead plus operating loads being supported.

8. $\mathrm{TH}=$ Thermal Load. Is the self-straining load caused by the restrained thermal expansion in pipes, horizontal vessels and heat exchangers. They result from a change in temperature and may result from both operating and environmental conditions.

9. $\mathrm{AF}=$ Pipe anchor and guide forces. Are the loads from the restraining guides and anchors derived from the pipe stress analyses and these act on pipe supports and pipe racks.

10. $\mathrm{TE}=$ Test Load. Is the weight of equipment and hydrotest fluid related to the pre-commissioning test load condition. Also represents the proof testing load of any overhead monorails or cranes required to be undertaken prior to operation, usually $125 \%$ of the SWL of the crane.

11. $\mathrm{BP}=$ Bundle Pull Load. Is the force required to extract internal tube bundles from heat exchangers. Shall be taken as the weight of the removable bundle but not less than $10 \mathrm{kN}$.

Friction loads shall be considered as temporary and shall not be combined with wind or earthquake ULS loads. The pipe anchor and guide forces excluding their friction components shall be combined with wind or earthquake ULS or SLS2 loads.

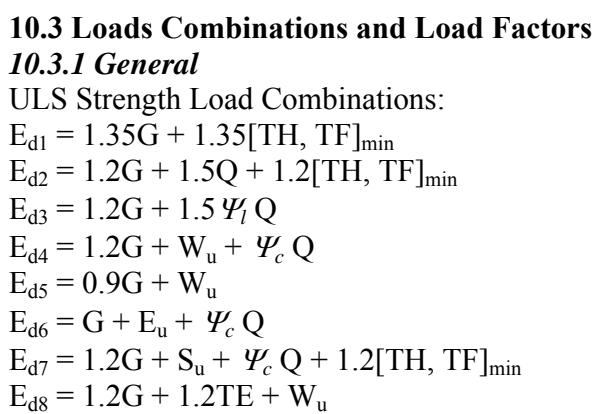

Where:

$\mathrm{E}_{\mathrm{u}} \quad$ Ultimate seismic load

$\mathrm{S}_{\mathrm{u}} \quad$ Ultimate load due to snow, liquid, rainwater

ponding or earth pressure

$\mathrm{W}_{\mathrm{u}} \quad$ Ultimate wind load

$\Psi_{l} \quad$ Imposed Action Long-term Factor

$\Psi_{c} \quad$ Imposed Action Combination Factor

SLS Load Combinations:

$\mathrm{S}_{1}=\mathrm{G}+\Psi_{l} \mathrm{Q}+[\mathrm{TH}, \mathrm{TF}]_{\min }$

$\mathrm{S}_{2}=\mathrm{G}+\Psi_{\mathrm{s}} \mathrm{Q}$

$\mathrm{S}_{3}=\mathrm{G}+\Psi_{l} \mathrm{Q}+\mathrm{E}_{\mathrm{s}}+[\mathrm{TH}, \mathrm{TF}]_{\min }$

$\mathrm{S}_{4}=\mathrm{G}+\Psi_{l} \mathrm{Q}+\mathrm{W}_{\mathrm{s}}+[\mathrm{TH}, \mathrm{TF}]_{\min }$

Where:

$\Psi_{s} \quad$ Imposed Action Short-term Factor

$\mathrm{E}_{\mathrm{s}} \quad$ Serviceability seismic load

$\mathrm{W}_{\mathrm{s}} \quad$ Serviceability wind load

Specific SLS conditions directly associated with process and operating requirements shall be assessed separately and shall apply where these are more critical.

WSD Method Load Combinations:

$\mathrm{A}_{1}=\mathrm{G}+[\mathrm{TH}, \mathrm{TF}]_{\min }$

$\mathrm{A}_{2}=\mathrm{G}+\mathrm{Q}+[\mathrm{TH}, \mathrm{TF}]_{\text {min }}$

$\mathrm{A}_{3}=\mathrm{G}+\Psi_{l} \mathrm{Q}$

$\mathrm{A}_{4}=\mathrm{G}+\mathrm{W}_{\mathrm{u}} / 1.5+\Psi_{c} \mathrm{Q}$

$\mathrm{A}_{5}=0.7 \mathrm{G}+\mathrm{W}_{\mathrm{u}} / 1.5$

$\mathrm{A}_{6}=\mathrm{G}+0.8 \mathrm{E}_{\mathrm{u}}+\Psi_{c} \mathrm{Q}$

$\mathrm{A}_{7}=\mathrm{G}+\mathrm{S}_{\mathrm{u}} / 1.5+\Psi_{c} \mathrm{Q}+[\mathrm{TH}, \mathrm{TF}]_{\min }$

Any load combination containing either a wind or earthquake ULS load case, the Allowable Stress Multiplier $=1 / 3$ if permitted by the allowable stress design standard. The use of a one third stress increase for load combinations including wind or earthquake shall not be allowed for designs using the standard AISC Steel Construction Manual (2005).

\subsubsection{Vessel and Equipment Support Design}

ULS Strength Load Combinations:

$\mathrm{E}_{\mathrm{d} 1}=1.35 \mathrm{G}+1.35 \mathrm{DV}+1.35[\mathrm{TH}, \mathrm{TF}]_{\min }$

$\mathrm{E}_{\mathrm{d} 2}=1.2 \mathrm{G}+1.2 \mathrm{DV}+1.5 \mathrm{Q}+1.2[\mathrm{TH}, \mathrm{TF}]_{\min }$ 
$\mathrm{E}_{\mathrm{d} 3}=1.2 \mathrm{G}+1.2 \mathrm{DV}+1.5 \Psi_{l} \mathrm{Q}$

$\mathrm{E}_{\mathrm{d} 4}=1.2 \mathrm{G}+1.2 \mathrm{DV}+\mathrm{W}_{\mathrm{u}}+\Psi_{c} \mathrm{Q}$

$\mathrm{E}_{\mathrm{d} 5}=0.9 \mathrm{G}+0.9 \mathrm{DV}+\mathrm{W}_{\mathrm{u}}$

$\mathrm{E}_{\mathrm{d} 6}=\mathrm{G}+\mathrm{DV}+\mathrm{E}_{\mathrm{u}}+\Psi_{\mathrm{c}} \mathrm{Q}$

$\mathrm{E}_{\mathrm{d} 7}=1.2 \mathrm{G}+1.2 \mathrm{DV}+\mathrm{S}_{\mathrm{u}}+\Psi_{c} \mathrm{Q}+1.2[\mathrm{TH}, \mathrm{TF}]_{\text {min }}$

$\mathrm{E}_{\mathrm{d} 8}=1.2 \mathrm{G}+1.2 \mathrm{TE}+\mathrm{W}_{\mathrm{u}}$

$\mathrm{E}_{\mathrm{d} 9}=1.2 \mathrm{G}+1.5 \mathrm{BP}$

SLS Load Combinations:

$\mathrm{S}_{1}=\mathrm{G}+\mathrm{DV}+\Psi_{l} \mathrm{Q}+[\mathrm{TH}, \mathrm{TF}]_{\min }$

$\mathrm{S}_{2}=\mathrm{G}+\mathrm{DV}+\Psi_{s} \mathrm{Q}$

$\mathrm{S}_{3}=\mathrm{G}+\mathrm{DV}+\Psi_{l} \mathrm{Q}+\mathrm{E}_{\mathrm{S}}+[\mathrm{TH}, \mathrm{TF}]_{\min }$

$\mathrm{S}_{4}=\mathrm{G}+\mathrm{DV}+\Psi_{l} \mathrm{Q}+\mathrm{W}_{\mathrm{s}}+[\mathrm{TH}, \mathrm{TF}]_{\min }$

Specific SLS conditions directly associated with process and operating requirements shall be assessed separately and shall apply where these are more critical.

\subsubsection{Pipe Rack and Pipe Support Design}

ULS Strength Load Combinations:

$\mathrm{E}_{\mathrm{d} 1}=1.35 \mathrm{G}+1.35(\mathrm{DP}+\mathrm{AF}+\mathrm{TH}+\mathrm{TF})$

$\mathrm{E}_{\mathrm{d} 2}=1.2 \mathrm{G}+1.2(\mathrm{DP}+\mathrm{AF}+\mathrm{TH}+\mathrm{TF})+1.5 \mathrm{Q}$

$\mathrm{E}_{\mathrm{d} 3}=1.2 \mathrm{G}+1.2(\mathrm{DP}+\mathrm{AF}+\mathrm{TF})+1.5 \Psi_{l} \mathrm{Q}$

$\mathrm{E}_{\mathrm{d} 4}=1.2 \mathrm{G}+1.2(\mathrm{DP}+\mathrm{AF})+\mathrm{W}_{\mathrm{u}}+\Psi_{c} \mathrm{Q}$

$\mathrm{E}_{\mathrm{d} 5}=0.9 \mathrm{G}+\mathrm{W}_{\mathrm{u}}$

$\mathrm{E}_{\mathrm{d} 6}=\mathrm{G}+\mathrm{DP}+\mathrm{AF}+\mathrm{E}_{\mathrm{u}}+\Psi_{c} \mathrm{Q}$

$\mathrm{E}_{\mathrm{d} 7}=1.2 \mathrm{G}+1.2(\mathrm{DP}+\mathrm{AF})+\mathrm{S}_{\mathrm{u}}+\Psi_{c} \mathrm{Q}$

$\mathrm{E}_{\mathrm{d} 8}=1.2 \mathrm{G}+1.2 \mathrm{TE}+\mathrm{W}_{\mathrm{u}}$

SLS Load Combinations:

$\mathrm{S}_{1}=\mathrm{G}+\mathrm{DP}+\mathrm{AF}+\mathrm{TH}+\mathrm{TF}+\Psi_{l} \mathrm{Q}$

$\mathrm{S}_{2}=\mathrm{G}+\mathrm{DP}+\mathrm{AF}+\mathrm{TF}+\Psi_{S} \mathrm{Q}$

$\mathrm{S}_{3}=\mathrm{G}+\mathrm{DP}+\mathrm{AF}+\mathrm{TH}+\mathrm{TF}+\Psi_{l} \mathrm{Q}+\mathrm{E}_{\mathrm{s}}$

$\mathrm{S}_{4}=\mathrm{G}+\mathrm{DP}+\mathrm{AF}+\mathrm{TH}+\mathrm{TF}+\Psi_{l} \mathrm{Q}+\mathrm{W}_{\mathrm{s}}$

Specific SLS conditions directly associated with process and operating requirements shall be assessed separately and shall apply where these are more critical.

\subsubsection{Pressure Equipment Design}

The WSD load combinations for the design of the pressure retaining envelope should be as per the applicable design code. To include wind, earthquake and snow loads as appropriate, the ULS effects are modified as follows; $\mathrm{W}_{\mathrm{u}} / 1.5$, $0.8 \mathrm{E}_{\mathrm{u}}$ and $\mathrm{S}_{\mathrm{u}} / 1.5$.

Any load combination containing a wind or earthquake ULS load case, the allowable stress multiplier $=1 / 3$ if permitted by the allowable stress design standard.

\section{GEOTECHNICAL CONSIDERATIONS}

\subsection{General}

Foundations for the items within an industrial plant are generally constructed from reinforced concrete and should comply with NZS 3101 .

The design of the foundations shall consider the full set of limit states as per the Verification Method B1/VM4 of the Department of Building and Housing Controls Division Compliance Document B1 "Structure" for short and long term loading effects including:

- $\quad$ Foundation bearing and sliding capacities.
- $\quad$ Pile and pile group vertical and lateral strengths.

\subsection{Geotechnical Considerations}

Existing geotechnical reports that cover the proposed site may be available from the plant's owner or the local authority. If not available, site investigations are usually required to obtain basic foundation data that is needed for the foundation design. Existing foundations in the location and their imposed loads do offer a guide to as what type of foundations may be suitable.

Alternatively, for smaller structures, a conservative estimate of soil properties can be used in design provided these are confirmed after excavations for the item have occurred and prior to any site concrete is poured. NZS 3604 Section 3 gives a relatively simple method for determining good ground.

The following is a list of items that ideally are addressed in a site investigation.

1. Evaluations of any existing data or geotechnical reports.

2. Depth to bedrock.

3. Ground water table location.

4. Soil stratification.

5. Unique site conditions such as sloping bedrock, proximity to faults, cliff areas, river beds and coastal areas.

6. Soil physical characteristics such as grain size distribution, index properties, organic content, void ratio, water content.

7. Soil mechanical properties for long and short term loadings.

8. Shear wave properties.

9. Propensity for liquefaction or settlement.

10. CBR values for pavement design.

11. Site soil class as per NZS 1170.5

12. Recommendations for suitable foundation types for the items to be supported.

13. Recommendations for bulk earthworks excavation and compaction methods and practices.

The site investigation reports should include descriptions of drilling, sampling and in-situ testing methods and photographs of test pits and core samples.

\section{CONCLUSION AND RECOMMENDATIONS}

The lack of a specific section within NZS 1170.5 for the seismic design of nonbuilding structures has meant that there will continue to be a degree of uncertainty as to how the new standard should be applied to those structures commonly found in industrial plant. However, it is possible to integrate the recently completed set of structural design actions standards with guidelines incorporated into overseas standards and guidelines for the determining of seismic actions and displacements for the nonbuilding-like structures commonly found in industrial and petrochemical plants.

The application of earthquake design in accordance with any standard for a structure is to use a method that has involved many approximations to arrive at the various equations put down in the standard. The lines showing the curves for the spectral shape factor in NZS 1170.5 Figures 3.1 and 3.2 when developed into the elastic site spectra for horizontal 
loading by using NZS 1170.5 equation 3.1(1) could be represented by a thick line. Thus the building structures design engineer operates in a regime that undue levels of accuracy in the calculation method are not warranted. But conscious decisions as to the use of the underlying assumptions inbuilt into the structural design actions standard are required when being applied to nonbuilding industrial structures.

The prediction of earthquake performance for buildings, building-like and nonbuilding-like structures is an art as Jury (2004) highlights. The design engineer for industrial structures is required to develop a feel for how nonbuilding structures behave with a shortage of research into their earthquake performance. A degree of conservatism in the design approach for these structures is warranted until their behaviour is more fully documented and researched.

There is a need for the following items to be clarified or updated for those who undertake design of industrial structures within New Zealand:

- Confirmation in NZS 1170.5-Supp 1 that the spectral shape factors given in Table 3.1, Figures 3.1 and 3.2 have been based on $5 \%$ damping.

- Confirmation whether the durability life required under the NZ Building Code can set the Design Working Life for the seismic design of parts and components whose durability life is less than the intended life of the building.

- How different levels of damping are to be incorporated into the ULS, SLS2 and SLS1 earthquake actions analysis for both elastic primary structures and for parts and components that are intended to remain largely elastic.

- Confirmation that $\mu$ and $\mu_{\mathrm{p}}$ have a maximum value of 1.25 for determining earthquake actions to be used with working stress standards.

- Confirmation of the 0.8 scaling factor for earthquake actions when using WSD standards.

- On how the requirement for increasing the deflections for concentrically braced frames set out in Clause 12.12.5.2(h) of NZS 3404 should be incorporated into Section 7 of NZS 1170.5. In particular whether the requirement should be used in conjunction with the drift modification factor $k_{\mathrm{dm}}$.

- $\quad$ Figure C7.1 in NZS 1170.5:Supp 1 to be updated to:

o Include all the deflection profiles as per Figure C4.7.1 of NZS 4203.

o Add a note to state that the inter-storey deflections need to include the drift modification factor $k_{\mathrm{dm}}$.

o Include the assumptions behind how the elastic profile, Profile 1 was developed including whether from an ESA or MRSA and whether P-delta effects have been allowed for. o Indicate how the ESA deflection scale factor $k_{\mathrm{d}}$ should be allowed for in Profiles 2 to 6 .

- Directions of earthquake actions to be clarified for parts and components and whether this is dependent on the part ductility factor $\mu_{\mathrm{p}}$.

- The use of Equation 8.3(3) clarified in determining $C_{\mathrm{Hi}}$ when $h_{\mathrm{n}}<12$ metres.

- Guidelines on how to incorporate MRSA and NITHA results into NZS 1170.5 Equation 8.2(1) for the design of parts and components.

- $\quad$ AS/NZS 1200 Appendix I to be revised to refer to AS/NZS 1170.0 and NZS 1170.5 and the minimum seismic hazard coefficients specified to be recalculated based on the seismic hazard map of New Zealand as set out in NZS 1170.5. The coefficients given need to specified as being either for working stress design or limit state design. The basis for the revised minimum seismic coefficients needs to be outlined so their use can be checked to ensure that higher values are not used unduly including the assumed design working life.

- The DoL ACOP documents for pressure equipment (ACPPE) and boilers need to be revised:

o As they refer to NZS 4203:1992 with its superseded seismic hazard map and this standard will eventually be withdrawn.

o As ACPPE refers to the repealed Engineers Registration Act 1924.

o So that the mechanical design life is referenced to the design working life in AS/NZS 1170.0.

o To remove the confusion between what is an ultimate limit state and what is a serviceability limit state and how these related to earthquake return periods.

o To provide bridging guidelines on how the minimum seismic coefficients shall be determined with respect to the NZS 1170.5 Hazard Factor Z until NZS 1200 is revised.

o To give a recommended relationship between the AS 4343 hazard level and the AS/NZS 1170.0 Importance Level.

o To require structures and foundations to comply with the Building Act unless exempt as part of the Act's definition of a building.

o To require structures and foundations to be subject to the obtaining of a building consent unless exempt as part of the Building Act's definition of a building or is a structure listed in Schedule 1 of the Building Act as being exempt from the consenting process.

o ACPPE Sections 5 to 8 need to be rationalised so the seismic provisions are consistent.

o To provide a reminder that both inertia and deflection effects have to be considered for 
items supported off different structures or off different levels of the same structure.

o To provide a pointer to Section 8 of NZS 1170.5 for the design of elevated pressure equipment.

\section{REFERENCES}

American Institute of Steel Construction (2005). "AISC ASD/LRFD Steel Construction Manual, 13th Edition", Washington DC, American Institute of Steel Construction.

American Petroleum Institute (1998). "Welded Steel Tanks for Oil Storage API 650:1998", Washington DC, American Petroleum Institute.

American Society of Civil Engineers (1997). "Guidelines for Seismic Evaluation and Design of Petrochemical Plants", Reston Virginia. American Society of Civil Engineers.

American Society of Civil Engineers (2002). "Minimum Design Loads for Buildings and Other Structures, ASCE 7-02", Reston Virginia, American Society of Civil Engineers.

American Society of Mechanical Engineers (2000). "Steel Stacks, STS-1 2000", New York, American Society of Mechanical Engineers.

American Society of Mechanical Engineers (2004). "International Boiler and Pressure Vessel Code ASME BPVC:2004", New York, American Society of Mechanical Engineers.

American Society of Mechanical Engineers (2004). "Process Piping B31.3:2004", New York, American Society of Mechanical Engineers.

American Lifelines Alliance (2002). Seismic Design and Retrofit of Piping Systems, Washington. Prepared by the ALA for ASCE and FEMA.

http://www.americanlifelinesalliance.org/pdf/Seismic_De sign_and_Retrofit_of_Piping_Systems.pdf

Retrieved 28 February 2006.

Department of Building and Housing - Building Controls, "The New Zealand Building Code Handbook and Compliance Documents", 1991.

Department of Labour (2001) - Approved Code of Practice for Pressure Equipment (Excluding Boilers), Wellington, Department of Labour.

http://www.osh.dol.govt.nz/order/catalogue/pdf/pressequi p-ac.pdf

Retrieved 28 February 2006.

Department of Labour (2004) - Approved Code of Practice for the Design, Safe Operation, Maintenance and Servicing of Boilers, Wellington, Department of Labour. http://www.osh.org.nz/order/catalogue/pdf/boilercode.pdf

Retrieved 28 February 2006.

FEMA (2003). "NEHRP Recommended Provisions for Seismic Regulations for New Buildings and Other Structures, FEMA 450", Washington, Prepared by the
Building Seismic Safety Council for the Federal Emergency Management Agency.

http://www.bssconline.org/NEHRP2003/provisions/ Retrieved 8 June 2005.

HERA (1995), "Report R4-76 Seismic Design Procedures for Steel Structures". Heavy Engineering Research Association.

Jury (2004), "The Prediction of Building Performance during Earthquakes - An Art or Science", Bulletin of the New Zealand National Society for Earthquake Engineering, 37(3): 134-138.

MWD (1981). "Seismic Design of Petrochemical Plants", Wellington, Prepared by the Ministry of Works and Development for the Ministry of Energy.

NZ National Society for Earthquake Engineering (2006), "Assessment and Improvement of the Structural Performance of Buildings in Earthquake".

NZ National Society for Earthquake Engineering (1986), "Seismic Design of Storage Tanks".

Standards New Zealand (1995). "Concrete Structures Standard, NZS 3101:Part 1:1995”, Wellington, Standards New Zealand.

Standards New Zealand (1997). "Steel Structures Standard, NZS 3404:1:1997”, Wellington, Standards New Zealand.

Standards New Zealand (1999). "Timber Framed Buildings, NZS 3604:1:1999”, Wellington, Standards New Zealand.

SANZ (1976). "Code of Practice for General Structural Design and Design Loadings for Buildings, NZS 4203:1976”, Wellington, Standards New Zealand.

SANZ (1984). "Code of Practice for General Structural Design and Design Loadings for Buildings, NZS 4203:1984”, Wellington, Standards New Zealand.

Standards New Zealand (1992). "Code of Practice for General Structural Design and Design Loadings for Buildings, NZS 4203:1992”, Wellington, Standards New Zealand.

Standards New Zealand (1996). "Cold Formed Steel Structures, NZS 4600:1:1996", Wellington, Standards New Zealand.

Standards New Zealand and British Standards (2003). "Specification for unfired fusion welded pressure vessels, NZS/BSPD 5500:2003", Wellington, Standards New Zealand.

Standards Australia (1993). "Minimum Design Loads on Structures Part 4: Earthquake Loads, AS 1170.4:1993", Sydney, Standards Australia.

Standards Australia (2005). "Pressure Equipment - Hazard Levels, AS 4343:2005”, Sydney, Standards Australia. 
Standards Australia and Standards New Zealand (2000). "Pressure Equipment, AS/NZS 1200:2000", Wellington, Standards New Zealand.

Standards Australia and Standards New Zealand (2002). "Structural Design Actions, AS/NZS 1170:2002 Parts 0, 1, 2 \& 3", Wellington, Standards New Zealand.

Standards New Zealand (2004). "'Structural Design Actions - Part 5 Earthquake Actions - New Zealand, NZS 1170.5:2004”, Wellington, Standards New Zealand.

US Nuclear Regulatory Commission Regulatory Guide (1973). "Regulatory Guide 1.61 - Damping for Seismic Design of Nuclear Power Plants", Washington DC, United States Nuclear Regulatory Commission.

US Nuclear Regulatory Commission NUREG/CR-6919 (2006). "Recommendations for Revision of Seismic Damping Values in Regulatory Guide 1.61", Washington DC, United States Nuclear Regulatory Commission.

International Conference of Building Officials (1997). "Uniform Building Code", Whittier CA,

Whittaker and Jury, "Seismic Design Load for Storage Tanks", Proc. Of the $12^{\text {th }}$ World Conference on Earthquake Engineering, Christchurch, 2000. 
APPENDIX A

PHOTOGRAPHS OF TYPICAL INDUSTRIAL STRUCTURES

\section{Building-like Structures:}

A.1 Vessel support structure:

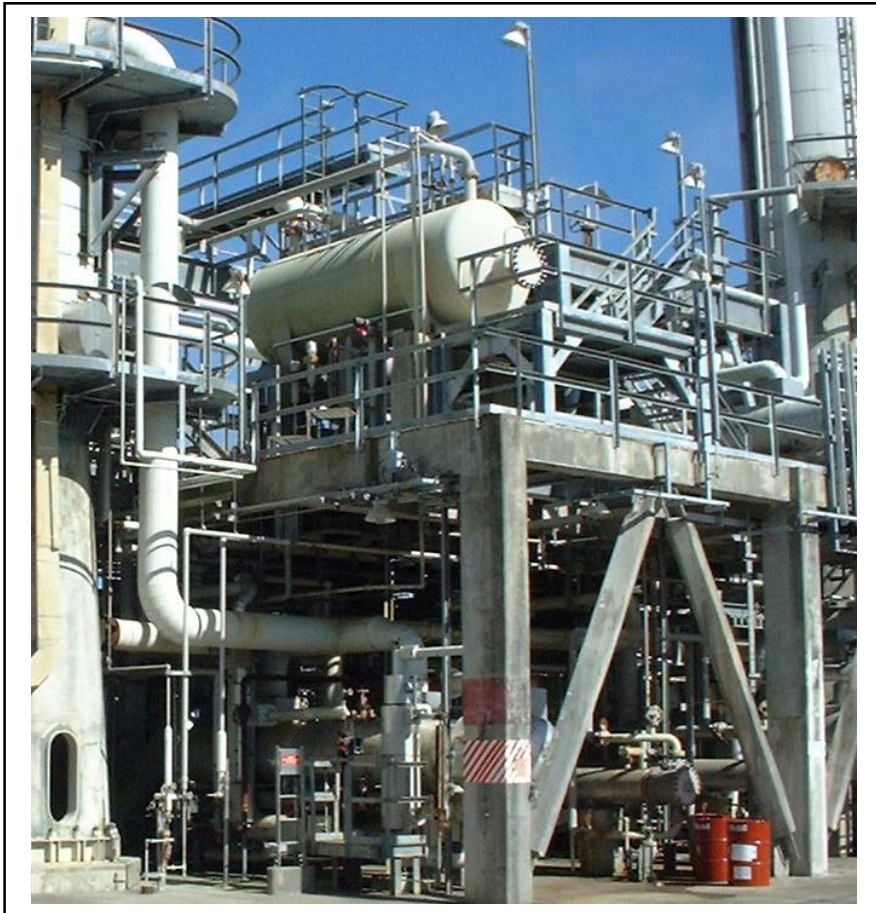

A.2 Pipe rack and pipe bridge:

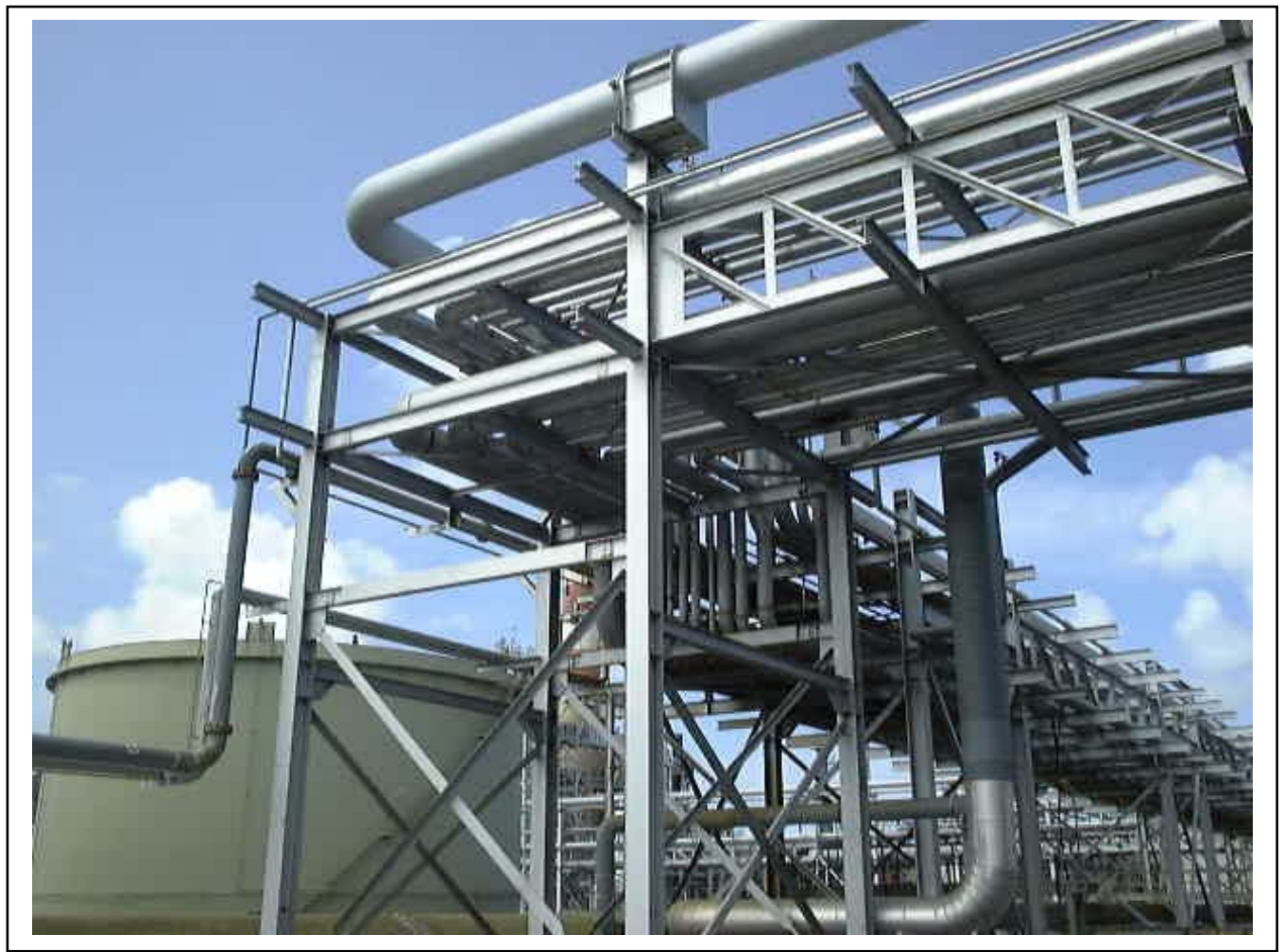




\section{Nonbuilding-like Structures:}

A.3 Rigid structures - pumps skid mounted at grade:

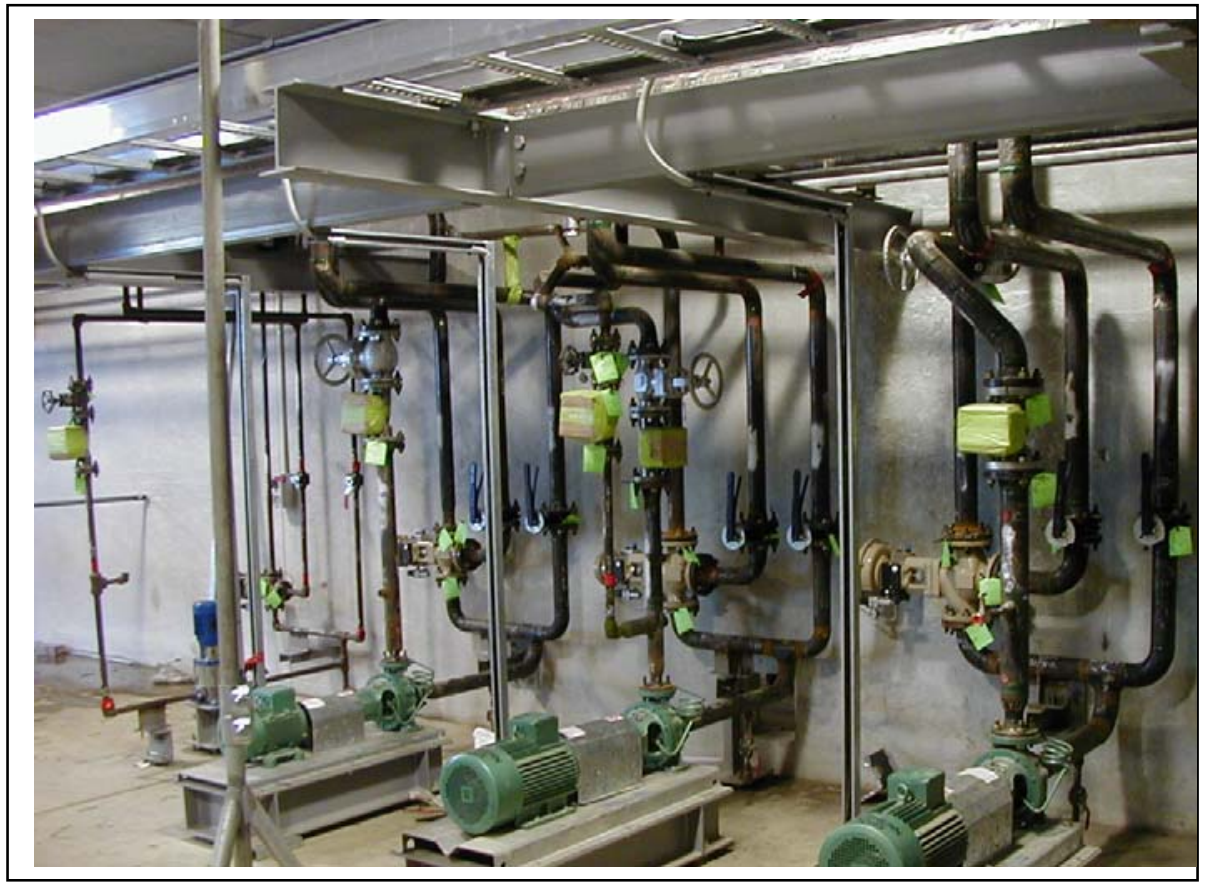

A.4 Flat Bottomed Tanks:

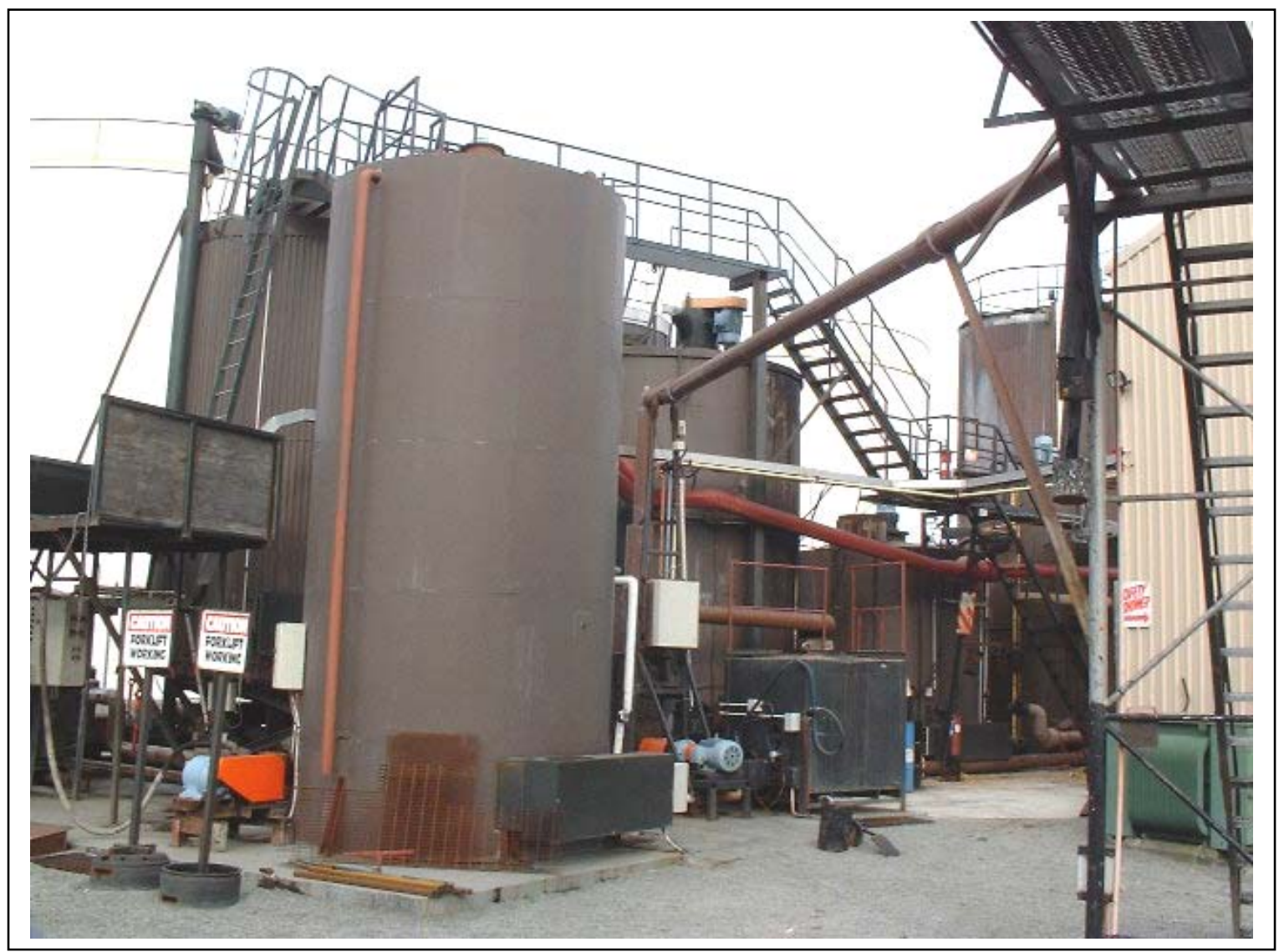


A.5 Combination Structure:

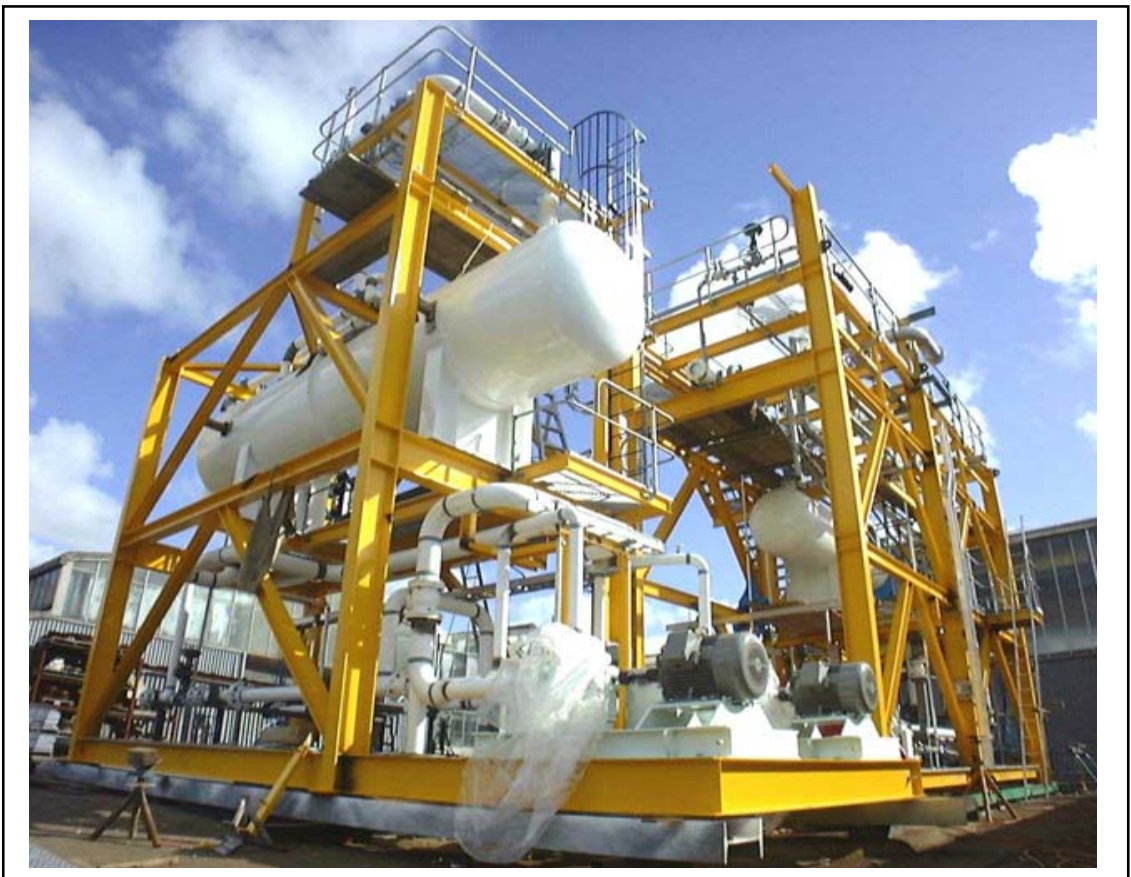

A.6 Combination Structure:

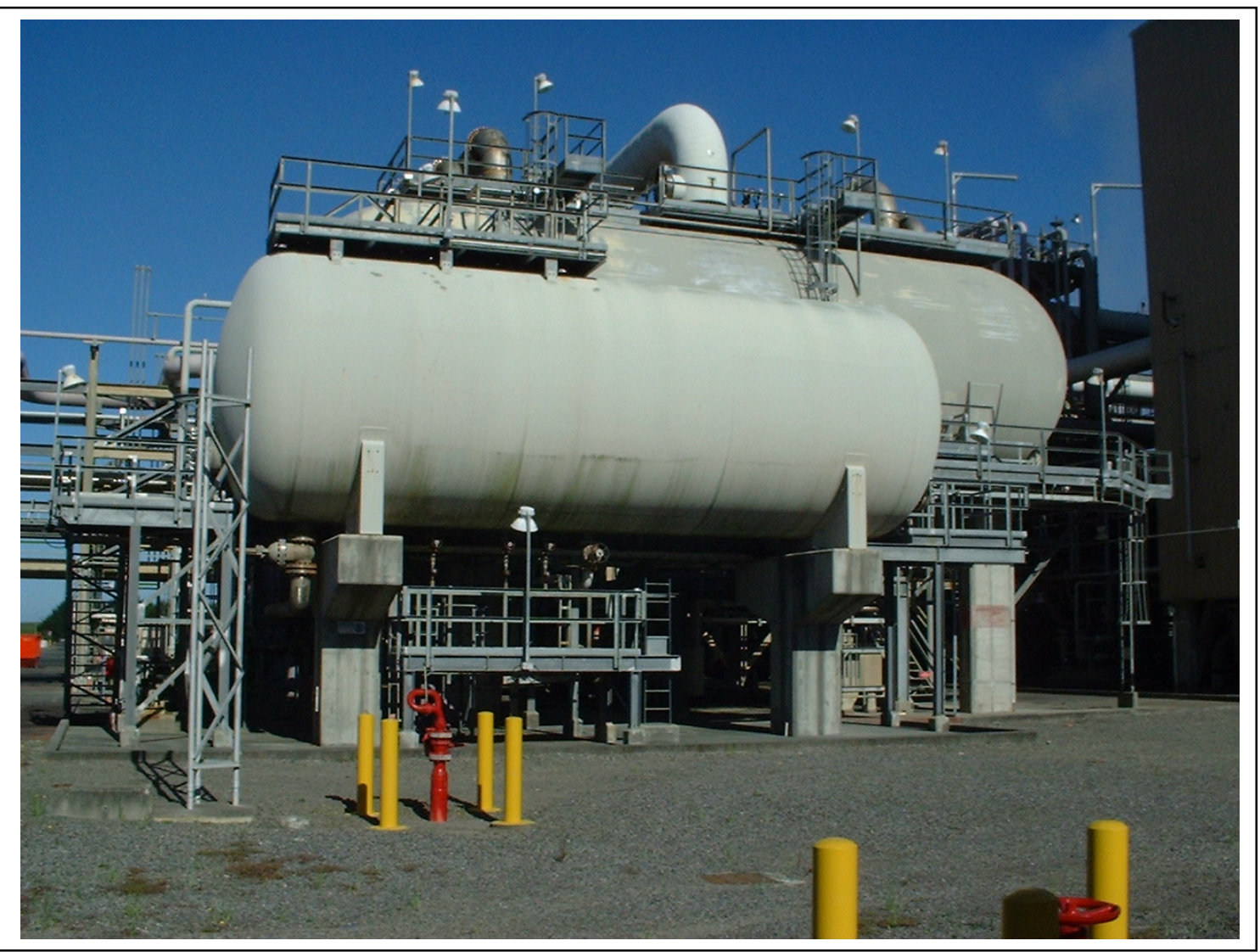


A.7 Vertical fired heater:

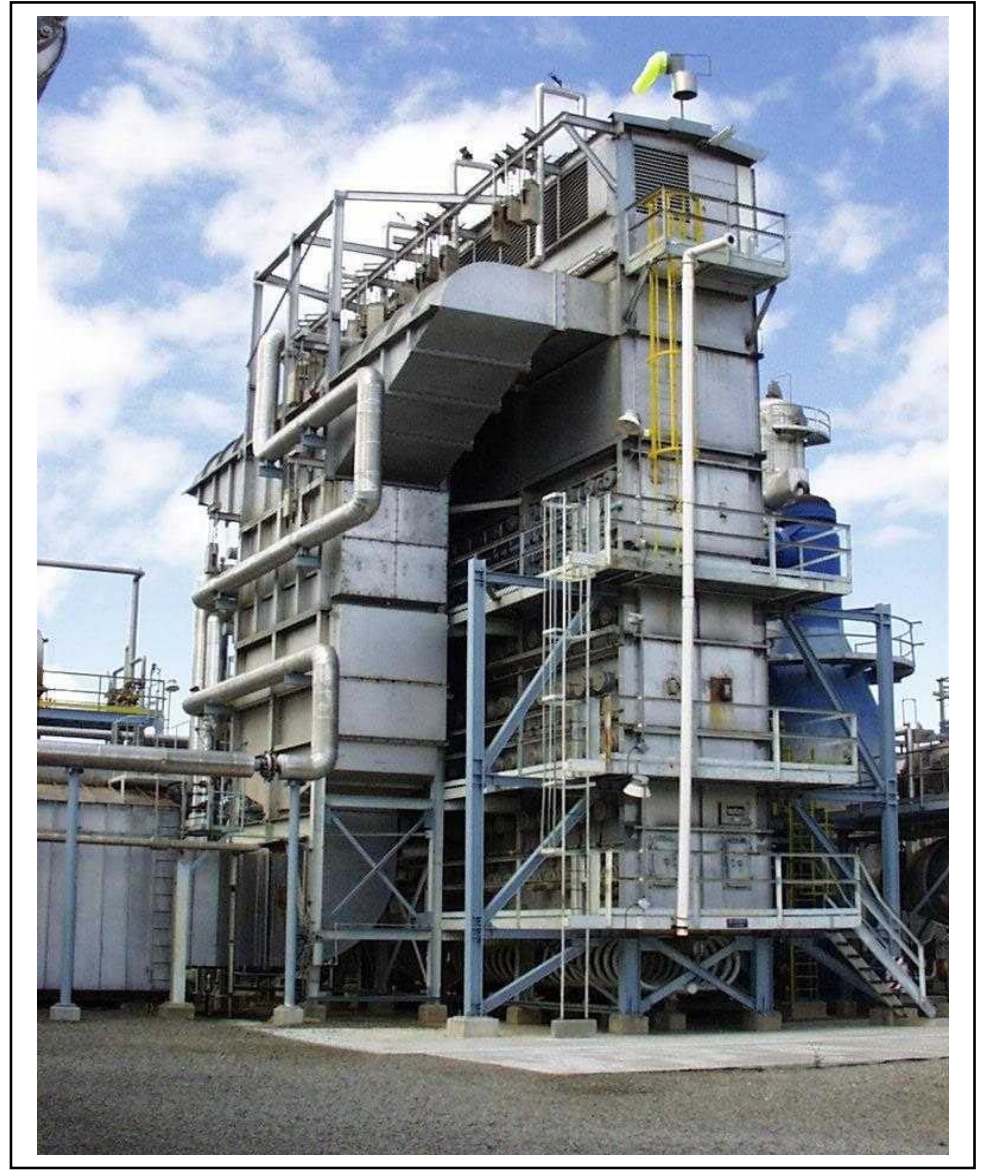

A.8 Floor Mounted Cabinets:




A.9 Guyed stack:

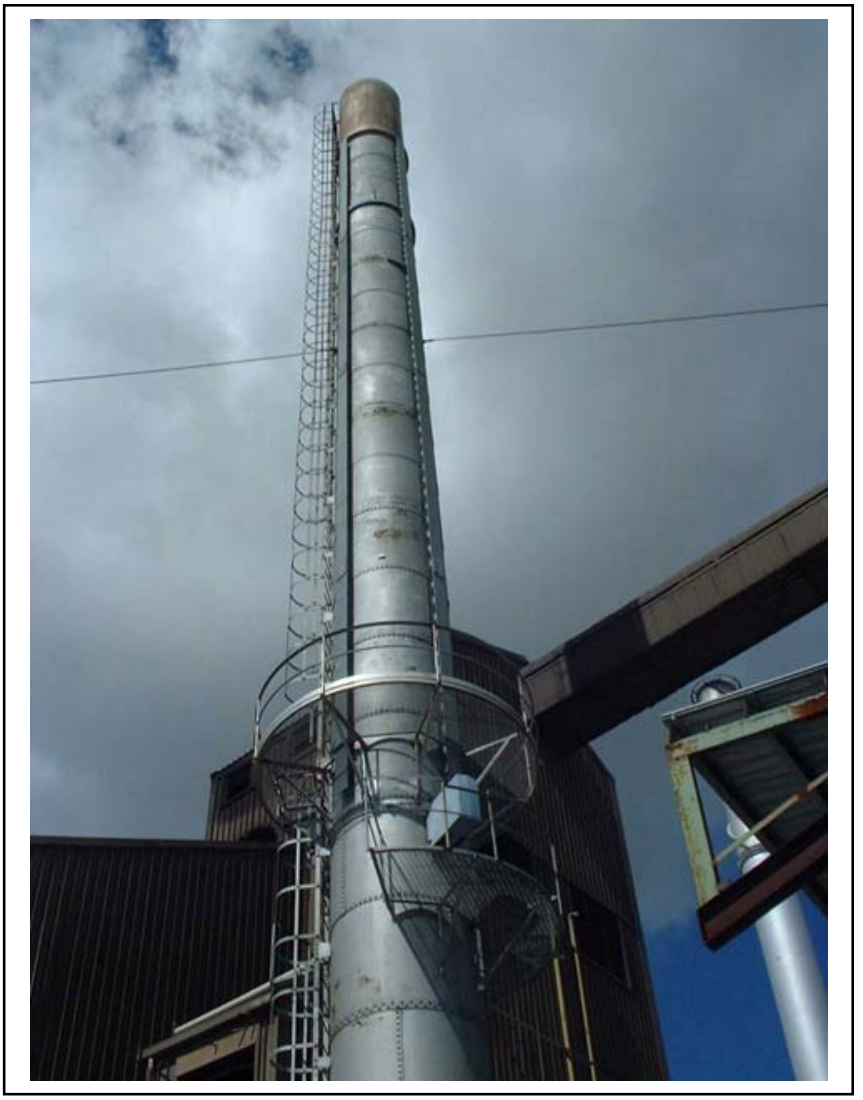

\section{Parts and Components:}

A.10 Pipes and pipe supports

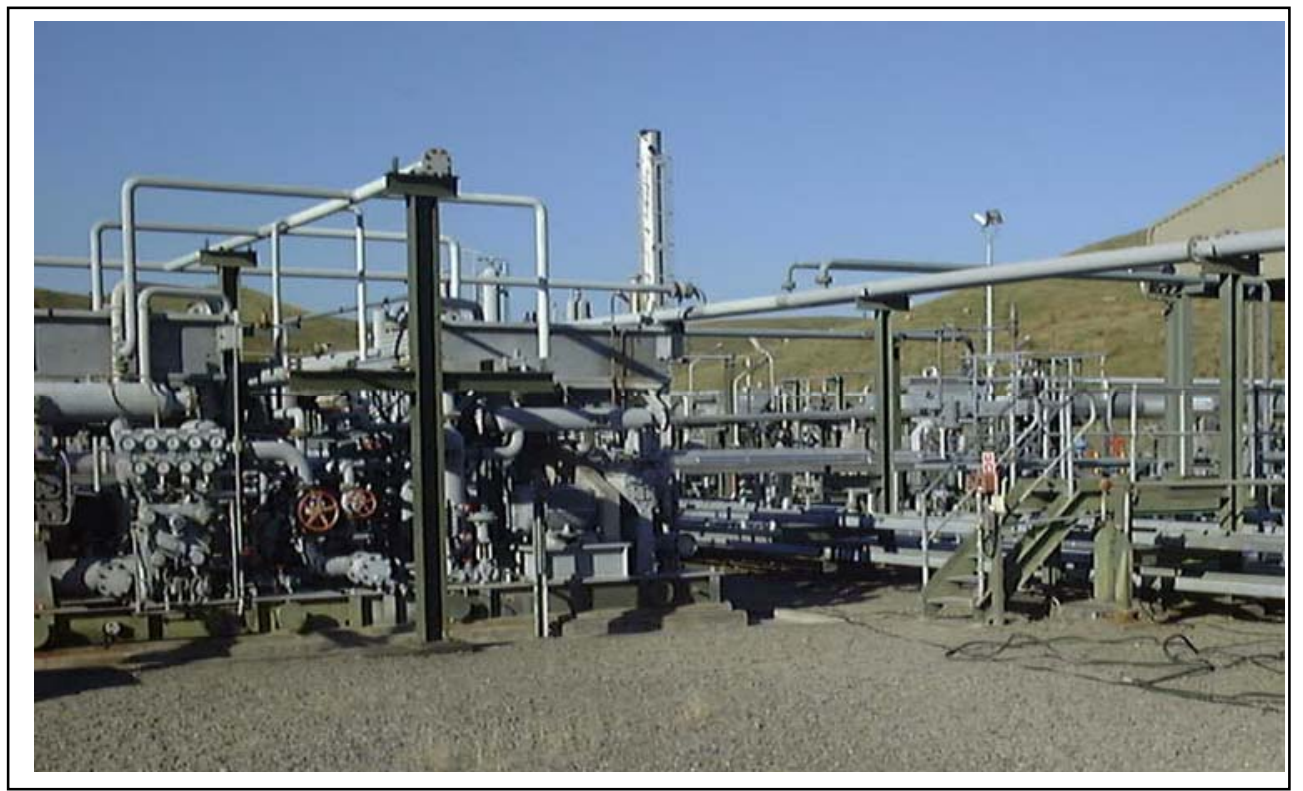




\section{APPENDIX B}

\section{EXAMPLES OF BASE SHEAR DETERMINATION FOR SELECTED STRUCTURES}

\section{Example 1 - Skirt Mounted Vertical Pressure Vessel at Ground Level}

Three types of analysis could be considered in accordance with NZS 1170.5 Section 6:

1. Equivalent static force analysis.

2. Modal response spectrum analysis.

3. Special study as a supplement to the modal response spectrum analysis, if so required by the Purchaser.

Horizontal torsion effects need not be considered for these structures where the geometry and mass distribution is symmetrical about both principal axes at all heights. For vessels operating at elevated temperatures, the applicable steel yield stress and modulus of elasticity shall be calculated for the normal operating temperature.

As no site specific seismic hazard study has been undertaken, the minimum seismic coefficient given in AS/NZS 1200 Appendix I applies for the pressure envelope, skirt and foundation, refer to ACPPE Clause 5.4.4(8). This minimum value is dependent on the NZS 4203:1992 Zone Factor Z. Assume that the vessel is located within a plant that is close to occupied dwellings and has a design pressure such that if released, toxic fumes would spread beyond the plant's boundary. The overall height is $37.15 \mathrm{~m}$ and the internal diameter of the pressure retaining vessel is set at $1300 \mathrm{~mm}$. The vessel is to operate at a temperature of $210^{\circ} \mathrm{C}$. The vessel is to be installed in a site in North Taranaki that has a Site Subsoil Class of C.

The shell and skirt shall comply with Tables 12.2.4, 12.2.6, 12.4 and 12.5 of NZS 3404:1997.

Any modal response spectrum analysis shall be as per Section 6.3 of NZS 1170.5.

Assume that the Importance Level has been set at IL $=4$.

\section{SKIRT MOUNTED VERTICAL PRESSURE VESSEL}

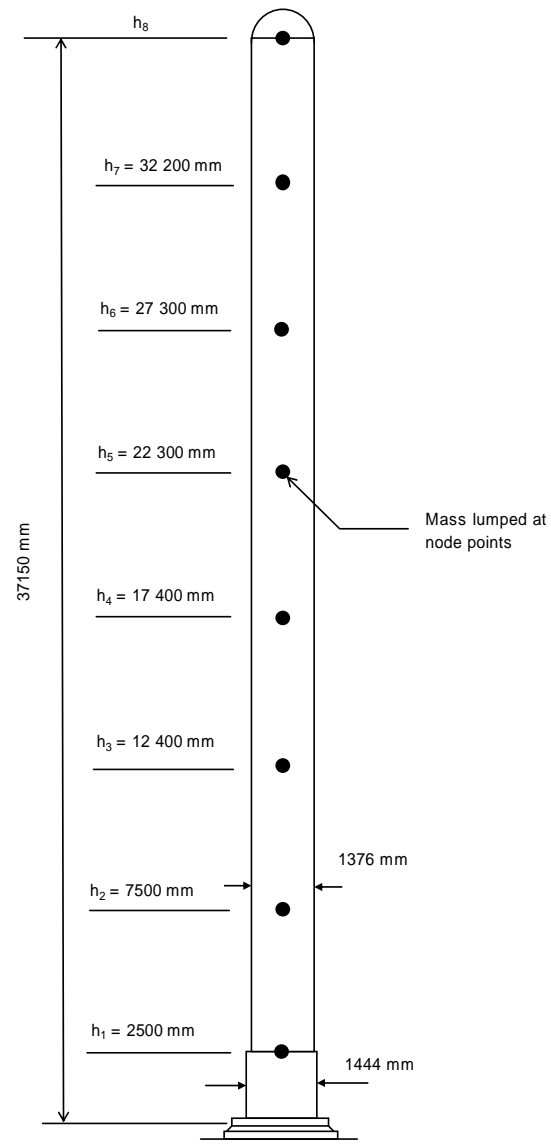

Table B1 -Equivalent Static Earthquake Coefficients Calculation for a Vertical Pressure Vessel

\section{Description}

NZ Building Code Category -

Clause A1 Classified Uses

Structural Type

Importance Level:

Design Working Life

Earthquake Return Periods: Table 3.3 AS/NZS 1170.0

Site Subsoil Class:
Nonbuilding

-like

\section{4}

\section{0 years}

\section{Consequence}

May be exempt some amenity provisions but required to comply with structural and safety provisions of NZBC

3 limit states $=$ ULS, SLS1 \& SLS2

Plant life of $50+$ years

$\mathrm{E}_{\mathrm{wsd}}=0.8 \mathrm{E}_{\mathrm{u}}$ \& possible overstress allowance $=1 / 3$

$\mathrm{E}_{\mathrm{wsd}}=\mathrm{E}_{\mathrm{sls} 2} \&$ no overstress allowance

$\mathrm{E}_{\mathrm{wsd}}=\mathrm{E}_{\mathrm{sls} 1}$ \& no overstress allowance

Table 3.1 for Spectral Shape Factor $C_{h}(T)$

Suitable for North Taranaki

NZS 1200 Appendix I minimum seismic coefficient for pressure equipment $=0.53$ 


\section{Table B1 -Equivalent Static Earthquake Coefficients Calculation for a Vertical Pressure Vessel Description \\ $\underline{\text { Parameter } \quad \underline{\text { alue }} \quad \text { Consequence }}$}

Return Period Factors:

$\begin{array}{rll}\text { Table 3.5 } & \mathrm{R}_{\mathrm{u}} & 1.8 \\ & \mathrm{R}_{\text {sls2 }} & 1.0 \\ & \mathrm{R}_{\text {sls1 }} & 0.25 \\ \text { Clause 3.1.1 } & \mathrm{Z} \mathrm{R}_{\mathrm{u}} & 0.32\end{array}$

$<0.7 \therefore$ O.K.

Near-fault factor:

Clause 3.1.6 N(T, D)

Not adjacent to any major faults, i.e. $\mathrm{D}>20 \mathrm{~km}$

System Parameters:

$\begin{aligned} \text { Operating Temperature } & \mathrm{T}_{\mathrm{op}} \\ \text { Overall Height } & \mathrm{h}_{\mathrm{n}} \\ \text { Skirt Internal Diameter } & \mathrm{D}_{\mathrm{s}} \\ \text { Vessel Internal Diameter } & \mathrm{D}_{\mathrm{v}} \\ \text { Skirt thickness } & \mathrm{t}_{\mathrm{skirt}} \\ \text { Shell thickness - bottom strake } & \mathrm{t}_{\text {shell }}\end{aligned}$

$210{ }^{\circ} \mathrm{C}$

$37.15 \mathrm{~m}$

$1372 \mathrm{~mm}$

$1300 \mathrm{~mm}$

$36 \mathrm{~mm}$

$36 \mathrm{~mm}$

42

60

170

$36 \mathrm{~mm}$

Structural Ductility Factors:

$$
\begin{array}{r}
\text { ULS - NZS } 3404 \text { Table 12.2.4 } \\
\text { SLS2 - Clause 4.3.2 } \\
\text { SLS1 - Clause 4.3.2 }
\end{array}
$$

\section{$\mu_{\mathrm{uls}}$}

$\mu_{\mathrm{sls} 2}$

$\mu_{\mathrm{sls} 1}$

Weight of components:

$$
\begin{aligned}
& \text { Weight of support skirt } \\
& \text { Weight of vessel }
\end{aligned}
$$

$$
\mathrm{W}_{\mathrm{s}}
$$$$
\mathrm{W}_{\mathrm{p}}
$$

Fundamental period:

$$
\text { Combined skirt }+ \text { vessel } \quad T_{1}
$$

Vertical Regularity Check:

$$
\text { Clause 4.5.1.2 }
$$

Suitability of Equivalent Static

Analysis Method Check:

$$
\begin{array}{lll}
\text { Clause 6.1.3.1(a) } & \mathrm{h}_{\mathrm{n}}<10 \mathrm{~m} & \text { No } \\
\text { Clause 6.1.3.1(b) } & \mathrm{T}_{1}<0.4 \text { secs } & \text { No } \\
\text { Clause 6.1.3.1(c) } & \text { Horiz. regular } & \text { Yes } \\
& \text { Vert. regular } & \text { No } \\
& \mathrm{T}_{1}<2.0 \text { secs } & \text { Yes }
\end{array}
$$

Review P-Delta effects:

$$
\begin{array}{lll}
\text { Clause 6.5.2(b) } & \mathrm{h}_{\mathrm{n}}>15 \mathrm{~m} & \text { Yes } \\
& \mathrm{T}_{1}>0.6 \mathrm{secs} & \text { Yes }
\end{array}
$$

ULS P-Delta Effects Factor:

$$
\text { Eqn 6.5(3) } \mathrm{k}_{\mathrm{p}}
$$

Young's Modulus reduced by $6.7 \%$. No effect on $\mathrm{F}_{\mathrm{y}}$.

$\mathrm{F}_{\mathrm{y}}=325 \mathrm{MPa}-$ from material spec.

$\mathrm{F}_{\mathrm{y}}=315 \mathrm{MPa}-$ from material spec.

$\therefore \mathrm{F}_{\mathrm{y}}>300 \mathrm{MPa}$. Skirt or shell cannot be a Category 1 member as per Table 12.4 of NZS 3404

Use Table 12.5 of NZS 3404 with outside diameters and thicknesses from above

$t_{\text {skirt }} \geq 45 \mathrm{~mm}$ and $\mathrm{t}_{\text {shell }} \geq 42 \mathrm{~mm}$

$\mathrm{t}_{\text {skirt }} \geq 32 \mathrm{~mm}$ and $\mathrm{t}_{\text {shell }} \geq 29 \mathrm{~mm}$

$\mathrm{t}_{\text {skirt }} \geq 11 \mathrm{~mm}$ and $\mathrm{t}_{\text {shell }} \geq 10 \mathrm{~mm}$

Minimum primary member category $=3$

Minimum structural ductility category $=3$ From NZS

3404 Table 12.2.6

Nominally ductile structure

Allow some ductility to happen for SLS2 event

From vessel vendor data.

From modal analysis. Assume applicable for all limits states.

Assumed as plate thicknesses vary up vessel

May not be able to use ESA

May not be able to use ESA

May not be able to use ESA

Modal Response Spectrum Analysis required but do ESA for checking MRSA

Need to consider P-Delta effects

Need to consider P-Delta effects

Therefore include P-Delta effects by Method A

With $\mu=1.25$ 
Table B1 -Equivalent Static Earthquake Coefficients Calculation for a Vertical Pressure Vessel

\section{Description}

Structural Performance Factors:

$\begin{aligned} \text { ULS } & \mathrm{S}_{\mathrm{pe}} \\ \text { ULS } & \mathrm{S}_{\mathrm{ps}} \\ \text { SLS2 } & \mathrm{S}_{\mathrm{pe}} \\ \text { SLS2 } & \mathrm{S}_{\mathrm{ps}} \\ \text { SLS1 } & \mathrm{S}_{\mathrm{pe}} \\ \text { SLS1 } & \mathrm{S}_{\mathrm{ps}}\end{aligned}$

System Damping Factors:

$\begin{array}{rll}\text { ULS } & \mathrm{C}_{\mathrm{f}}(2) & 1.32 \\ \text { SLS2 } & \mathrm{C}_{\mathrm{f}}(1) & 1.53 \\ \text { SLS1 } & \mathrm{C}_{\mathrm{f}}(0.5) & 1.67\end{array}$

Ductility Factors:

$\begin{array}{rll}\text { ULS } & \mathrm{k}_{\mu \mathrm{uls}} & 1.25 \\ \text { SLS2 } & \mathrm{k}_{\mu \mathrm{sls} 2} & 1.25 \\ \text { SLS1 } & \mathrm{k}_{\mu \mathrm{sls} 1} & 1.0\end{array}$

Spectral Shape Factor:

P-Delta Scaling Factor:

$$
\begin{array}{lll}
\text { ULS } & \mathrm{C}_{\mathrm{d}}\left(\mathrm{T}_{1}\right) & 0.377 \\
& \mathrm{k}_{1} & 1.045
\end{array}
$$

Material Code Scaling Factor:

$$
\begin{array}{cc}
\text { ULS } & \mathrm{k}_{2} \\
\therefore & \mathrm{K}
\end{array}
$$

Elastic Site Hazard Values:

$\begin{array}{rll}\text { ULS } & \mathrm{C}\left(\mathrm{T}_{1}\right)_{\mathrm{uls}} & 0.386 \\ \text { SLS2 } & \mathrm{C}\left(\mathrm{T}_{1}\right)_{\mathrm{sls} 2} & 0.214 \\ \text { SLS1 } & \mathrm{C}\left(\mathrm{T}_{1}\right)_{\mathrm{sls} 1} & 0.054\end{array}$

Unscaled 5\% Damped Design Actions:

$\begin{array}{rll}\text { ULS } & \mathrm{C}_{\mathrm{d}}\left(\mathrm{T}_{1}\right)_{\mathrm{uls}} & 0.285 \\ \text { Eqn 5.2(2) } & (\mathrm{Z} / 20+0.02) \mathrm{R}_{\mathrm{u}} & 0.052 \\ & & \\ \text { SLS2 } & \mathrm{C}_{\mathrm{d}}\left(\mathrm{T}_{1}\right)_{\mathrm{sls} 2} & 0.159 \\ \mathrm{SLS} 1 & \mathrm{C}_{\mathrm{d}}\left(\mathrm{T}_{1}\right)_{\mathrm{sls} 1} & 0.037\end{array}$

Horiz. Design EQ Forces:

ULS - To avoid collapse

WSD - No loss of contents

$\therefore$ For pressure envelope

$\therefore$ For skirt and foundation

SLS2 - To remain operational SLS1 - To sustain no damage
$\mathrm{E}_{\mathrm{u}}=\mathrm{V}_{\mathrm{uls}}$ $\mathrm{E}_{\mathrm{wsd}}=0.8 \mathrm{E}_{\mathrm{u}}$

$\mathrm{E}_{\mathrm{wsd}}$

$\mathrm{E}_{\mathrm{u}}$

$\mathrm{E}_{\mathrm{sls} 1}=\mathrm{V}_{\mathrm{sls} 1}$
$\mathrm{E}_{\mathrm{sls} 2}=\mathrm{V}_{\mathrm{sls} 2}$

925

0.925

0.925

0.7

7

53

25

25

\section{9}

0.53

0.53
Site Subsoil Class $=\mathrm{C} \& \mathrm{~T}_{1}=1.0 \mathrm{secs}$

Eqn 6.5(2)

$\mathrm{C}_{\mathrm{d}}\left(\mathrm{T}_{1}\right)=1.19 * 1.8 * 0.18 * 1.0 * 1.32 * 0.925 / 1.25$

$\mathrm{k}_{1}=\left[\mathrm{k}_{\mathrm{p}}+\mathrm{C}_{\mathrm{d}}\left(\mathrm{T}_{1}\right)\right] \div \mathrm{C}_{\mathrm{d}}\left(\mathrm{T}_{1}\right)$

Increase of $4.5 \%$ in base shear to account for P-Delta effects

No steel standard requirement to scale ULS earthquake $\mathrm{K}=\mathrm{k}_{1} * \mathrm{k}_{2}=1.045 * 1.0$

Eqn 3.1(1)

$\mathrm{C}\left(\mathrm{T}_{1}\right)=\mathrm{C}_{\mathrm{h}}(\mathrm{T}) \mathrm{R} \mathrm{Z} \mathrm{N}(\mathrm{T}, \mathrm{D})$

$\mathrm{C}\left(\mathrm{T}_{1}\right)_{\mathrm{uls}}=1.19 * 1.8 * 0.18 * 1.0$

$\mathrm{C}\left(\mathrm{T}_{1}\right)_{\mathrm{sls} 2}=1.19 * 1.0 * 0.18 * 1.0$

$\mathrm{C}\left(\mathrm{T}_{1}\right)_{\mathrm{sls} 1}=1.19 * 0.25 * 0.18 * 1.0$

Eqn 5.2(1)

$\mathrm{C}_{\mathrm{d}}\left(\mathrm{T}_{1}\right)_{\mathrm{uls}}=\mathrm{C}\left(\mathrm{T}_{1}\right) * \mathrm{~S}_{\mathrm{p}} / \mathrm{k}_{\mathrm{\mu}}$

$\mathrm{C}_{\mathrm{d}}\left(\mathrm{T}_{1}\right)_{\mathrm{uls}}=0.386 * 0.925 / 1.25$

$\therefore \mathrm{C}_{\mathrm{d}}\left(\mathrm{T}_{1}\right)_{\mathrm{uls}}=0.285$

$\mathrm{C}_{\mathrm{d}}\left(\mathrm{T}_{1}\right)_{\mathrm{sls} 2}=0.214 * 0.925 / 1.25$

$\mathrm{C}_{\mathrm{d}}\left(\mathrm{T}_{1}\right)_{\mathrm{sls} 1}=0.054 * 0.7 / 1.0$

$=\mathrm{C}_{\mathrm{d}}\left(\mathrm{T}_{1}\right)_{\mathrm{uls}} * \mathrm{C}_{\mathrm{f}}(2) * \mathrm{~K} * \mathrm{~W}_{\mathrm{t}}$

$=0.8 * 0.39+$ possible over-stress allowance of $1 / 3$. Too

low, AS/NZS 1200 Appendix I min. value $=0.53$.

$0.24 \mathrm{~W}_{\mathrm{t}}$

$0.06 \mathrm{~W}_{\mathrm{t}}$
$=\mathrm{C}_{\mathrm{d}}\left(\mathrm{T}_{1}\right)_{\mathrm{sls} 2} * \mathrm{C}_{\mathrm{f}}(1) * \mathrm{~W}_{\mathrm{t}}$

$=\mathrm{C}_{\mathrm{d}}\left(\mathrm{T}_{1}\right)_{\mathrm{sls} 1} * \mathrm{C}_{\mathrm{f}}(0.5) * \mathrm{~W}_{\mathrm{t}}$

Foundation and vessel HD bolts to be designed for the minimum of the over-strength of collapse mechanism or the elastic level earthquake 


\section{Table B1 -Equivalent Static Earthquake Coefficients Calculation for a Vertical Pressure Vessel \\ Description \\ Value $\quad$ Consequence}

Horiz. Elastic Level EQ Forces on foundation and HD bolts:

ULS

NZS 3404 Clause 12.9.1.2.2 (4) (b)

Clause 4.4.1

Clause 5.2.1.1

Unscaled ULS Design Action ULS P-Delta Scaling Factor

ULS - To avoid premature nonductile failure and overturning or sliding failure

\section{Horiz. Design EQ Displacements}

No. of storeys assumed for ESA Storey heights

Capacity design undertaken

$$
\begin{array}{r}
\text { ESA undertaken? } \\
\text { Included P-Delta effects in force } \\
\text { analysis? } \\
\text { Distance to nearest boundary or } \\
\text { deflected element within the plant }
\end{array}
$$

Scaling factors:

P-Delta scaling factor

ESA Elastic Analysis scaling factor

ESA Inelastic scaling factor

ESA ULS1 deflection scaling factor

ULS Deflections as per NZS 1170.5 Clause 7.2:

ESA Force analysis deflections $\delta_{\text {i sa }}$

$\begin{aligned} \text { Elastic deflections } & \\ & \delta_{\text {elastic }} \\ \text { Elastic deflection at uppermost } & \mathrm{U}_{\mathrm{el}} \\ \text { level } & \\ \text { Scaled elastic deflections } & \\ & \delta_{\text {scaled elastic }} \\ \text { ULS1 deflections } & \\ & \delta_{\mathrm{uls} 1} \\ \text { Maximum ULS deflection } & \delta_{\mathrm{uls}}\end{aligned}$

$1.19 \quad$ From above

1.0

1.0 Can also be used to check overall stability of structure

1.0

$\begin{array}{lll}\mathrm{C}_{\mathrm{f}}(1) & 1.53 & \text { Damping }=1 \% \text { of critical for elastic case } \\ \mathrm{C}\left(\mathrm{T}_{1}\right) & 0.386 & \mathrm{C}\left(\mathrm{T}_{1}\right)=1.19 * 1.8 * 0.18 * 1.0\end{array}$

$\mathrm{C}_{\mathrm{d}}\left(\mathrm{T}_{1}\right)^{\mathrm{o}}$ uls $\quad 0.386 \quad \mathrm{C}_{\mathrm{d}}\left(\mathrm{T}_{1}\right)=0.386 * 1.0 / 1.0$

$\mathrm{k}_{1} \quad 1.03 \quad$ Eqn 6.5(2)

$\mathrm{K} \quad 1.03$

$\mathrm{E}_{\max }=\mathrm{V}_{\text {uls }}^{\mathrm{o}} \quad 0.61 \mathrm{~W}_{\mathrm{t}} \quad=\mathrm{C}\left(\mathrm{T}_{1}\right) * \mathrm{~S}_{\mathrm{p}} * \mathrm{C}_{\mathrm{f}}(1) * \mathrm{~K} / \mathrm{k}_{\mu} * \mathrm{~W}_{\mathrm{t}}$

Check that any yielding doesn't spread to upper strakes thinner than $36 \mathrm{~mm}$.

8

$\mathrm{h}_{1}, \ldots . \mathrm{h}_{8} \quad=(2.5,7.5,12.4,17.4,22.3,27.3,32.2,37.2) \mathrm{m}$

Yes Static push-over undertaken to determine collapse mechanism for HD Bolt and foundation sizing. Scaled elastic deflections to be used for deflection profiles. As vertical cantilever type structure, no beam sidesway mechanisms need be considered.

Yes Deflection scaling factors in NZS 1170.5 Table 6.1 can be used.

$0.85 \quad$ NZS 1170.5 Table 6.1

Yes Elastic deflections from force analysis already scaled for P-Delta effects

$400 \mathrm{~mm} \quad$ Clearance to adjacent deflected structure using its max ULS deflected shape.

1.045

0.813

1.25

1.31

$\alpha=\mathrm{k}_{\mathrm{d}} / \mathrm{k}_{1}=0.85 / 1.045$

$\mu=\mu_{\mathrm{uls}}$ from Cl. 7.2.1.1

$\beta=\mu * \mathrm{k}_{1}$ from Cl. 7.2.1.1(a) and 7.2.1.2

$$
\delta_{\text {elastic }}=\alpha * \delta_{\text {i esa }}
$$

$(7,23,43,66,90,119,151,183) \mathrm{mm}$

$183 \mathrm{~mm}$

$$
\delta_{\text {elastic }} @ \mathrm{~h}_{8}=37.2 \mathrm{~m}
$$

$$
\delta_{\text {scaled elastic }}=\mu * \delta_{\text {elastic }}
$$

$(8,28,54,82,113,149,189,229) \mathrm{mm}$

$$
\delta_{\text {uls } 1}=\beta * \delta_{\text {elastic }}
$$

$(9,30,56,86,118,155,198,239) \mathrm{mm}$

$\operatorname{Max}\left(\delta_{\mathrm{uls} 1}\right)=239 \mathrm{~mm}$ 
Table B1 -Equivalent Static Earthquake Coefficients Calculation for a Vertical Pressure Vessel

\section{Description

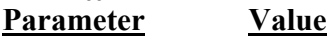 \\ Consequence}

Inter-storey deflections as per NZS 1170.5 Clause 7.3:

Structure height $h_{n}$

Drift modification factor $\mathrm{k}_{\mathrm{dm}}$

Unmodified ULS deflections $\quad \delta_{\text {scaled elastic }}$

ULS inter-storey deflections $\quad \delta_{\text {inter-storey }}$

Scaled inter-storey deflections

$\delta_{\text {scaled inter-storey }}$

Maximum inter-storey deflections

Max allowable inter-storey

deflection

$\delta_{\max \text { inter-storey }}$

$\delta_{\max }$

$\mathrm{h}_{\mathrm{i}}$

$\delta_{\max }$
37.2 metres

$1.50 \quad$ For $\mathrm{h}_{\mathrm{n}}>30 \mathrm{~m}-$ Table 7.1.

$(8,28,54,82,113,148,189,229) \mathrm{mm}$

$(8,20,25,28,31,36,41,40) \mathrm{mm}$

$\delta_{\text {scaled }}=\delta_{\text {inter-storey }} * \mathrm{k}_{\mathrm{dm}}$

$(12,31,38,43,46,53,61,59) \mathrm{mm}$

$(12,31,38,43,46,53,61,59) \mathrm{mm}$

$2.5 \%$ storey

height

$2.5,7.45,12.40,17.35,22.30,27.25,32.20,37.15) \mathrm{m}$

$(63,124,124,124,124,124,124,124) \mathrm{mm}$

Therefore have no inter-storey deflections that exceed the maximum allowable. Would check the pushover analysis to confirm that no mechanisms formed above the base level.

DEFLECTIONS - ULTIMATE LIMIT STATE

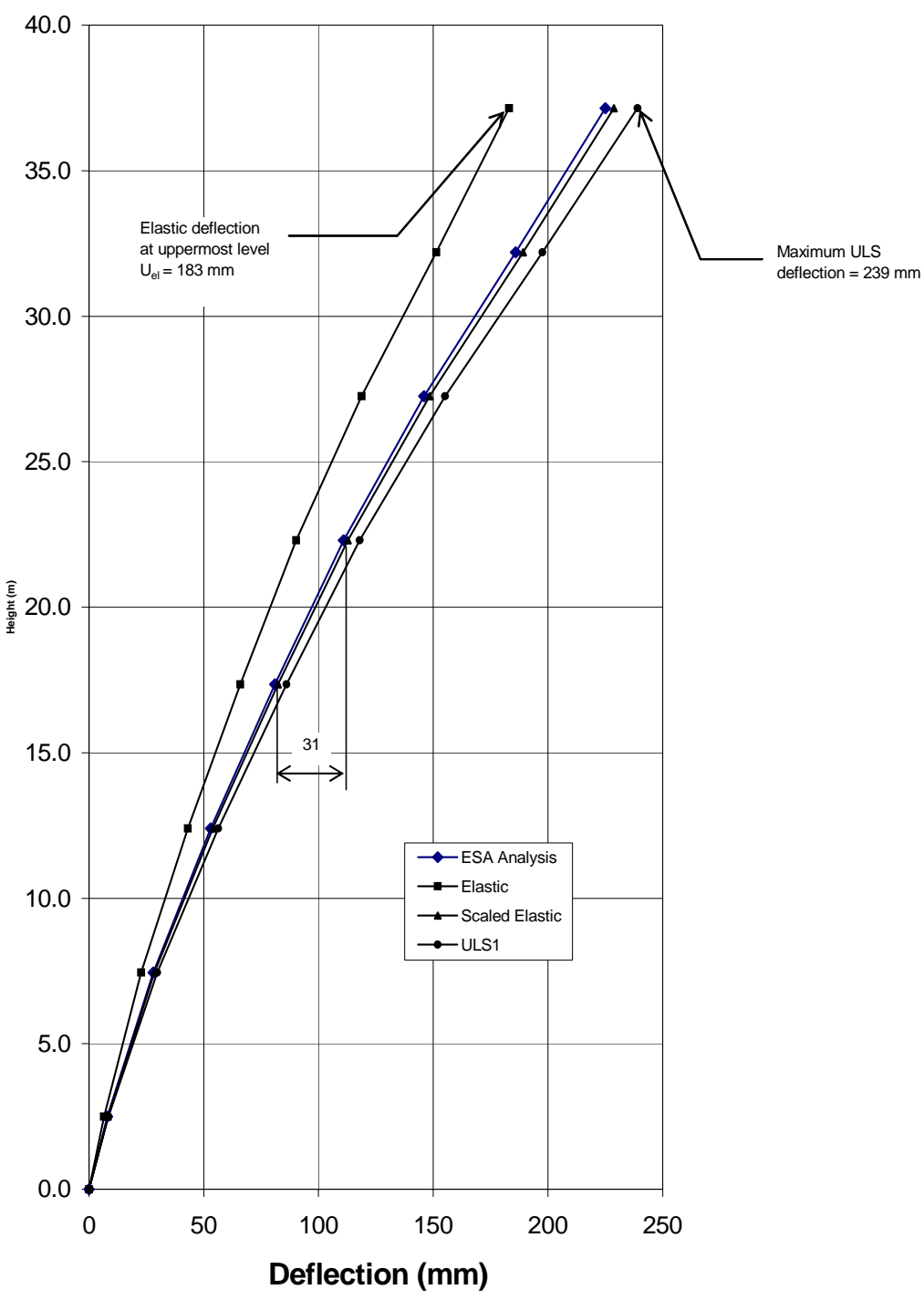


INTER-STORY DEFLECTIONS - ULTIMATE LIMIT STATE

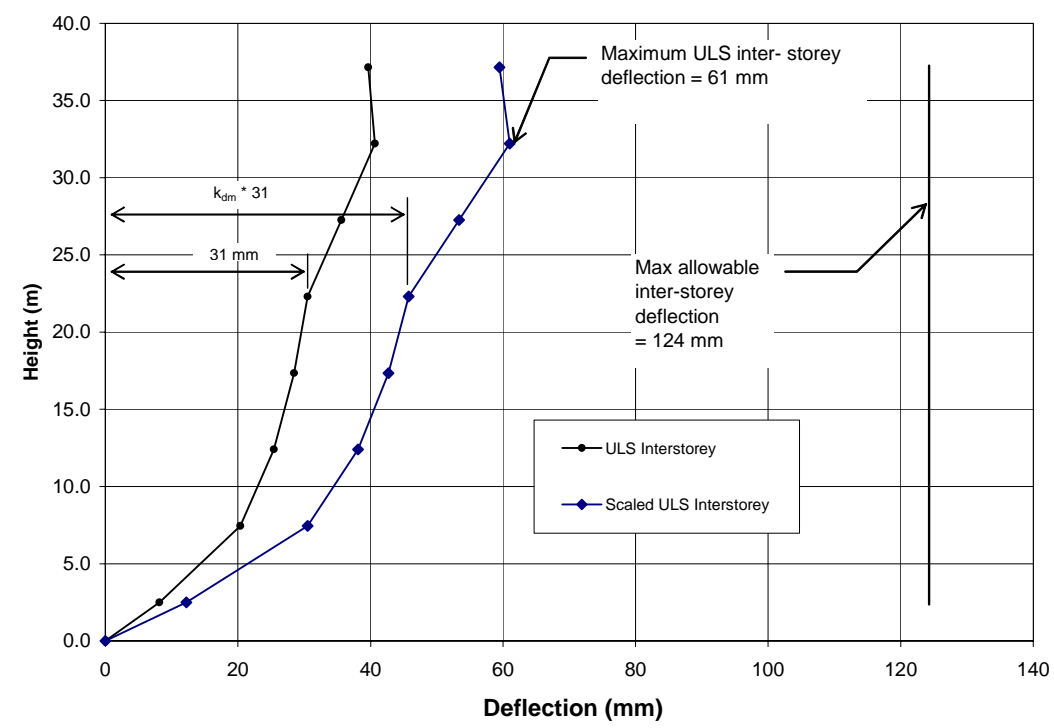

PIPING SUPPORTED OFF A

VERTICAL PRESSURE VESSEL

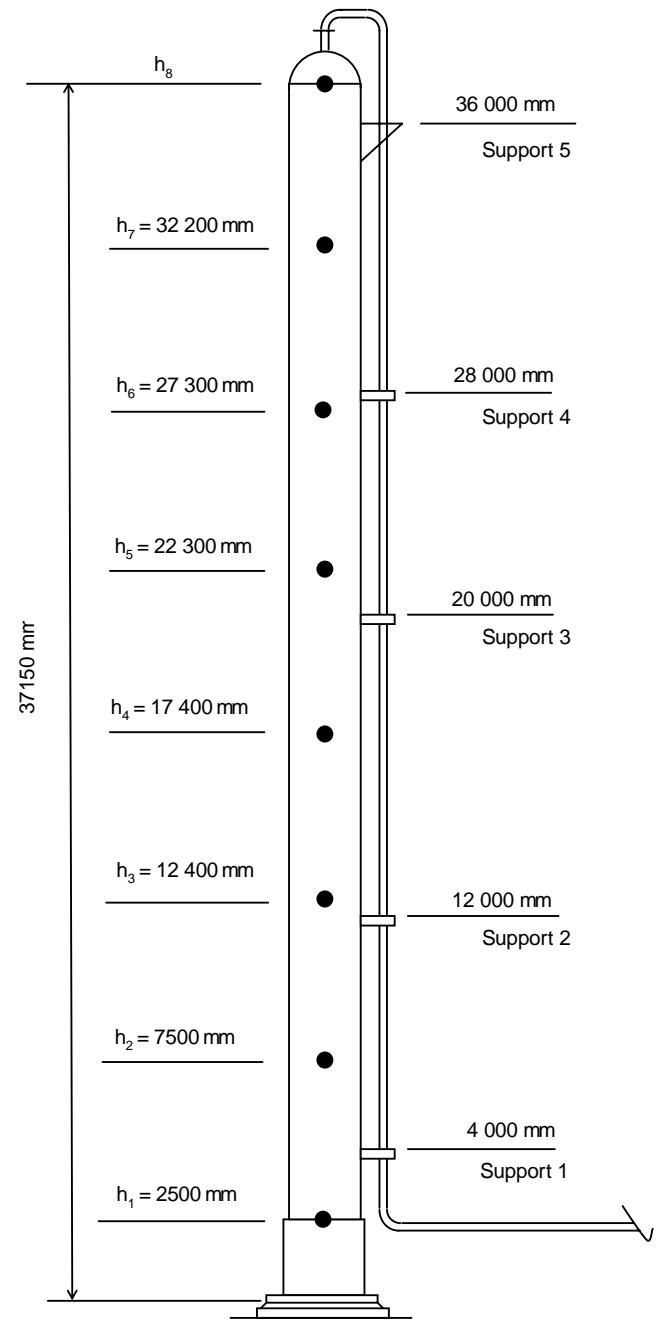

Example 2 - Pressure Piping Supported off the Vessel from Example 1

Assume that a $300 \mathrm{NB}$ pressure pipe with an AS 4343 hazard level of B coming off the top of the vessel analysed in Example 1 .

It is to be supported vertically and restrained for sideways movement near the top of the vessel $\left(h_{i}=36 \mathrm{~m}\right)$. Then at $8 \mathrm{~m}$ intervals down the vessel, these supports are to restrain the pipe laterally, total of 5 supports up the vessel. 
Table B2 -Equivalent Static Earthquake Coefficients Calculation for Pressure Piping Supported off Example 1

\section{Description}

Importance Level:

Earthquake Return Periods:

Site Subsoil Class:

$$
\text { Clause 3.1.3.4 }
$$

Hazard Factor:

$$
\begin{array}{rr}
\text { Clause 3.1.4 } & \text { Z } \\
\text { NZS 4203 Clause 4.6.2.5 } & Z \\
\text { Zone Factor } &
\end{array}
$$

\section{Parameter}

IL

ULS

SLS2

SLS1

Return Period Factors:

$\begin{array}{lll}\text { Table 3.5 } & \mathrm{R}_{\mathrm{u}} & 1.8 \\ & \mathrm{R}_{\text {sls } 2} & 1.0 \\ & \mathrm{R}_{\text {sls } 1} & 0.25\end{array}$

Near-fault factor:

$$
\text { Clause 3.1.6 N(T, D) }
$$

$405 \mathrm{kN}$ $<0.20 * \mathrm{~W}_{\mathrm{p}}$

From Example 1

Weight of components:

$$
\begin{array}{cc}
\text { Weight of support } & W_{s} \\
\text { Weight of piping } & W_{p}
\end{array}
$$

Overall Height:

$$
\mathrm{h}_{\mathrm{n}}
$$

37.2 metres

Support Locations:

$\begin{array}{ll}\text { Support } 5 & \mathrm{~h}_{\mathrm{i} 5} \\ \text { Support } 4 & \mathrm{~h}_{\mathrm{i} 4} \\ \text { Support } 3 & \mathrm{~h}_{\mathrm{i} 3} \\ \text { Support 2 } & \mathrm{h}_{\mathrm{i} 2} \\ \text { Support 1 } & \mathrm{h}_{\mathrm{i} 1}\end{array}$

Level of allowable deformity

Horizontal Fundamental periods:

$$
\text { Support including piping } T_{1}
$$

Vertical Fundamental periods:

$$
\text { Support including piping } \mathrm{T}_{\mathrm{v} 1}
$$

$$
\text { Table } 3.1 \quad \mathrm{C}_{\mathrm{h}}(0)
$$$$
\mathrm{C}\left(\mathrm{T}_{\mathrm{v} 1}\right)
$$

Displacement Ductility Factors:

$\begin{array}{rr}\text { ULS } & \mu_{\mathrm{p}} \\ \text { SLS2 } & \mu_{\mathrm{p}} \\ \text { SLS1 } & \mu_{\mathrm{p}}\end{array}$

Risk Factor for Parts:

$\begin{array}{rr}\text { ULS } & R_{\mathrm{p}} \\ \text { SLS2 } & R_{\mathrm{p}} \\ \text { SLS1 } & R_{\mathrm{p}}\end{array}$

Parts Response Factors:
36.0 metres $28.0 \mathrm{~m}$

$20.0 \mathrm{~m}$

$12.0 \mathrm{~m}$

$4.0 \mathrm{~m}$

Low

$1.0 \mathrm{secs}$

$0.06 \mathrm{secs}$

0.01 secs

From modal analysis

Site Subsoil Class $=C \& T_{1}=0.0$ secs

Site Subsoil Class $=C \& T_{\mathrm{v} 1}=0.01 \mathrm{secs}$

Clause 8.5

Allow some ductility for ULS event

Table 8.1

1.0

1.0

0.85

1.0

1.0 event, $\therefore \mu_{\mathrm{p}} \leq 1.25$

From modal analysis

From pipe stress engineer

Table 8.1

Table 8.2

For horizontal forces
Suitable for North Taranaki

NZS 1200 Appendix I minimum seismic coefficient for pressure equipment $=0.53$

Large dia. piping with low tolerance for leaks after an 


\section{Table B2 -Equivalent Static Earthquake Coefficients Calculation for Pressure Piping Supported off Example 1}

\section{Description}

System Damping Factors for supporting structure:

$\begin{array}{rlll}\text { ULS } & C_{\mathrm{pv}} & 1.0 & \text { For vertical forces } \\ \text { SLS2 } & C_{\mathrm{pv}} & 1.0 & \\ \text { SLS1 } & C_{\mathrm{pv}} & 1.0 & \end{array}$

$\begin{array}{rll}\text { ULS } & \mathrm{C}_{\mathrm{f}}(2) & 1.32 \\ \text { SLS2 } & \mathrm{C}_{\mathrm{f}}(1) & 1.53 \\ \text { SLS1 } & \mathrm{C}_{\mathrm{f}}(0.5) & 1.67\end{array}$

Part Category:

$\begin{array}{llll}\text { Table } 8.1 & \text { ULS } & \text { P.4 } & R_{\text {pu }}=1.0 \\ & \text { SLS2 } & \text { P.5 } & R_{\text {psls2 } 2}=1.0 \\ & \text { SLS1 } & \text { P.7 } & R_{\text {psls } 1}=1.0\end{array}$

Floor Spectral Shape Factor:

Clause $8.4 \quad \mathrm{C}_{\mathrm{i}}\left(T_{\mathrm{p}}\right)$

Floor Height Coefficients:

\section{Support 5}

Support $2 \quad \mathrm{C}_{\mathrm{Hi}}$

Support $1 \quad \mathrm{C}_{\mathrm{Hi}}$

Horizontal Forces on Part:

5\% Damped Elastic spectrum @ T $=0 \mathrm{sec}$ :

$\begin{array}{rll}\text { ULS } & \text { C }(0) & 0.431 \\ \text { SLS2 } & \text { C }(0) & 0.239 \\ \text { SLS1 } & \text { C }(0) & 0.060\end{array}$

Spectral Ordinate of the Part:

Support 5 :

ULS

SLS2

$C_{\mathrm{p}}\left(T_{\mathrm{p}}\right)$

$C_{\mathrm{p}}\left(T_{\mathrm{p}}\right)$

SLS1 $\quad C_{\mathrm{p}}\left(T_{\mathrm{p}}\right)$

Support 2:

ULS $\quad C_{\mathrm{p}}\left(T_{\mathrm{p}}\right)$

SLS2 $\quad C_{\mathrm{p}}\left(T_{\mathrm{p}}\right)$

SLS1 $\quad C_{\mathrm{p}}\left(T_{\mathrm{p}}\right)$

Support 1:

ULS $\quad C_{\mathrm{p}}\left(T_{\mathrm{p}}\right)$

SLS2 $\quad C_{\mathrm{p}}\left(T_{\mathrm{p}}\right)$

SLS1 $\quad C_{\mathrm{p}}\left(T_{\mathrm{p}}\right)$

Horizontal Design EQ Actions:

Support 5:

ULS - No collapse

WSD - No loss of contents

SLS2 - To remain operational

SLS1 - To sustain no damage

Support 2:

ULS - No collapse

WSD - No loss of contents

SLS2 - To remain operational

SLS1 - To sustain no damage

Support 1:

ULS - No collapse

WSD - No loss of contents
$\mathrm{E}_{\mathrm{u}}=F_{\mathrm{ph}}$

$\mathrm{E}_{\mathrm{wsd}}=0.8 \mathrm{E}_{\mathrm{u}}$

$\mathrm{E}_{\mathrm{s}}=F_{\mathrm{ph}}$

$\mathrm{E}_{\mathrm{s}}=F_{\mathrm{ph}}$

$\mathrm{E}_{\mathrm{u}}=F_{\mathrm{ph}}$

$\mathrm{E}_{\mathrm{wsd}}=0.8 \mathrm{E}_{\mathrm{u}}$

$2.91 \mathrm{~W}$

$2.33 \mathrm{~W}_{\mathrm{p}}$

$\mathrm{E}_{\mathrm{s}}=F_{\mathrm{ph}}$

$2.19 \mathrm{~W}_{\mathrm{p}}$

$\mathrm{E}_{\mathrm{s}}=F_{\mathrm{ph}}$

$0.60 \mathrm{~W}_{\mathrm{p}}$

$\mathrm{E}_{\mathrm{u}}=F_{\mathrm{ph}}$

$\mathrm{E}_{\mathrm{wsd}}=0.8 \mathrm{E}_{\mathrm{u}}$

$1.62 \mathrm{~W}_{\mathrm{p}}$
2.0

Chosen values from Example 1:

Damping $=2 \%$ of critical

Damping $=1 \%$ of critical

Damping $=0.5 \%$ of critical

$R_{\mathrm{pu} 2}=1.0$

$R_{\mathrm{psls} 1}=1.0$

$T_{\mathrm{p}}<0.75 \mathrm{secs}$

Eqns 8.3(1), 8.3(2) and 8.3(3)

$\mathrm{C}_{\mathrm{Hi}}$ constant for $12 \mathrm{~m} \leq \mathrm{h}_{\mathrm{i}} \leq 37.2 \mathrm{~m}$ as per Eqn 8.3(3)

Seismic forces will be the same for the upper 4 supports

Eqn 8.3(1) governs

$\mathrm{C}(0)=\mathrm{C}_{\mathrm{h}}(0) \mathrm{R} \mathrm{Z} \mathrm{N}(0, \mathrm{D})$

$\mathrm{C}(0)=1.33 * 1.8 * 0.18 * 1.0$

$\mathrm{C}(0)=1.33 * 1.0 * 0.18 * 1.0$

$\mathrm{C}(0)=1.33 * 0.25 * 0.18 * 1.0$

$C_{\mathrm{p}}\left(T_{\mathrm{p}}\right)=C(0) * C_{\mathrm{Hi}} * C_{\mathrm{i}}\left(T_{\mathrm{p}}\right)-$ Eqn 8.2(1)

$C_{\mathrm{p}}\left(T_{\mathrm{p}}\right)=0.431 * 3.0 * 2.0$

$C_{\mathrm{p}}\left(T_{\mathrm{p}}\right)=0.239 * 3.0 * 2.0$

$C_{\mathrm{p}}\left(T_{\mathrm{p}}\right)=0.059 * 3.0 * 2.0$

$C_{\mathrm{p}}\left(T_{\mathrm{p}}\right)=0.431 * 3.0 * 2.0$

$C_{\mathrm{p}}\left(T_{\mathrm{p}}\right)=0.239 * 3.0 * 2.0$

$C_{\mathrm{p}}\left(T_{\mathrm{p}}\right)=0.059 * 3.0 * 2.0$

$C_{\mathrm{p}}\left(T_{\mathrm{p}}\right)=0.431 * 1.67 * 2.0$

$C_{\mathrm{p}}\left(T_{\mathrm{p}}\right)=0.239 * 1.67 * 2.0$

$C_{\mathrm{p}}\left(T_{\mathrm{p}}\right)=0.060 * 1.67 * 2.0$

$F_{\mathrm{ph}}=C_{\mathrm{p}}\left(T_{\mathrm{p}}\right) * C_{\mathrm{ph}} * R_{\mathrm{p}} * \mathrm{C}_{\mathrm{f}}(\xi) * W_{\mathrm{p}}-\operatorname{Eqn} 8.5(1)$

$F_{\mathrm{ph}}=2.59 * 0.85 * 1.0 * 1.32 * \mathrm{~W}_{\mathrm{p}}$

$=0.8 * 2.93+$ possible over-stress allowance of $1 / 3$

$F_{\mathrm{ph}}=1.44 * 1.0 * 1.0 * 1.53 * \mathrm{~W}_{\mathrm{p}}$

$F_{\mathrm{ph}}=0.36 * 1.0 * 1.0 * 1.67 * \mathrm{~W}_{\mathrm{p}}$

$F_{\mathrm{ph}}=2.59 * 0.85 * 1.0 * 1.32 * \mathrm{~W}_{\mathrm{p}}$

$=0.8 * 2.93+$ possible over-stress allowance of $1 / 3$

$F_{\mathrm{ph}}=1.44 * 1.0 * 1.0 * 1.53 * \mathrm{~W}_{\mathrm{p}}$

$F_{\mathrm{ph}}=0.36 * 1.0 * 1.0 * 1.67 * \mathrm{~W}_{\mathrm{p}}$

$F_{\mathrm{ph}}=1.44 * 0.85 * 1.0 * 1.32 * \mathrm{~W}_{\mathrm{p}}$

$=0.8 * 2.93+$ possible over-stress allowance of $1 / 3$ 
Table B2 -Equivalent Static Earthquake Coefficients Calculation for Pressure Piping Supported off Example 1

\section{Description}

SLS2 - To remain operational

SLS1 - To sustain no damage

WSD

SLS2

SLS1

Horiz Design Actions due to EQ deflections:

ULS deflections at pipe support locations

\begin{tabular}{|c|c|}
\hline Inter-storey & $\begin{array}{l}\delta_{\text {inter-storey }} \\
\delta_{\text {scaled inter-storey }}\end{array}$ \\
\hline Totals & $\delta_{\text {scaled inter-storey }}$ \\
\hline Support 5 & $\delta_{5}$ \\
\hline Support 4 & $\delta_{4}$ \\
\hline Support 3 & $\delta_{3}$ \\
\hline Support 2 & $\delta_{2}$ \\
\hline Support 1 & $\delta_{1}$ \\
\hline
\end{tabular}

WSD

SLS2

\section{$\mathrm{E}_{\mathrm{s}}=F_{\mathrm{ph}}$}

$\mathrm{E}_{\mathrm{s}}=F_{\mathrm{ph}}$
$1.22 \mathrm{~W}_{\mathrm{p}}$
$0.33 \mathrm{~W}_{\mathrm{p}}$

$F_{\mathrm{ph}}=0.80 * 1.0 * 1.0 * 1.53 * \mathrm{~W}_{\mathrm{p}}$

$F_{\mathrm{ph}}=0.20 * 1.0 * 1.0 * 1.67 * \mathrm{~W}_{\mathrm{p}}$

Piping system analysed for:

- WSD case of $2.33 \mathrm{~g}$ in two principal directions analysed separately. Internal forces and moments $=\mathrm{M}_{\mathrm{iux}} \& \mathrm{M}_{\mathrm{iuy}}$

- $\quad$ SLS2 case of $2.19 \mathrm{~g}$ in two principal directions being analysed separately.

Internal forces and moments $=\mathrm{M}_{\text {is } 2 x} \& \mathrm{M}_{\text {is } 2 \mathrm{y}}$

- $\quad$ SLS1 case of $0.60 \mathrm{~g}$ in two principal directions being analysed separately.

Internal forces and moments $=\mathrm{M}_{\text {is } 1 \mathrm{x}} \& \mathrm{M}_{\text {is } 1 \mathrm{y}}$

O.K. - AS/NZS 1200 Appendix I min. value =0.53.

From Example 1:

$(8,20,25,28,31,36,41,40) \mathrm{mm}$

$(12,31,38,43,46,53,61,59) \mathrm{mm}$

$(12,43,81,124,169,223,284,343) \mathrm{mm}$

330 In $\mathrm{mm}$, interpolated for the actual support locations

233 using the deflections calculated as per Clause 7.3 as

148 required by Clause 8.5 .3

78

21

Piping system analysed for:

- ULS deflection case with the above imposed deflections in two principal directions analysed separately.

Internal forces and moments $=\mathrm{M}_{\delta \mathrm{ux}} \& \mathrm{M}_{\delta \mathrm{uy}}$

- $\quad$ SLS2 deflection case with the SLS2 imposed deflections in two principal directions analysed separately. Internal forces and moments $=M_{\delta s 2 x} \& M_{\delta s 2 y}$

- $\quad$ SLS1 deflection case with the SLS1 imposed deflections in two principal directions analysed separately. Internal forces and moments $=\mathrm{M}_{\delta \mathrm{s} 1 \mathrm{x}} \& \mathrm{M}_{\delta \mathrm{s} 1 \mathrm{y}}$

Cummulative Interstorey Deflections

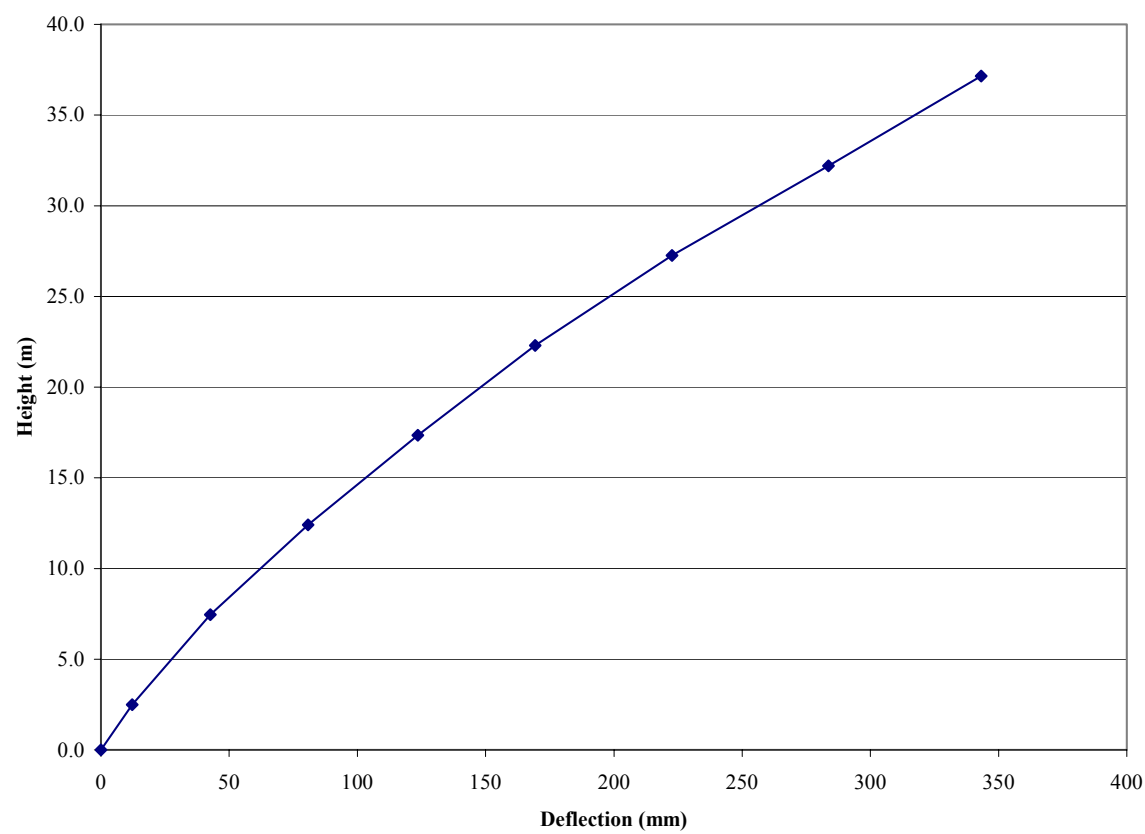


Table B2 -Equivalent Static Earthquake Coefficients Calculation for Pressure Piping Supported off Example 1

\section{Description}

\section{Piping Horizontal Design Actions}

due to EQ acting on vessel

WSD:

$$
\begin{aligned}
& \text { X direction } \quad \mathrm{M}_{\text {hux }} \\
& \mathrm{Y} \text { direction } \mathrm{M}_{\text {huy }} \\
& \left(\mathrm{M}_{\mathrm{iux}}{ }^{2}+\mathrm{M}_{\delta \mathrm{ux}}{ }^{2}\right)^{0.5}
\end{aligned}
$$

SLS2:

SLS1:

$$
\text { X direction } \quad \mathrm{M}_{\mathrm{hs} 2 \mathrm{x}}
$$$$
\text { Y direction } \mathrm{M}_{\mathrm{hs} 2 \mathrm{y}}
$$

$\mathrm{X}$ direction

$\mathrm{Y}$ direction

$$
\mathrm{M}_{\mathrm{hs} 1 \mathrm{x}}
$$$$
\mathrm{M}_{\mathrm{hsly}}
$$

Vertical Forces on Piping:

5\% Damped Elastic spectrum @ T $=\mathrm{T}_{\mathrm{v} 1} \mathrm{sec}$ :

$\begin{aligned} \text { ULS } & \mathrm{C}_{\mathrm{v}}\left(\mathrm{T}_{\mathrm{v} 1}\right) \\ \text { SLS2 } & \mathrm{C}_{\mathrm{v}}\left(\mathrm{T}_{\mathrm{v} 1}\right) \\ \text { SLS1 } & \mathrm{C}_{\mathrm{v}}\left(\mathrm{T}_{\mathrm{v} 1}\right) \\ \text { ULS } & \mathrm{C}_{\mathrm{vd}} \\ \text { SLS2 } & \mathrm{C}_{\mathrm{vd}} \\ \text { SLS1 } & \mathrm{C}_{\mathrm{vd}}\end{aligned}$

\section{Vertical Design EQ Forces:}

ULS - No collapse WSD - No loss of contents

SLS2 - To remain operational

SLS1 - To sustain no damage

$\mathrm{E}_{\mathrm{u}}=\mathrm{F}_{\mathrm{pv}}$

$\mathrm{E}_{\mathrm{wsd}}=0.8 \mathrm{E}_{\mathrm{u}}$

$\left(\mathrm{M}_{\mathrm{is} 2 \mathrm{x}}{ }^{2}+\mathrm{M}_{\delta \mathrm{s} 2 \mathrm{x}}{ }^{2}\right)^{0.5}$

$\left(\mathrm{M}_{\mathrm{is} 2 \mathrm{y}}{ }^{2}+\mathrm{M}_{\delta \mathrm{s} 2 \mathrm{y}}{ }^{2}\right)^{0.5}$

$\left(\mathrm{M}_{\mathrm{is} 1 \mathrm{x}}{ }^{2}+\mathrm{M}_{\delta \mathrm{s} 1 \mathrm{x}}{ }^{2}\right)^{0.5}$

$\left.\left(\mathrm{M}_{\mathrm{is} 1 \mathrm{y}}{ }^{2}+\mathrm{M}_{\delta \mathrm{s} 1 \mathrm{y}}\right)^{2}\right)^{0.5}$

\section{Consequence}

$0.34 \mathrm{~W}_{\mathrm{p}}$ $0.27 \mathrm{~W}_{\mathrm{p}}$

0.338

0.188

0.047

0.34

0.19

0.05

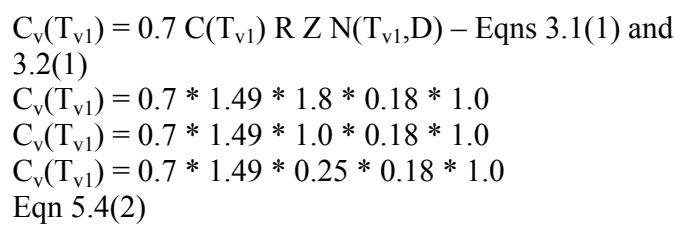

$\mathrm{F}_{\mathrm{pv}}=C_{\mathrm{vd}} * C_{\mathrm{pv}} * R_{\mathrm{p}} * W_{\mathrm{p}}-$ Eqn 8.5(2) $\mathrm{F}_{\mathrm{pv}}=0.34 * 1.0 * 1.0 * W_{\mathrm{p}}$ $=0.8 * 0.34+$ possible over-stress allowance of $1 / 3$ WSD case of $0.27 \mathrm{~g}$ in vertical direction. Internal forces and moments $=\mathrm{M}_{\mathrm{uv}}$

$0.19 \mathrm{~W}_{\mathrm{p}} \quad \mathrm{F}_{\mathrm{pv}}=0.19 * 1.0 * 1.0 * \mathrm{~W}_{\mathrm{p}}$

SLS2 case of $0.19 \mathrm{~g}$ in vertical direction. Internal forces and moments $=\mathrm{M}_{\mathrm{s} 2 \mathrm{v}}$ $\mathrm{F}_{\mathrm{pv}}=0.05 * 1.0 * 1.0 * \mathrm{~W}_{\mathrm{p}}$ SLS1 case of $0.05 \mathrm{~g}$ in vertical direction. Internal forces and moments $=\mathrm{M}_{\mathrm{s} 1 \mathrm{v}}$

\section{Piping Total Design Actions due}

\section{to EQ}

WSD:

SLS2:

$\begin{array}{lll}\text { X direction } & \mathrm{M}_{\mathrm{xu}} & \mathrm{M}_{\mathrm{hux}}+\mathrm{M}_{\mathrm{uv}} \\ \text { Y direction } & \mathrm{M}_{\mathrm{yu}} & \mathrm{M}_{\mathrm{huy}}+\mathrm{M}_{\mathrm{uv}} \\ & & \\ \text { X direction } & \mathrm{M}_{\mathrm{xs} 2} & \mathrm{M}_{\mathrm{hs} 2 \mathrm{x}}+\mathrm{M}_{\mathrm{s} 2 \mathrm{v}} \\ \text { Y direction } & \mathrm{M}_{\mathrm{ys} 2} & \mathrm{M}_{\mathrm{hs} 2 \mathrm{y}}+\mathrm{M}_{\mathrm{s} 2 \mathrm{v}}\end{array}$

SLS1:

$\begin{array}{lll}\text { X direction } & \mathrm{M}_{\mathrm{xs} 1} & \mathrm{M}_{\mathrm{hs} 1 \mathrm{x}}+\mathrm{M}_{\mathrm{s} 1 \mathrm{v}} \\ \mathrm{Y} \text { direction } & \mathrm{M}_{\mathrm{ys} 1} & \mathrm{M}_{\mathrm{hs} 1 \mathrm{y}}+\mathrm{M}_{\mathrm{s} 1 \mathrm{v}}\end{array}$

These earthquake actions need be combined with normal operating pressure and temperature conditions for pipe stress checking. 


\section{Example 3 - Combination Structure supporting 3 Vertical Pressure Vessels}

This is an adaptation of the example given in ASCE (1997) Appendix 4B. Three heavy pressure vessels are to be supported 5 metres off the ground by reinforced concrete moment resisting frames spanning in both principal directions.

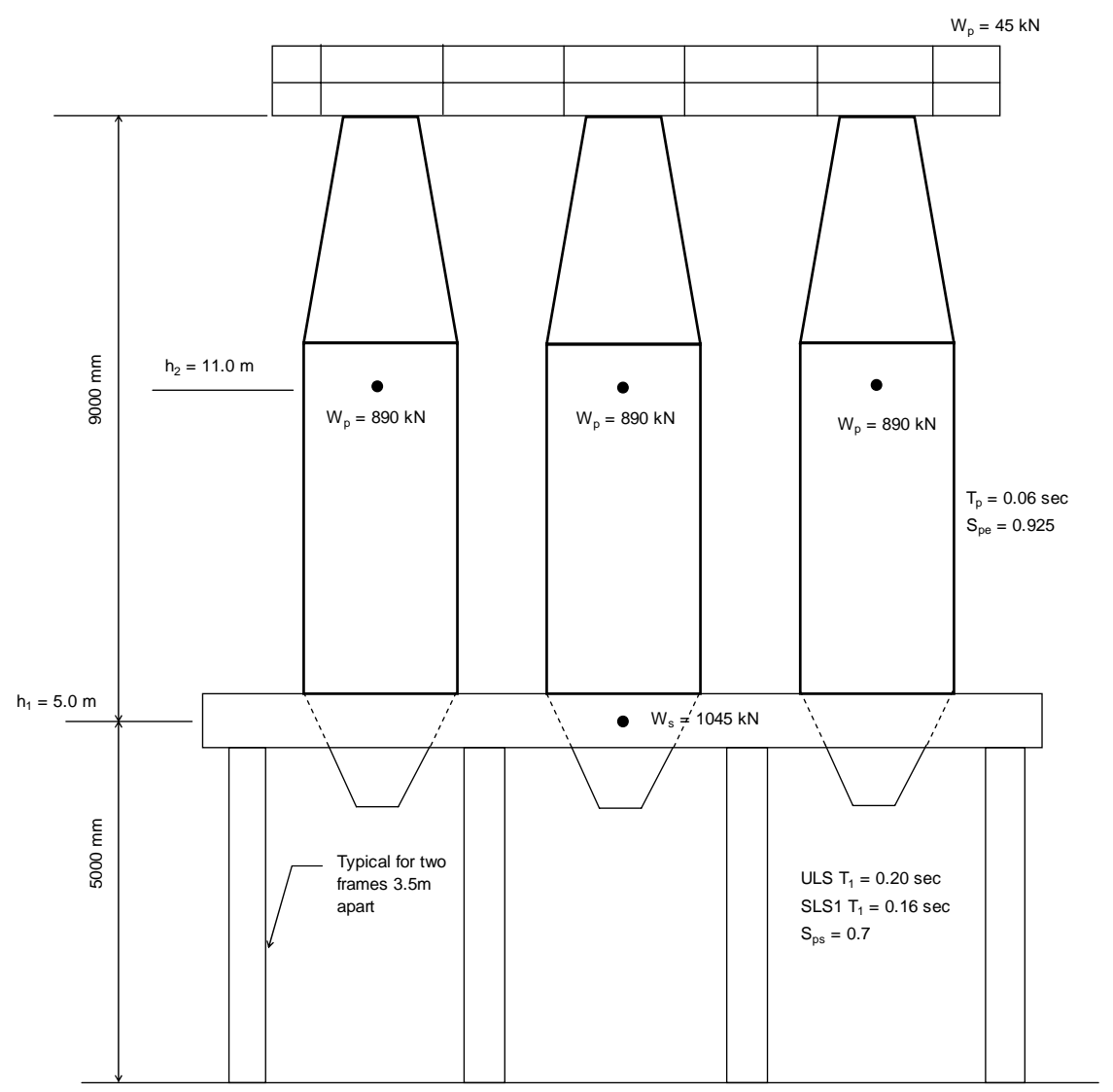

Assume:

- The structure is to be installed on the outskirts of Blenheim on a soft soil site (very deep gravels).

- That the structure is located within a plant that is in an area zoned as industrial and the vessels have a design pressure such that if released, toxic fumes are not likely to spread beyond the plant's boundary.

- No site specific seismic hazard study has been undertaken.

- The vessel's fundamental horizontal period $T_{\mathrm{p}}<0.06 \mathrm{secs}$, therefore Case 1 of Table $11 \mathrm{can}$ be used.

- The vessels have a mechanical design life of $30+$ years.

The minimum seismic coefficient given in AS/NZS 1200 Appendix I applies for the pressure envelope, vessel hold down and foundation, refer to ACPPE Clause 5.4.4(8). This minimum value is dependent on the NZS 4203:1992 Zone Factor Z.

Table B3 -Equivalent Static Earthquake Coefficients Calculation for a Combination Structure

Description

NZ Building Code Category -

Clause A1 Classified Uses

Structural Type

Importance Level:

Design Working Life

Earthquake Return Periods:

Table 3.3 AS/NZS 1170.0 ULS

\section{$\underline{\text { Parameter } \quad \underline{\text { alue }} \quad \text { Consequence }}$}

Ancillary May be exempt some amenity provisions but required to comply with structural and safety provisions of NZBC

SLS1

Combination structure

IL 2

50 years

500 years

25 years
Weight of supported vessels over $70 \%$ of total weight, Case 1 as per Table 11 above.

2 limit states $=$ ULS \& SLS 1

Plant life of 50+ years and mechanical design life of vessels $=30+$ years. 


\section{Table B3 -Equivalent Static Earthquake Coefficients Calculation for a Combination Structure \\ Description}

Site Subsoil Class:

Clause 3.1.3.4

D

0.33

NZS 4203 Clause 4.6.2.5 Z

Zone Factor

Return Period Factors:

$\begin{array}{ll}\text { Table } 3.5 & \mathrm{R}_{\mathrm{u}} \\ & \mathrm{R}_{\mathrm{sls}}\end{array}$

Clause 3.1.1 Z R

Fundamental periods:

Combined system - ULS $T_{1}$

Combined system - SLS1 $T_{1}$

Vessel - ULS and SLS1 $T_{\mathrm{p}}$

Near-fault factor:

$$
\begin{aligned}
\text { Clause 3.1.6.2 } & \mathrm{N}(\mathrm{T}, \mathrm{D}) \\
\text { Table 3.7 } & \mathrm{N}_{\max }(0.2)
\end{aligned}
$$

Structural Ductility Factors:

$$
\text { ULS - NZS } 3101 \text { Table } 4.1
$$

SLS1 - NZS 3101 Clause 4.4.2.3

ULS - NZS 3404 Table 12.2.4

SLS1 - Clause 4.3.2

Design ULS

Design SLS1

Weight of components:

Weight of support structure

Weight of vessels \& platforms

Heights to seismic weights:

Height to centre of mass for combined system

Vertical Regularity Check:

Clause 4.5.1.1
$\mathrm{W}_{\mathrm{s}}$

$\mathrm{W}_{\mathrm{p}}$

$\mathrm{h}_{1}=\mathrm{h}_{\mathrm{n}}$

$\mathrm{h}$

$\mu_{\mathrm{s} l s 1}$

$\mu_{\mathrm{p}}$

$\mu_{\text {sls1 }}$

$\mu_{\mathrm{uls}}$

$\mu_{\mathrm{sls}}$
1.0

0.25

0.33

$0.20 \mathrm{secs}$

$0.16 \mathrm{secs}$

$0.06 \mathrm{sec}$

$\mathrm{N}_{\max }(\mathrm{T})$

1.0

6.0

1.0

1.25

1.0

6.0

1.0

$1045 \mathrm{kN}$

$2715 \mathrm{kN}$

$5 \mathrm{~m}$

$11 \mathrm{~m}$

$9.332 \mathrm{~m}$

No

Suitability of Equivalent Static

Analysis Method Check:

$\begin{array}{lll}\text { Clause 6.1.3.1(a) } & \mathrm{h}_{\mathrm{n}}<10 \mathrm{~m} & \text { No } \\ \text { Clause 6.1.3.1(b) } & \mathrm{T}_{1}<0.4 \text { secs } & \text { Yes } \\ \text { Clause 6.1.3.1(c) } & \text { Horiz. regular } & \text { Yes } \\ & \text { Vert. regular } & \text { No } \\ & \mathrm{T}_{1}<2.0 \mathrm{secs} & \text { Yes }\end{array}$

Review P-Delta effects:

$$
\begin{array}{lll}
\text { Clause 6.5.2(a) } & \mathrm{T}_{1}>0.4 \text { secs } & \text { No } \\
\text { Clause 6.5.2(b) } & \mathrm{h}_{\mathrm{n}}>15 \mathrm{~m} & \text { No } \\
& \mathrm{T}_{1}>0.6 \mathrm{secs} & \text { No }
\end{array}
$$

Weight of vessels $>150 \%$ of supporting structure

Table 3.1 for Spectral Shape Factor $C_{h}(T)$

\section{Suitable for Blenheim}

NZS 1200 Appendix I minimum seismic coefficient for pressure equipment and supports $=0.6$

$$
<0.7 \therefore \text { O.K. }
$$

From Example 4B ASCE (1997). From C4.1.2.2 of NZS 1170.5 Supp 1

Assumed.

Adjacent to major fault (Wairau), i.e. $\mathrm{D}<2 \mathrm{~km}$ Period not long enough to be influenced by near-fault effects

Ductile reinforced concrete support structure

Nominally ductile pressure vessels

Can use $\mu_{\mathrm{s}}$ as supported vessels rigid as per FEMA 450 $\mathrm{Cl} 14.1 .5$

From Example 4B ASCE (1997).

Seismic weight $\mathrm{W}_{\mathrm{t}}=3760 \mathrm{kN}$

Support structure

Vessels cog

May not be able to use ESA

OK to use ESA

May not be able to use ESA

$\therefore$ ESA OK using Cl. 6.1.3.1(b)

No need to consider P-Delta effects $\therefore \mathrm{k}_{1}=1.0$ 


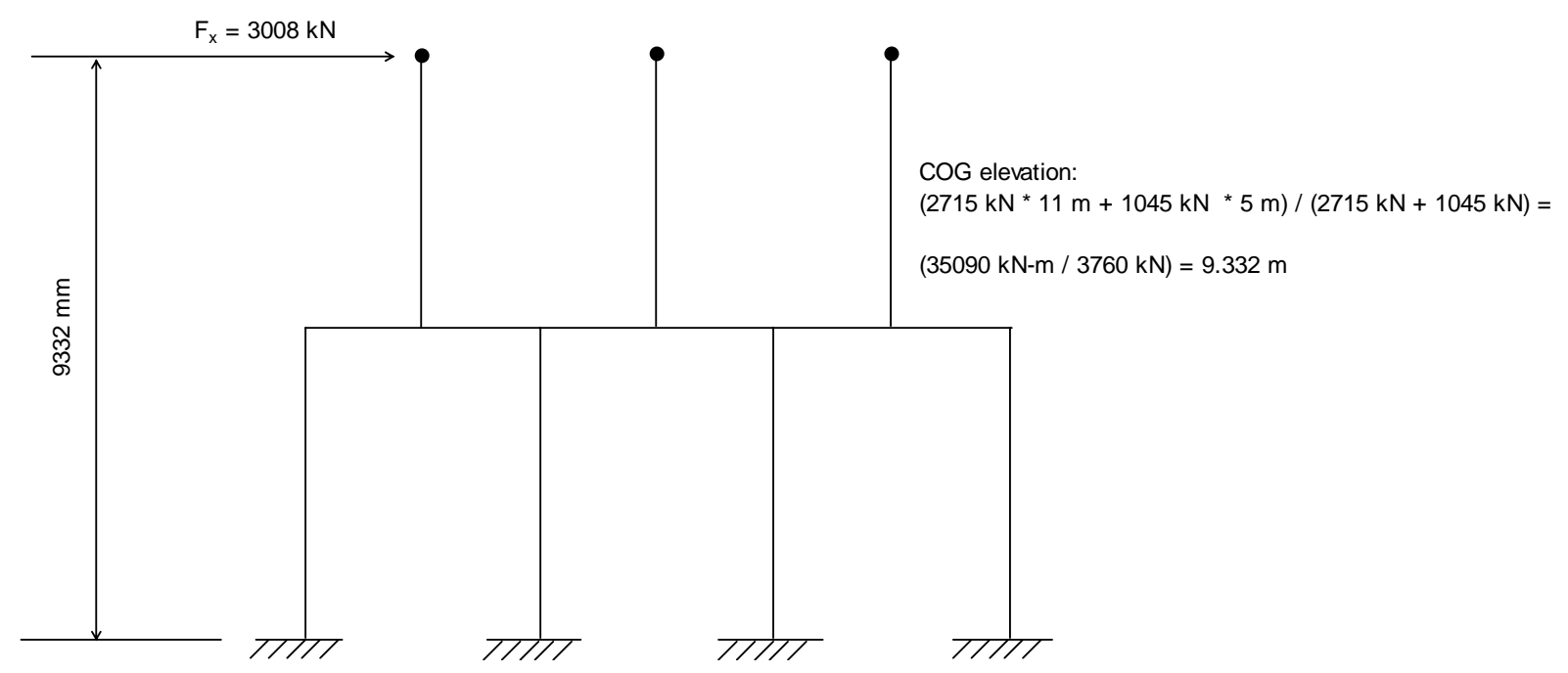

Table B3 -Equivalent Static Earthquake Coefficients Calculation for a Combination Structure

\section{Description}

$\begin{array}{rc}\text { ULS } & \mathrm{S}_{\mathrm{p}} \\ \text { ULS } & \mathrm{S}_{\mathrm{p}} \\ & \\ \text { SLS1 } & \mathrm{S}_{\mathrm{p}} \\ \text { SLS1 } & \mathrm{S}_{\mathrm{p}} \\ & \\ \text { Design ULS } & \mathrm{S}_{\mathrm{p}} \\ \text { Design SLS1 } & \mathrm{S}_{\mathrm{p}}\end{array}$

System Damping Factors:

ULS $\mathrm{C}_{\mathrm{f}}(5)$

SLS1 $\quad \mathrm{C}_{\mathrm{f}}(1)$

$$
\begin{array}{cc}
\text { ULS } & \mathrm{k}_{2} \\
\therefore & \mathrm{K}
\end{array}
$$

Ductility Factors:

$$
\begin{aligned}
\text { ULS } & \mathrm{k}_{\mu \mathrm{uls}} \\
\text { SLS1 } & \mathrm{k}_{\mu \text { sls } 1}
\end{aligned}
$$

Spectral Shape Factor:

$$
\text { Table 3.1 } \mathrm{C}_{\mathrm{h}}\left(\mathrm{T}_{1}\right)
$$

Elastic Site Hazard Values:

Unscaled 5\% Damped Design

$$
\begin{array}{rll}
\text { ULS } & \mathrm{C}\left(\mathrm{T}_{1}\right)_{\mathrm{uls}} & 0.990 \\
\text { SLS1 } & \mathrm{C}\left(\mathrm{T}_{1}\right)_{\mathrm{sls} 1} & 0.248
\end{array}
$$

Actions:

ULS $\mathrm{C}_{\mathrm{d}}\left(\mathrm{T}_{1}\right)_{\mathrm{uls}} \quad 0.180$ Eqn 5.2(2) $\quad(\mathrm{Z} / 20+0.02) \mathrm{R}_{\mathrm{u}} \quad 0.037$

$$
\text { SLS1 } \quad C_{d}\left(T_{1}\right)_{\text {sls } 1}
$$

0.7

\section{Consequence}

Ductile support structure with 8 columns

Nominally ductile pressure vessel designed using WSD mechanical codes

Cl. 4.4.4

$0.7 \quad \mathrm{~S}_{\mathrm{p}}=\mathrm{S}_{\mathrm{ps}}$

Chosen values:

Damping $=5 \%$ of critical

Damping $=1 \%$ of critical

No concrete standard requirement to scale ULS earthquake

$\mathrm{K}=\mathrm{k}_{1} * \mathrm{k}_{2}$

Cl. 5.2.1.1 with $\mathrm{T}_{1}$ taken as $=0.4$ secs

Cl. 5.2.1.2

Site Subsoil Class $=\mathrm{D} \& \mathrm{~T}_{1}=0.2 \mathrm{secs}(\mathrm{ULS})$ and $\mathrm{T}_{1}=$ 0.16 secs ( $\mathrm{SLS} 1$ )

Eqn 3.1(1)

$\mathrm{C}\left(\mathrm{T}_{1}\right)=\mathrm{C}_{\mathrm{h}}(\mathrm{T}) \mathrm{R} \mathrm{Z} \mathrm{N}(\mathrm{T}, \mathrm{D})$

$\mathrm{C}\left(\mathrm{T}_{1}\right)_{\mathrm{uls}}=3.0 * 1.0 * 0.33 * 1.0$

$\mathrm{C}\left(\mathrm{T}_{1}\right)_{\mathrm{sls} 1}=3.0 * 0.25 * 0.33 * 1.0$

Eqn 5.2(1)

$\mathrm{C}_{\mathrm{d}}\left(\mathrm{T}_{1}\right)_{\mathrm{uls}}=\mathrm{C}\left(\mathrm{T}_{1}\right) * \mathrm{~S}_{\mathrm{p}} / \mathrm{k}_{\mathrm{\mu}}$

$\mathrm{C}_{\mathrm{d}}\left(\mathrm{T}_{1}\right)_{\mathrm{uls}}=0.99 * 0.7 / 3.857$

$\therefore \mathrm{C}_{\mathrm{d}}\left(\mathrm{T}_{1}\right)_{\mathrm{uls}}=0.18$

$\mathrm{C}_{\mathrm{d}}\left(\mathrm{T}_{1}\right)_{\mathrm{sls} 1}=0.248 * 0.7 / 1.0$ 


\section{Table B3 -Equivalent Static Earthquake Coefficients Calculation for a Combination Structure \\ Description \\ Consequence}

Horiz. Design EQ Forces:

\section{ULS - To avoid collapse with $\mu=6$} ULS -with $\mu=2$ as above

$E_{u}$

ULS -with $\mu=1.25$ as above with $5 \%$ damping

\section{$\therefore$ For support structure \\ SLS1 - To sustain no damage}

Horizontal shear acting at base

Equivalent static horizontal forces

$$
\mathrm{F}_{\mathrm{y}}=0.3 * \mathrm{~F}_{\mathrm{x}}
$$

$E_{u}=V_{\text {uls }}$

$\mathrm{E}_{\mathrm{u}}$

$0.18 \mathrm{~W}_{\mathrm{t}}$ $0.44 \mathrm{~W}_{\mathrm{t}}$

$0.80 \mathrm{~W}_{\mathrm{t}}$

$$
\mathrm{E}_{\mathrm{u}}=\mathrm{V}_{\mathrm{uls}} \quad 0.80 \mathrm{~W}_{\mathrm{t}}
$$$$
\mathrm{E}_{\mathrm{sls} 1}=\mathrm{V}_{\mathrm{sls} 1}
$$$$
0.27 \mathrm{~W}_{\mathrm{t}}
$$

$3008 \mathrm{kN}$

\section{$3008 \mathrm{kN}$} $902 \mathrm{kN}$
$=\mathrm{C}_{\mathrm{d}}\left(\mathrm{T}_{1}\right)_{\mathrm{uls}} * \mathrm{C}_{\mathrm{f}}(5) * \mathrm{~K} * \mathrm{~W}_{\mathrm{t}}=0.18 * 1^{2} * \mathrm{~W}_{\mathrm{t}}$

Values too low - AS/NZS 1200 Appendix I min. value $=0.60$.

No benefit in using a ductile or a limited ductile structure. Either:

- Commission a site specific seismic hazard study and use a ductile structure with $\mu=6$.

- $\quad$ Special study using a NITHA

- Use $\mu=1.25$ and accept higher seismic loads

\section{O.K. - AS/NZS 1200 Appendix I min. value =0.60.}

Apply in two horizontal directions concurrently $-\mathrm{V}_{\mathrm{uls}} \&$ 0.3* $\mathrm{V}_{\text {uls }}$ in accordance with $\mathrm{Cl}$ 5.3.1.2

$=\mathrm{C}_{\mathrm{d}}\left(\mathrm{T}_{1}\right)_{\mathrm{sls} 1} * \mathrm{C}_{\mathrm{f}}(1) * \mathrm{~W}_{\mathrm{t}}$

$=0.80 * 3760 \mathrm{kN}$

Acting at $9.332 \mathrm{~m}$ above base.

Acting at $9.332 \mathrm{~m}$ above base at right angles to $F_{x}$. Foundation to be designed for the minimum of the overstrength of collapse mechanism or the elastic level earthquake

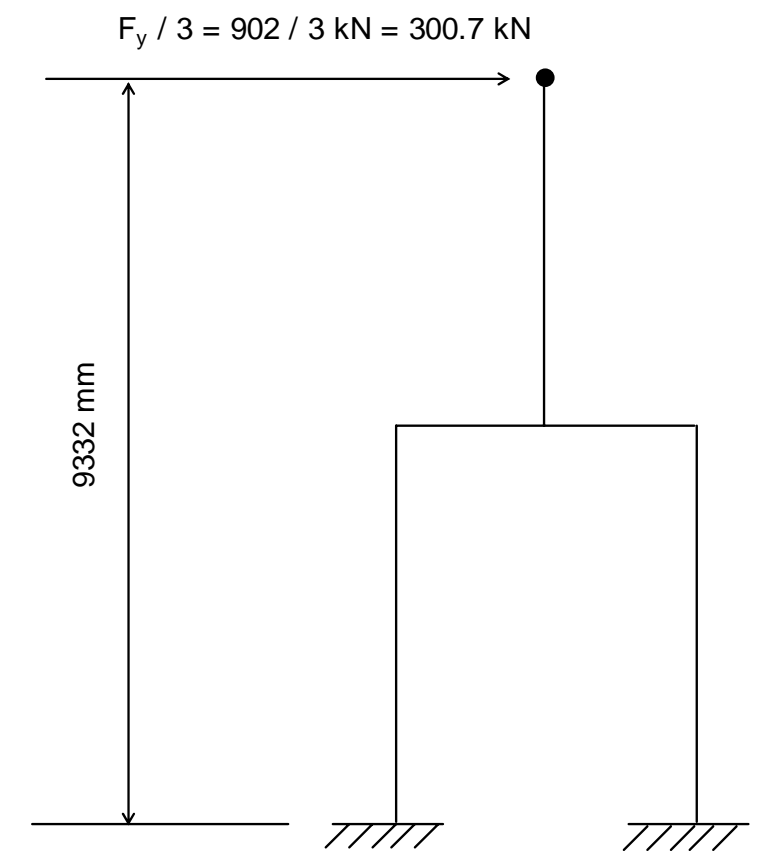

Horiz. Elastic Level EQ Forces on foundation:

$\begin{array}{rll}\text { ULS } & \mathrm{C}_{\mathrm{h}}\left(\mathrm{T}_{1}\right) & 3.0 \\ \text { NZS 3101 Table 4.1 } & \mu & 1.0 \\ \text { Cl. 4.4.2 } & \mathrm{S}_{\mathrm{p}} & 1.0 \\ \text { Cl. 5.2.1.1 } & \mathrm{k}_{\mu} & 1.0 \\ & \mathrm{C}_{\mathrm{f}}(5) & 1.0 \\ & \mathrm{C}_{1}\left(\mathrm{~T}_{1}\right) & 0.9 \\ \text { Unscaled ULS Design Action } & \mathrm{C}_{\mathrm{d}}\left(\mathrm{T}_{1}\right)^{\mathrm{o}}{ }_{\text {uls }} & 0.9\end{array}$

3.0

1.0

.0

1.0

0.99
Since the table top structure has a rigid diaphragm, the lateral force is distributed to each bent per its relative stiffness. As the stiffness of each bent is the same, the lateral force to each bent is identical. 
Table B3 -Equivalent Static Earthquake Coefficients Calculation for a Combination Structure

\section{Description}

ULS - To avoid premature nonductile failure

Equivalent static horizontal force

\section{Horiz. Design EQ Displacements:}

No. of storeys assumed for ESA Storey heights

Capacity design undertaken

ESA undertaken?

Included P-Delta effects in force analysis?

Distance to nearest boundary or deflected element within the plant

Scaling factors:

P-Delta scaling factor ESA Elastic Analysis scaling factor

ESA Inelastic scaling factor

ESA ULS deflection scaling factor ULS Deflections:

ESA Force analysis deflections

Elastic deflections Profile 1

Elastic deflection at uppermos level Scaled elastic deflections

ULS deflections Profile 2

Beam sidesway deflections Profile 3

Column sidesway deflections Profile 4

Maximum ULS deflection

Inter-storey deflections:

Structure height Drift modification factor Unmodified ULS deflections:

$\mathrm{k}_{\mathrm{dm}}$

\section{$\delta_{\text {scaled elastic }}$} $\delta_{\mathrm{uls} 3} / \mathrm{k}_{1}$

$\delta_{\mathrm{uls} 4} / \mathrm{k}_{1}$

ULS inter-storey deflections:

$\begin{array}{ll}\Delta_{\text {scaled elastic }} & 44 \mathrm{~mm} \\ \Delta_{\text {uls } 3} & 70 \mathrm{~mm} \\ \Delta_{\text {uls } 4} & 44 \mathrm{~mm}\end{array}$

Scaled inter-storey deflections:

Maximum inter-storey deflections

$\mathrm{E}_{\max }=\mathrm{V}^{\mathrm{o}}$

$0.99 \mathrm{~W}_{\mathrm{t}}$

$\mathrm{F}_{1}$

$3722 \mathrm{kN}$

1

$5.0 \mathrm{~m}$

No

Yes

1.0

No

$250 \mathrm{~mm}$

1.0

1.25

1.25

$35 \mathrm{~mm}$

$35 \mathrm{~mm}$

$35 \mathrm{~mm}$

$44 \mathrm{~mm}$

$44 \mathrm{~mm}$

$70 \mathrm{~mm}$

$44 \mathrm{~mm}$

1.20

$44 \mathrm{~mm}$

$70 \mathrm{~mm}$

$44 \mathrm{~mm}$

$44 \mathrm{~mm}$

$53 \mathrm{~mm}$

$84 \mathrm{~mm}$

$53 \mathrm{~mm}$

$84 \mathrm{~mm}$

$\begin{array}{ll}\Delta_{\text {scaled elastic }} * \mathrm{k}_{\mathrm{dm}} & 53 \mathrm{~mm} \\ \Delta_{\mathrm{uls} 3} * \mathrm{k}_{\mathrm{dm}} & 84 \mathrm{~mm} \\ \Delta_{\mathrm{uls} 4} * \mathrm{k}_{\mathrm{dm}} & 53 \mathrm{~mm} \\ \Delta_{\text {max inter-storey }} & 84 \mathrm{~mm}\end{array}$

$\operatorname{Max}\left(\delta_{\mathrm{uls} 1}, \delta_{\mathrm{uls} 2}, \delta_{\mathrm{uls} 3}, \delta_{\mathrm{uls} 4}\right)$ at level $1=70 \mathrm{~mm}$

$70 \mathrm{~mm}<250 \mathrm{~mm} \therefore$ ULS deflections OK.

5 metres

Scaled elastic inter-storey deflections Beam sidesway inter-storey deflections Column sidesway deflections
Beam and column sidesway mechanisms to be considered Deflection scaling factors in Table 6.1 can be used. Table 6.1

$\mathrm{k}_{1}=1.0$

Assumed clearance to adjacent deflected structure using its max ULS deflected shape (at Level 1).

From above

$\alpha=\mathrm{k}_{\mathrm{d}} / \mathrm{k}_{1}=1.0 / 1.0$

$\mu=\mu_{\mathrm{uls}}$ from Cl. 7.2.1.1

$\beta=\mu^{*} \mathrm{k}_{1}$ from Cl. 7.2.1.1(a) and 7.2.1.2

Results from EQ analysis

$\delta_{\text {elastic }}=\alpha * \delta_{\text {i esa }}$

$\delta_{\text {elastic }} @ \mathrm{~h}_{1}=5.0 \mathrm{~m}$

$\delta_{\text {scaled elastic }}=\mu * \delta_{\text {elastic }}$

$\delta_{\mathrm{uls} 2}=\beta * \delta_{\text {elastic }}$

$\delta_{\mathrm{uls} 3}=\left(\mathrm{U}_{\mathrm{el}} * \mathrm{~h}_{\mathrm{i}} / \mathrm{h}_{\mathrm{n}}+\delta_{\text {elastic }}\right) * \mathrm{k}_{1}$

$\delta_{\mathrm{uls} 4}=\left(\mathrm{U}_{\mathrm{el}} *(1-\mu)+\delta_{\text {elastic }}\right) * \mathrm{k}_{1}$

Sidesway in concrete columns 


\section{Table B3 -Equivalent Static Earthquake Coefficients Calculation for a Combination Structure \\ Description}

Max allowable inter-storey deflection

$\Delta_{\max }$

\section{Determine forces on vessels for}

\section{vessel's stress analysis:}

Level of allowable deformity

Overall Height:

$\mathrm{h}_{\mathrm{n}}$

Horizontal Fundamental periods Support including vessels $T_{1}$ Vessel $\quad T_{\mathrm{p}}$

Vertical Fundamental periods: Support including vessels $\quad \mathrm{T}_{\mathrm{v} 1}$

Table $3.1 \quad \mathrm{C}_{\mathrm{h}}(0)$

$\mathrm{C}_{h}\left(\mathrm{~T}_{\mathrm{v}}\right)$

Displacement Ductility Factors:

$\begin{array}{rr}\text { ULS } & \mu_{\mathrm{p}} \\ \text { SLS1 } & \mu_{\mathrm{p}}\end{array}$

Risk Factor for Parts:

$$
\begin{aligned}
\text { ULS } & R_{\mathrm{p}} \\
\text { SLS1 } & R_{\mathrm{p}}
\end{aligned}
$$

Parts Response Factors

ULS

SLS1 $C_{\mathrm{pv}}$

System Damping Factors:

ULS $\mathrm{C}_{\mathrm{f}}(5)$

SLS1 $\quad C_{f}(1)$

Part Category:

\section{Table 8.1 ULS}

SLS1

Floor Spectral Shape Factor:

$$
\text { Clause } 8.4 \quad C_{\mathrm{i}}\left(T_{\mathrm{p}}\right)
$$

Floor Height Coefficients:

$$
\text { Support } \mathrm{C}_{\mathrm{Hi}}
$$

\section{Horizontal Forces on Part:}

5\% Damped Elastic spectrum @ T $=0 \mathrm{sec}$ :

$\begin{aligned} \text { ULS } & C(0) \\ \text { SLS1 } & C(0)\end{aligned}$

1.12

1.0

1.0

0.85

1.0

1.0
$2.5 \%$ storey height

$125 \mathrm{~mm}$ Only need to consider the first storey

Therefore have no inter-storey deflections that exceed the maximum allowable. No need to include P-Delta effects.

Low

Heavy walled vessels with some ductility $\therefore \mu_{\mathrm{p}}=1.25$

5.0 metres

$0.20 \mathrm{secs}$

$0.16 \mathrm{secs}$

From above for ULS

0.06 secs

From above for SLS1

From mechanical engineer

0.10 secs $\quad$ Assumed for structure including vessels

Site Subsoil Class $=\mathrm{D} \& \mathrm{~T}=0.0 \mathrm{secs}$

Site Subsoil Class $=\mathrm{D} \& \mathrm{~T}_{\mathrm{v}}=0.1 \mathrm{secs}$

Clause 8.5

Table C8.2

Table 8.1

Table 8.2 and Clause 8.6

For horizontal forces

For vertical forces

Chosen values:

Damping $=5 \%$ of critical

Damping $=1 \%$ of critical

$\begin{array}{ll}1.0 & \text { Damping } \\ 1.53 & \text { Damping }=1 \% \text { of critical }\end{array}$

High pressure system representing danger to those working within plant. $R_{\mathrm{pu}}=1.0$

$R_{\mathrm{psls} 1}=1.0$

$T_{\mathrm{p}}<0.75$ secs

Eqns 8.3(1), 8.3(2) and 8.3(3)

As $\mathrm{h}_{\mathrm{n}}<12$ m, Eqn 8.3(1) applies \& 8.3(3) not applicable.

$\mathrm{C}(0)=\mathrm{C}_{\mathrm{h}}(0) \mathrm{R} \mathrm{Z} \mathrm{N}(0, \mathrm{D})$

0.370

$C(0)=1.12 * 1.0 * 0.33 * 1.0$

$C(0)=1.12 * 0.25 * 0.33 * 1.0$ 
Table B3 -Equivalent Static Earthquake Coefficients Calculation for a Combination Structure

\section{Description}

Spectral Ordinate of the Part:

$\begin{array}{rll}\text { ULS } & C_{\mathrm{p}}\left(T_{\mathrm{p}}\right) & 1.385 \\ \text { SLS1 } & C_{\mathrm{p}}\left(T_{\mathrm{p}}\right) & 0.338\end{array}$

Horizontal Design EQ Actions:

ULS - No collapse

WSD - No loss of contents

$\mathrm{E}_{\mathrm{u}}=F_{\mathrm{ph}}$

$\mathrm{E}_{\mathrm{wsd}}=0.8 \mathrm{E}_{\mathrm{u}}$

$1.15 \mathrm{~W}_{\mathrm{p}}$

$0.92 \mathrm{~W}_{\mathrm{p}}$

$\therefore \quad \mathrm{E}_{\mathrm{wsd}}$

$0.92 \mathrm{~W}_{\mathrm{p}}$

SLS1 - To sustain no damage $\quad \mathrm{E}_{\mathrm{s}}=F_{\mathrm{ph}}$

$0.52 \mathrm{~W}_{\mathrm{p}}$

WSD

SLS1
$C_{\mathrm{p}}\left(T_{\mathrm{p}}\right)=\mathrm{C}(0) * \mathrm{C}_{\mathrm{Hi}} * \mathrm{C}_{\mathrm{i}}\left(\mathrm{T}_{\mathrm{p}}\right)-$ Eqn 8.2(1)
$C_{\mathrm{p}}\left(T_{\mathrm{p}}\right)=0.37 * 1.83 * 2.0$
$C_{\mathrm{p}}\left(T_{\mathrm{p}}\right)=0.092 * 1.83 * 2.0$

$F_{\mathrm{ph}}=C_{\mathrm{p}}\left(T_{\mathrm{p}}\right) * C_{\mathrm{ph}} * R_{\mathrm{p}} * C_{\mathrm{f}}(\xi) * W_{\mathrm{p}}-$ Eqn $8.5(1)$

$F_{\mathrm{ph}}=1.39 * 0.85 * 1.0 * 1.0 * W_{\mathrm{p}} \leq 3.6 W_{\mathrm{p}}$

$=0.8 * 1.15+$ possible over-stress allowance of $1 / 3$

O.K. as AS/NZS 1200 Appendix I min. value = 0.60.

Plus possible over-stress allowance $=1 / 3$

$F_{\mathrm{ph}}=0.338 * 1.0 * 1.0 * 1.53 * \mathrm{~W}_{\mathrm{p}}$

Vessels to be analysed for:

WSD case of $0.92 \mathrm{~g}$ in two principal directions being analysed separately.

Internal forces and moments $=\mathrm{M}_{\mathrm{iux}} \& \mathrm{M}_{\mathrm{iuy}}$

- $\quad$ SLS1 case of $0.52 \mathrm{~g}$ in two principal directions being analysed separately. Over-stress allowance $=1.0$.

Internal forces and moments $=\mathrm{M}_{\mathrm{is} 1 \mathrm{x}} \& \mathrm{M}_{\text {is } 1 \mathrm{y}}$

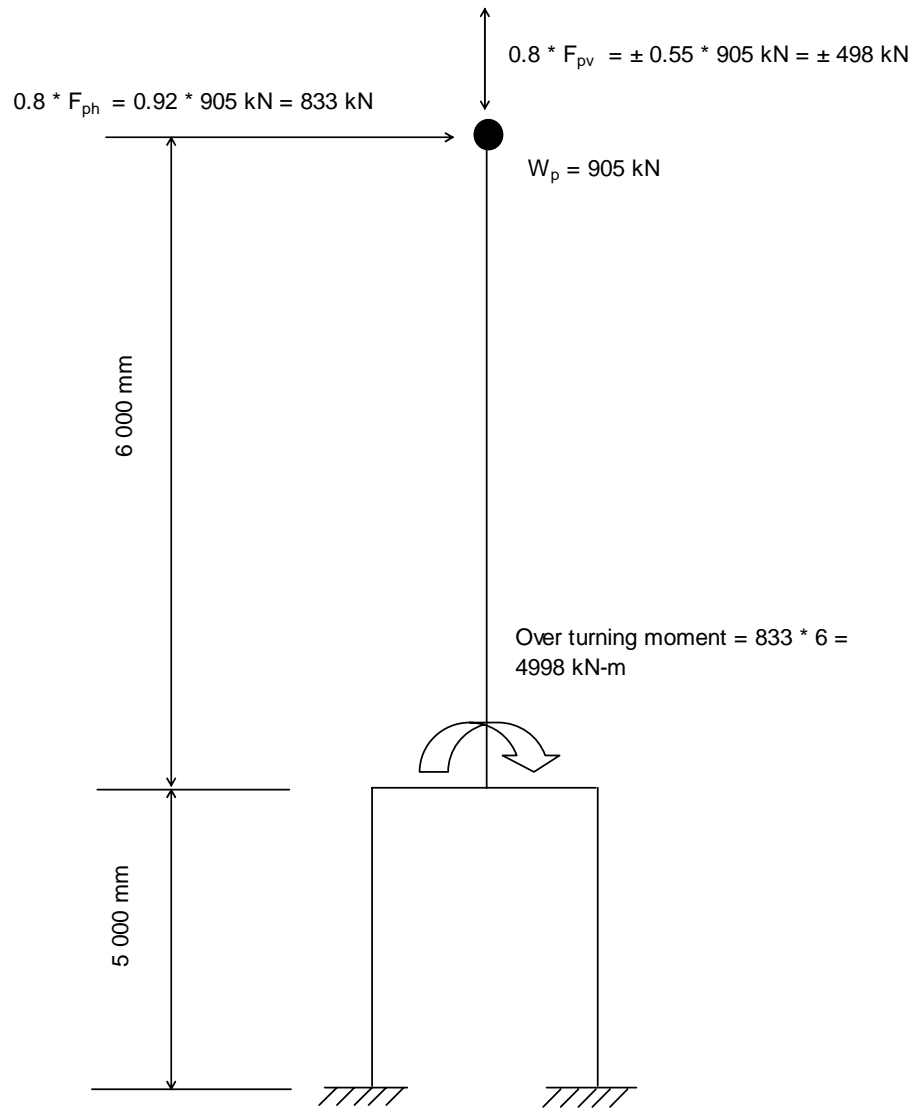

WSD forces on the vessel in the transverse direction.

Table B3 -Equivalent Static Earthquake Coefficients Calculation for a Combination Structure

Value

Consequence

Horiz Design Actions due to EQ

\section{deflections:}

ULS deflections at support $\delta_{\text {esa }}$

$70 \mathrm{~mm}$
Vessels supported at one level. No displacement induced seismic actions. 
Table B3 -Equivalent Static Earthquake Coefficients Calculation for a Combination Structure

Description

\section{Vessel Design Horizontal Actions}

\section{due to EQ}

WSD:

SLS1:

$\begin{array}{ccc}\text { X direction } & \mathrm{M}_{\text {hux }} & \mathrm{M}_{\text {iux }} \\ \text { Y direction } & \mathrm{M}_{\text {huy }} & \mathrm{M}_{\text {iuy }} \\ & & \\ \text { X direction } & \mathrm{M}_{\mathrm{hslx}} & \mathrm{M}_{\text {islx }} \\ \text { Y direction } & \mathrm{M}_{\mathrm{hsly}} & \mathrm{M}_{\text {isly }}\end{array}$

\section{Vertical Forces on Part:}

5\% Damped Elastic spectrum @ T $=\mathrm{T}_{\mathrm{v} 1}$ sec:

$\begin{array}{rll}\text { ULS } & \mathrm{C}_{\mathrm{v}}\left(\mathrm{T}_{\mathrm{v}}\right) & 0.693 \\ \text { SLS1 } & \mathrm{C}_{\mathrm{v}}\left(\mathrm{T}_{\mathrm{v}}\right) & 0.173 \\ & & \\ \text { ULS } & \mathrm{C}_{\mathrm{vd}} & 0.693 \\ \text { SLS1 } & \mathrm{C}_{\mathrm{vd}} & 0.173\end{array}$

\section{Vertical Design EQ Forces:}

ULS - No collapse WSD - No loss of contents

$\mathrm{E}_{\mathrm{u}}=\mathrm{F}_{\mathrm{pv}}$

$\mathrm{E}_{\mathrm{wsd}}=0.8 \mathrm{E}_{\mathrm{u}}$

SLS1 - To sustain no damage

$\mathrm{E}_{\mathrm{s}}=\mathrm{F}_{\mathrm{pv}}$

$0.17 W_{\mathrm{p}}$

$\mathrm{M}_{\text {hux }}+\mathrm{M}_{\mathrm{uv}}$

$\mathrm{M}_{\text {huy }}+\mathrm{M}_{\mathrm{uv}}$

SLS1:

$\mathrm{X}$ direction

$\mathrm{Y}$ direction $\mathrm{M}_{\mathrm{yu}}$

$\mathrm{M}_{\mathrm{hs} 1 \mathrm{x}}+\mathrm{M}_{\mathrm{s} 1 \mathrm{v}}$

X direction $\quad \mathrm{M}_{\mathrm{xs}}$

$\mathrm{Y}$ direction $\quad \mathrm{M}_{\mathrm{ys}}$
$\mathrm{C}_{\mathrm{v}}\left(\mathrm{T}_{\mathrm{v} 1}\right)=0.7 \mathrm{C}_{\mathrm{h}}\left(\mathrm{T}_{\mathrm{v}}\right) \mathrm{R} \mathrm{Z} \mathrm{N}\left(\mathrm{T}_{\mathrm{v}}, \mathrm{D}\right)-$ Eqns 3.1(1) and $3.2(1)$

$\mathrm{C}_{\mathrm{v}}\left(\mathrm{T}_{\mathrm{v}}\right)=0.7 * 3.0 * 1.0 * 0.33 * 1.0$

$\mathrm{C}_{\mathrm{v}}\left(\mathrm{T}_{\mathrm{v}}\right)=0.7 * 3.0 * 0.25 * 0.33 * 1.0$

Eqn 5.4(2)

$\mathrm{F}_{\mathrm{pv}}=C_{\mathrm{vd}} * C_{\mathrm{pv}} * R_{\mathrm{p}} * W_{\mathrm{p}}-\operatorname{Eqn} 8.5(2)$

$\mathrm{F}_{\mathrm{pv}}=0.693 * 1.0 * 1.0 * W_{\mathrm{p}} \leq 2.5 W_{\mathrm{p}}$

$=0.8 * 0.693+$ possible over-stress allowance of $1 / 3$

WSD case of $0.55 \mathrm{~g}$ in vertical direction. Possible overstress allowance $=1 / 3$.

Internal forces and moments $=\mathrm{M}_{\mathrm{uv}}$

$\mathrm{F}_{\mathrm{pv}}=0.173 * 1.0 * 1.0 * W_{\mathrm{p}}$

SLS1 case of $0.17 \mathrm{~g}$ in vertical direction. Over-stress allowance $=1.0$.

Internal forces and moments $=\mathrm{M}_{\mathrm{s} 1 \mathrm{v}}$

These earthquake actions need to be combined with normal operating pressure and temperature conditions for the vessel's stress checking. 


\section{Example 4-Pump Mounted at Ground Level}

Assume that a water pump with a mass of $1200 \mathrm{~kg}$ is located at grade on a concrete slab foundation within a plant that is far from occupied dwellings and has a mechanical design life of 25 years. The plant is located south of Hastings on the Heuretanga Plains. As a pressure equipment item, pump design should comply with Parts 3 and 8 of the DoL Approved Code of Practice for Pressure Equipment (ACPPE).

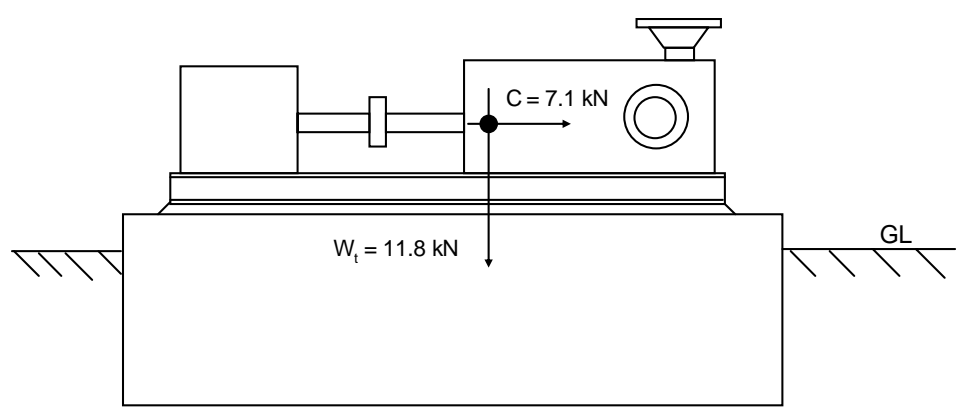

Assume no site specific seismic hazard study has been undertaken and hence the minimum seismic coefficient is given in AS/NZS 1200 Appendix I applies for the pressure envelope, HD bolts and foundation in a similar fashion to pressure vessels, refer to ACPPE Clause 5.4.4(8). This minimum value is dependent on the NZS 4203:1992 Zone Factor Z.

\author{
Table B4 -Equivalent Static Earthquake Coefficients Calculation for a Rigid Pump at Grade \\ Description \\ NZ Building Code Category - \\ Clause A1 Classified Uses \\ Structural Type \\ Importance Level: \\ IL \\ Parameter \\ Design Working Life \\ Earthquake Return Periods: \\ Table 3.3 AS/NZS 1170.0

\section{Consequence} \\ Ancillary May be exempt some amenity provisions but required to \\ comply with structural and safety provisions of NZBC \\ Nonbuilding \\ like \\ 2 limit states $=$ ULS \& SLS1 \\ 25 years Mechanical design life of 25 years \\ $\mathrm{E}_{\mathrm{wsd}}=0.8 \mathrm{E}_{\mathrm{u}} \&$ possible overstress allowance $=1 / 3$ \\ $\mathrm{E}_{\mathrm{wsd}}=\mathrm{E}_{\mathrm{sls} 1} \&$ no overstress allowance
}

Site Subsoil Class:
Clause 3.1.3.4

Hazard Factors:

$$
\text { Clause 3.1.4 Z }
$$

NZS 4203 Clause 4.6.2.5 Z

Zone Factor

0.39

Return Period Factors:

$$
\text { Table } 3.5 \quad \mathrm{R}
$$

Clause 3.1.1 Z R

$$
\begin{aligned}
& \mathrm{R}_{\mathrm{u}} \\
& \mathrm{R}_{\mathrm{sls} 1}
\end{aligned}
$$

Near-fault factor:

$$
\text { Clause 3.1.6 N(T, D) }
$$

1.0

$$
\begin{array}{rr}
\text { ULS } & \mu_{\mathrm{uls}} \\
\text { SLS1 - Clause 4.3.2 } & \mu_{\mathrm{sls} 1}
\end{array}
$$

Fundamental period:
Located on deep gravels. Table 3.1 for Spectral Shape Factor $\mathrm{C}_{\mathrm{h}}(\mathrm{T})$

Suitable for Hastings

NZS 1200 Appendix I minimum seismic coefficient for pressure equipment $=0.60$

$<0.7 \therefore$ O.K.

Not adjacent to any major faults, i.e. $\mathrm{D}>20 \mathrm{~km}$

From pump vendor data.

Nominally ductile structure

0.02 secs Effectively rigid. Applicable for all limits states. 


\section{Table B4 -Equivalent Static Earthquake Coefficients Calculation for a Rigid Pump at Grade \\ Description}

Suitability of Equivalent Static

Analysis Method Check:

$$
\begin{array}{lll}
\text { Clause 6.1.3.1(a) } & \mathrm{h}_{\mathrm{n}}<10 \mathrm{~m} & \text { Yes } \\
\text { Clause 6.1.3.1(b) } & \mathrm{T}_{1}<0.4 \mathrm{secs} & \text { Yes } \\
\text { Clause 6.1.3.1(c) } & \text { Horiz. regular } & \text { Yes } \\
& \text { Vert. regular } & \text { Yes } \\
& \mathrm{T}_{1}<2.0 \text { secs } & \text { Yes }
\end{array}
$$

System Damping Factors:

$$
\text { ULS } \mathrm{C}_{\mathrm{f}}(2)
$$$$
\text { SLS1 } \mathrm{C}_{\mathrm{f}}(0.5)
$$

Structural Performance Factors:

$$
\begin{aligned}
\text { ULS } & \mathrm{S}_{\mathrm{p}} \\
\text { SLS1 } & \mathrm{S}_{\mathrm{p}}
\end{aligned}
$$

Ductility Factors:

Spectral Shape Factor:

$$
\begin{aligned}
\text { ULS } & \mathrm{k}_{\mu \mathrm{uls}} \\
\text { SLS1 } & \mathrm{k}_{\mu \mathrm{sls} 1}
\end{aligned}
$$

$$
\text { Table } 3.1 \quad \mathrm{C}_{\mathrm{h}}\left(\mathrm{T}_{1}\right)
$$

Elastic Site Hazard Values:

$$
\begin{aligned}
\text { ULS } & \mathrm{C}\left(\mathrm{T}_{1}\right)_{\mathrm{uls}} \\
\text { SLS1 } & \mathrm{C}\left(\mathrm{T}_{1}\right)_{\mathrm{sls} 1}
\end{aligned}
$$

Unscaled 5\% Damped Design

Actions:

$$
\begin{array}{rll}
\text { ULS } & \mathrm{C}_{\mathrm{d}}\left(\mathrm{T}_{1}\right)_{\mathrm{uls}} & 0.71 \\
\text { Eqn 5.2(2) } & (\mathrm{Z} / 20+0.02) \mathrm{R}_{\mathrm{u}} & 0.03 \\
& & \\
\text { SLS1 } & \mathrm{C}_{\mathrm{d}}\left(\mathrm{T}_{1}\right)_{\mathrm{sls} 1} & 0.21
\end{array}
$$

Horiz. Design EQ Forces:

$$
\begin{array}{r}
\text { ULS - To avoid collapse } \\
\text { WSD - No loss of contents } \\
\therefore \text { For pressure envelope } \\
\therefore \text { For foundation and HD Bolts } \\
\text { SLS1 - To sustain no damage }
\end{array}
$$

Horiz. Elastic Level EQ Forces on foundation and HD bolts:

NZS 3404 Clause 12.9.1.2.2 (4) (b) Clause 4.4.1 Clause 5.2.1.1

Unscaled ULS Design Action

ULS - To avoid premature nonductile failure \& overturning or sliding failure
$\mathrm{E}_{\mathrm{u}}=\mathrm{V}_{\mathrm{uls}} \quad 0.71 \mathrm{~W}_{\mathrm{t}}$ $\mathrm{E}_{\mathrm{wsd}}=0.8 \mathrm{E}_{\mathrm{u}} \quad 0.57 \mathrm{~W}_{\mathrm{t}}$

$E_{w s d}$

0.60

$\begin{array}{ll}\mathrm{E}_{\mathrm{u}} & 0.60\end{array}$

$\mathrm{E}_{\mathrm{sls} 1}=\mathrm{V}_{\mathrm{sls} 1} \quad 0.21 \mathrm{~W}_{\mathrm{t}}$
3.0

1.0

1.0

1.0

1.0
$\begin{array}{lll}\mathrm{C}\left(\mathrm{T}_{1}\right) & 0.878 & \mathrm{C}\left(\mathrm{T}_{1}\right)=3.0 * 0.75 * 0.39 \\ \mathrm{C}_{\mathrm{d}}\left(\mathrm{T}_{1}\right)^{\mathrm{o}}{ }_{\text {uls }} & 0.88 & \mathrm{C}_{\mathrm{d}}\left(\mathrm{T}_{1}\right)=0.878 * 1.0 / 1.0\end{array}$

$\begin{array}{lll}\mathrm{C}\left(\mathrm{T}_{1}\right) & 0.878 & \mathrm{C}\left(\mathrm{T}_{1}\right)=3.0 * 0.75 * 0.39 * 1 . \\ \mathrm{C}_{\mathrm{d}}\left(\mathrm{T}_{1}\right)^{\mathrm{o}} \text { uls } & 0.88 & \mathrm{C}_{\mathrm{d}}\left(\mathrm{T}_{1}\right)=0.878 * 1.0 / 1.0\end{array}$

$\mathrm{E}_{\max }=\mathrm{V}_{\text {uls }}^{\mathrm{o}} \quad 0.88 \mathrm{~W}_{\mathrm{t}} \quad=\mathrm{C}\left(\mathrm{T}_{1}\right) * \mathrm{~S}_{\mathrm{p}} * / \mathrm{k}_{\mu} * \mathrm{~W}_{\mathrm{t}}$

Able to use ESA

Able to use ESA

Able to use ESA

Equivalent Static Analysis O.K.

Chosen values:

Damping $=2 \%$ of critical

Damping $=0.5 \%$ of critical

Effectively rigid so damping has no effect on response.

Clause 4.4.2

With $\mu=1.25$

Allow code value for SLS1 case

Clause 5.2.1.1

As $\mathrm{T}_{1}<0.4 \mathrm{sec}$

Site Subsoil Class $=\mathrm{D} \& \mathrm{~T}_{1}=0.02$ secs

Eqn 3.1(1)

$\mathrm{C}\left(\mathrm{T}_{1}\right)=\mathrm{C}_{\mathrm{h}}(\mathrm{T}) \mathrm{R} \mathrm{Z} \mathrm{N}(\mathrm{T}, \mathrm{D})$

$\mathrm{C}\left(\mathrm{T}_{1}\right)_{\mathrm{uls}}=3.0 * 0.75 * 0.39 * 1.0$

$\mathrm{C}\left(\mathrm{T}_{1}\right)_{\mathrm{sls} 1}=3.0 * 0.25 * 0.39 * 1.0$

Eqn 5.2(1)

$\mathrm{C}_{\mathrm{d}}\left(\mathrm{T}_{1}\right)_{\mathrm{uls}}=\mathrm{C}\left(\mathrm{T}_{1}\right) * \mathrm{~S}_{\mathrm{p}} / \mathrm{k}_{\mathrm{\mu}}$

$\mathrm{C}_{\mathrm{d}}\left(\mathrm{T}_{1}\right)_{\mathrm{uls}}=0.878 * 0.925 / 1.14$

$\therefore \mathrm{C}_{\mathrm{d}}\left(\mathrm{T}_{1}\right)_{\mathrm{uls}}=0.71$

$\mathrm{C}_{\mathrm{d}}\left(\mathrm{T}_{1}\right)_{\mathrm{sls} 1}=0.293 * 0.7 / 1.0$

$=\mathrm{C}_{\mathrm{d}}\left(\mathrm{T}_{1}\right)_{\mathrm{uls}} * \mathrm{~W}_{\mathrm{t}}$

$=0.8 * 0.71$ Too low, AS/NZS 1200 Appendix I min. value $=0.60$.

$\mathrm{C}=0.6 * 11.8=7.1 \mathrm{kN}$

$=\mathrm{C}_{\mathrm{d}}\left(\mathrm{T}_{1}\right)_{\mathrm{sls} 1} * \mathrm{~W}_{\mathrm{t}}$

Foundation and HD bolts to be designed for the minimum of the over-strength of collapse mechanism or the elastic level earthquake

From above

Can also be used for overall structure's stability check

$\begin{array}{lll}\mathrm{C}\left(\mathrm{T}_{1}\right) & 0.878 & \mathrm{C}\left(\mathrm{T}_{1}\right)=3.0 * 0.75 * 0.39 * 1.0 \\ \mathrm{C}_{\mathrm{d}}\left(\mathrm{T}_{1}\right)^{\mathrm{o}} \text { uls } & 0.88 & \mathrm{C}_{\mathrm{d}}\left(\mathrm{T}_{1}\right)=0.878 * 1.0 / 1.0\end{array}$ 


\section{Example 5-Vertical Cantilever Pipe Support and Earthquake Forces on Piping Supported}

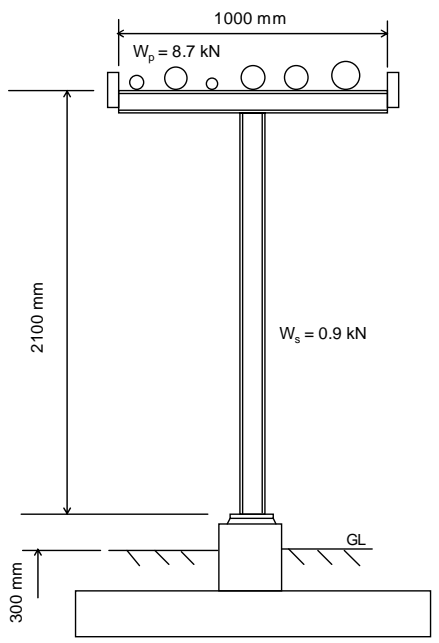

Assume a welded steel cantilever T post supported on a concrete foundation. A $150 \mathrm{NB}$ steel water filled pipe operating at pressures greater than $50 \mathrm{kPa}$ in the same complex as the pump in Example 4 is to be supported $2.4 \mathrm{~m}$ off the ground at $6 \mathrm{~m}$ intervals by individual pipe supports that also support other piping on a 1 metre wide support. The water line is not part of fire suppression system or for vital potable water supply or are any other of the items supported on the support but that the client design specification calls for piping to be designed for both horizontal and vertical earthquake design actions.

From Note 5 of Appendix B of NZS 3404, the maximum ductility factor for a short period Category 2 vertical cantilever $=5$ but limit the maximum $\mu_{\text {uls }}=3$ as per Item 1.7 of NZS 3404 Appendix B.

As the $150 \mathrm{NB}$ piping is classed as pressure piping in the DoL ACPPE, the design of piping, supports and foundations is governed by Sections 3.4 and 6 of the ACPPE.

\section{Table B5 -Equivalent Static Earthquake Coefficients Calculation for a Vertical Cantilever Pipe Support and Supported Piping Description \\ Parameter \\ Consequence}

NZ Building Code Category Clause A1 Classified Uses

Structural Type

Importance Level:

Design Working Life

Earthquake Return Periods: Table 3.3 AS/NZS 1170.0
IL

25 years

250 years

25 years

\section{2}

Ancillary May be exempt some amenity provisions but required to comply with structural and safety provisions of NZBC

Nonbuilding

-like

2 limit states $=$ ULS \& SLS1

Plant life of 25 years

$\mathrm{E}_{\mathrm{wsd}}=0.8 \mathrm{E}_{\mathrm{u}}$ \& possible overstress allowance $=1 / 3$ depending on design code for piping.

$\mathrm{E}_{\mathrm{wsd}}=\mathrm{E}_{\mathrm{sls} 1} \&$ no overstress allowance

Site Subsoil Class:

$$
\text { Clause 3.1.3.4 }
$$

Table 3.1 for Spectral Shape Factor $\mathrm{C}_{\mathrm{h}}(\mathrm{T})$

Hazard Factors:

$\begin{array}{rll}\text { Clause 3.1.4 } & Z & 0.39 \\ \text { NZS 4203 Clause 4.6.2.5 } & Z & 1.2 \\ \text { Zone Factor } & & \end{array}$

Return Period Factors:

$\begin{array}{rll}\text { Table 3.5 } & \mathrm{R}_{\mathrm{u}} & 0.75 \\ & \mathrm{R}_{\text {sls1 }} & 0.25 \\ \text { Clause 3.1.1 } & \mathrm{Z} \mathrm{R}_{\mathrm{u}} & 0.29\end{array}$

Near-fault factor:

$$
\text { Clause 3.1.6 N(T, D) }
$$

Structural Ductility Factors:

$\begin{array}{rll}\text { ULS - NZS } 3404 \text { Table 12.2.4 } & \mu_{\text {uls }} & 1.25 \\ & & 3.0 \\ \text { Want to do capacity design? } & \text { No } \\ & & \text { Yes } \\ \text { SLS1 - Clause 4.3.2 } & \mu_{\text {sls } 1} & 1.0\end{array}$

Nominally ductile structure

Limited ductility structure

Apply earthquake Horiz:Horiz:Vert $=1.0: 0.3: 0.0$ as per 5.3.1.2(a) and $\mu_{\text {uls }}=1.25$

Apply earthquake Horiz:Horiz:Vert $=1.0: 0.0: 0.0$ as per 5.3.1.1(a) and $\mu_{\mathrm{uls}}=3.0$ 


\section{Table B5 -Equivalent Static Earthquake Coefficients Calculation for a Vertical Cantilever Pipe Support and Supported Piping \\ Description \\ Parameter}

Weight of components:

$$
\begin{array}{r}
\text { Weight of steel support } \\
\text { Weight of piping } \\
\text { Seismic weight }
\end{array}
$$

$\begin{array}{ll}\mathrm{W}_{\mathrm{s}} & 0.9 \mathrm{kN} \\ \mathrm{W}_{\mathrm{p}} & 8.7 \mathrm{kN} \\ \mathrm{W}_{\mathrm{t}} & 9.2 \mathrm{kN}\end{array}$

Fundamental periods:

$\begin{array}{cll}\text { Horizontal } & \mathrm{T}_{1} & 0.25 \text { secs } \\ & \mathrm{T}_{2} & 0.20 \\ \text { Vertical } & \mathrm{T}_{\mathrm{V}} & 0.01\end{array}$

Vertical Regularity Check:

$$
\text { Clause 4.5.1.2 }
$$

Suitability of Equivalent Static Analysis Method Check:

$\begin{array}{lll}\text { Clause 6.1.3.1(a) } & \mathrm{h}_{\mathrm{n}}<10 \mathrm{~m} & \text { Yes } \\ \text { Clause 6.1.3.1(b) } & \mathrm{T}_{1}<0.4 \text { secs } & \text { Yes } \\ \text { Clause 6.1.3.1(c) } & \text { Horiz. regular } & \text { Yes } \\ & \text { Vert. regular } & \text { Yes } \\ & \mathrm{T}_{1}<2.0 \text { secs } & \text { Yes }\end{array}$

Review P-Delta effects:

$$
\begin{array}{ll}
\text { Clause 6.5.2(a) } & \mathrm{T}_{1}>0.4 \mathrm{secs} \\
\text { Clause 6.5.2(b) } & \mathrm{h}_{\mathrm{n}}>15 \mathrm{~m} \\
& \mathrm{~T}_{1}>0.6 \mathrm{secs} \\
& \mathrm{k}_{1}
\end{array}
$$

Structural Performance Factors:

Nominally ductile structure:

ULS

$$
\mathrm{S}_{\mathrm{p}}
$$

ULS

$\mathrm{S}_{\mathrm{p}}$

System Damping Factors:

Nominally ductile structure:

ULS

Limited ductility structure:

$$
\text { ULS } C_{\mathrm{f}}(5)
$$$$
\text { SLS1 } \quad C_{\mathrm{f}}(1)
$$

Material Code Scaling Factor:

$$
\text { ULS } \mathrm{k}_{2}
$$

$$
\mathrm{K}
$$

Ductility Factors:

Nominally ductile structure:

$$
\begin{aligned}
\text { ULS } & \mathrm{k}_{\mu \text { uls }} \\
\text { SLS1 } & \mathrm{k}_{\mu \text { sls1 }}
\end{aligned}
$$

Limited ductility structure:

ULS $\mathrm{k}_{\mu \text { uls }}$

SLS1 $\mathrm{k}_{\mu \text { sls } 1}$

Spectral Shape Factor:
Assume 150UC30.

Assume piping area load $=1.45 \mathrm{kPa}$.

Eqn $4.2(1) \therefore \mathrm{W}_{\mathrm{t}}=8.7+0.9 / 2$

Applicable for ULS.

Applicable for SLS1.

Applicable for all limit states.

Single storey structure

Able to use ESA

Able to use ESA

Able to use ESA

Equivalent Static Analysis O.K.

No need to consider P-Delta effects

No need to consider P-Delta effects

Therefore don't include P-Delta effects

From Clause 4.4.2:

With $\mu=1.25$

With $\mu=3.0$. Even though no redundancy, as not a critical item use minimum value of $S_{p}$.

Allow code value for SLS1 case

Chosen values for fully welded steel structure:

Damping $=3 \%$ of critical

Damping $=1 \%$ of critical

Damping $=5 \%$ of critical as yielding expected with $\mu=3$

Damping $=1 \%$ of critical

No steel standard requirement to scale ULS earthquake $\mathrm{K}=\mathrm{k}_{1} * \mathrm{k}_{2}=1.0$

Clause 5.2.1.1

With $\mu=1.25$

With $\mu=3.0$

Site Subsoil Class $=\mathrm{D} \& \mathrm{~T}_{1}=0.25$ secs

Site Subsoil Class $=\mathrm{D} \& \mathrm{~T}_{2}=0.20 \mathrm{secs}$ 
Table B5 -Equivalent Static Earthquake Coefficients Calculation for a Vertical Cantilever Pipe Support and Supported Piping

\section{Description}

Elastic Site Hazard Values:

$\begin{array}{lll}\text { ULS } & \mathrm{C}\left(\mathrm{T}_{1}\right)_{\mathrm{uls}} & 0.878 \\ \text { SLS1 } & \mathrm{C}\left(\mathrm{T}_{2}\right)_{\text {sls } 1} & 0.293\end{array}$

Unscaled 5\% Damped Design

Actions:

Nominally ductile structure:

ULS

Eqn 5.2(2)

Limited ductility structure:

$$
\text { ULS } \quad \mathrm{C}_{\mathrm{d}}\left(\mathrm{T}_{1}\right)_{\mathrm{uls}}
$$$$
\mathrm{C}_{\mathrm{d}}\left(\mathrm{T}_{1}\right)_{\mathrm{uls}}
$$$$
(\mathrm{Z} / 20+0.02) \mathrm{R}
$$

SLS1 $\quad C_{d}\left(T_{2}\right)_{\text {sls1 }}$

\section{Horiz. Design EQ Forces:}

Nominally ductile structure:

ULS - To avoid collapse

$\therefore$ For support

$E_{\mathrm{u}}=\mathrm{V}_{\mathrm{uls}}$

$\mathrm{E}_{\mathrm{u}}$
$\mathrm{V}_{\mathrm{uls}}$

$0.84 \mathrm{~W}_{\mathrm{t}}$

$0.84 \mathrm{~W}_{\mathrm{t}}$

$7.7 \mathrm{kN}$

SLS1 - To sustain no damage

$\mathrm{E}_{\mathrm{sls} 1}=\mathrm{V}_{\mathrm{sls} 1}$

$0.31 \mathrm{~W}_{\mathrm{t}}$

Limited ductility structure:

ULS - To avoid collapse

$\therefore$ For support

$\mathrm{E}_{\mathrm{u}}=\mathrm{V}_{\mathrm{uls}}$

$0.29 \mathrm{~W}_{\mathrm{t}}$

$\mathrm{E}_{\mathrm{u}}$

$0.60 \mathrm{~W}_{\mathrm{t}}$

$\mathrm{V}_{\text {uls }}$

$5.5 \mathrm{kN}$

Nominally ductile structure force model

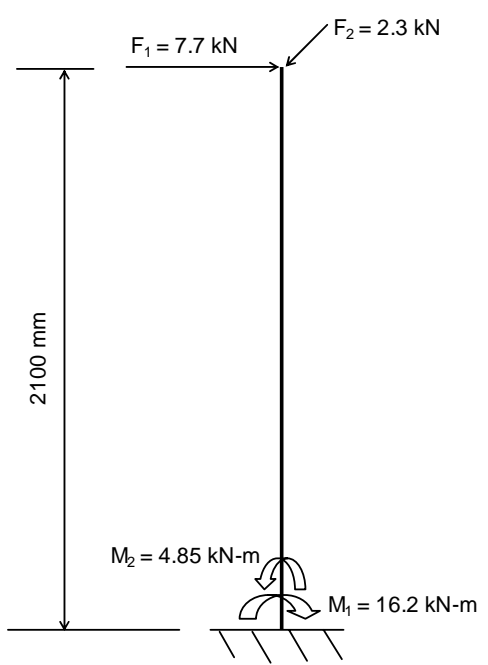

Eqn 3.1(1)

$\mathrm{C}\left(\mathrm{T}_{1}\right)=\mathrm{C}_{\mathrm{h}}(\mathrm{T}) \mathrm{R} \mathrm{Z} \mathrm{N}(\mathrm{T}, \mathrm{D})$

$\mathrm{C}\left(\mathrm{T}_{1}\right)_{\mathrm{uls}}=3.0 * 0.75 * 0.39 * 1.0$

$\mathrm{C}\left(\mathrm{T}_{2}\right)_{\mathrm{sls} 1}=3.0 * 0.25 * 0.39 * 1.0$

Eqn 5.2(1)

$\mathrm{C}_{\mathrm{d}}\left(\mathrm{T}_{1}\right)_{\mathrm{uls}}=\mathrm{C}\left(\mathrm{T}_{1}\right) * \mathrm{~S}_{\mathrm{p}} / \mathrm{k}_{\mu}$

$\mathrm{C}_{\mathrm{d}}\left(\mathrm{T}_{1}\right)_{\mathrm{uls}}=0.878 * 0.925 / 1.14$

$\therefore \mathrm{C}_{\mathrm{d}}\left(\mathrm{T}_{1}\right)_{\mathrm{uls}}=0.71$

$\mathrm{C}_{\mathrm{d}}\left(\mathrm{T}_{1}\right)_{\mathrm{sls} 2}=0.878 * 0.7 / 2.14$

$\mathrm{C}_{\mathrm{d}}\left(\mathrm{T}_{2}\right)_{\mathrm{sls} 1}=0.293 * 0.7 / 1.0$
$=\mathrm{C}_{\mathrm{d}}\left(\mathrm{T}_{1}\right)_{\mathrm{uls}} * \mathrm{C}_{\mathrm{f}}(3) * \mathrm{~W}_{\mathrm{t}}$

O.K. AS/NZS 1200 Appendix I min. value $=0.60$.

Apply in two horizontal directions concurrently $-7.7 \&$ $0.3 * 7.7 \mathrm{kN}$.

Check if any piping guides, line stops or anchor forces apply greater total horizontal force than $7.7 \mathrm{kN}$. If not: $150 \mathrm{UC} 30$ Grade $300+\mathrm{OK}$, load capacity ratio $=0.23$.

$=\mathrm{C}_{\mathrm{d}}\left(\mathrm{T}_{2}\right)_{\mathrm{sls} 1} * \mathrm{C}_{\mathrm{f}}(1) * \mathrm{~W}_{\mathrm{t}}$

$=\mathrm{C}_{\mathrm{d}}\left(\mathrm{T}_{1}\right)_{\mathrm{uls}} * \mathrm{C}_{\mathrm{f}}(5) * \mathrm{~W}_{\mathrm{t}}$

$\underline{\text { Too low AS/NZS } 1200 \text { Appendix I min. value }=0.60}$.

Apply in two horizontal directions separately.

Check if any piping guides, line stops or anchor forces apply greater total horizontal force than $5.5 \mathrm{kN}$. If not: $150 \mathrm{UC} 30$ Grade $300+$ OK, load capacity ratio $=0.16$.

Foundation and support's HD bolts to be designed for the minimum of the over-strength of collapse mechanism or the elastic level earthquake 
Table B5 -Equivalent Static Earthquake Coefficients Calculation for a Vertical Cantilever Pipe Support and Supported Piping

\section{Description}

Horiz. Elastic Level EQ Forces on foundation and HD bolts:

Nominally ductile structure: NZS 3404 Clause 12.9.1.2.2 (4) (b) Clauses 4.4.1 \& 4.4.2

Clause 5.2.1.1

Unscaled ULS Design Action

ULS - To avoid premature nonductile failure

Limited ductility structure NZS 3404 Clause 12.9 .1 .22 (4) (b)

Clause 4.4.1

Clause 4.4.2

Clause 5.2.1.1

.

Unscaled ULS Design Actions: HD bolts \& foundation Foundation stability

ULS - To avoid premature nonductile failure of HD bolts and reinforced concrete foundation

ULS - To avoid sliding or overturning of the foundation
Parameter

Value

\section{Consequence}

\section{$C_{h}\left(T_{1}\right)$}

3.0

$\mu$

$\mathrm{S}_{\mathrm{p}}$

1.0

1.0

1.0

$\mathrm{C}_{\mathrm{f}}(2)$

$\mathrm{C}\left(\mathrm{T}_{1}\right)$

$\mathrm{C}_{\mathrm{d}}\left(\mathrm{T}_{1}\right)^{\mathrm{o}}{ }_{\mathrm{uls}}$

1.32

0.878

0.878

$E_{\max }=V^{o}{ }_{u l s}$

$1.16 \mathrm{~W}_{\mathrm{t}}$

\section{$\mu$}

$\mathrm{S}_{\mathrm{p}}$

$\mathrm{S}_{\mathrm{p}}$

$\mathrm{k}_{\mu}$

$\mathrm{C}_{\mathrm{f}}(2)$

$\mathrm{C}\left(\mathrm{T}_{1}\right)$

$\mathrm{C}_{\mathrm{d}}\left(\mathrm{T}_{1}\right)^{\mathrm{o}}{ }_{\mathrm{uls}}$

$\mathrm{C}_{\mathrm{d}}\left(\mathrm{T}_{1}\right)^{\mathrm{o}}{ }_{\text {ot }}$

$\mathrm{E}_{\max }=\mathrm{V}_{\text {uls }}^{\mathrm{o}}$

$\mathrm{E}_{\max }=\mathrm{V}_{\mathrm{ot}}^{\mathrm{o}}$

$0.96 \mathrm{~W}_{\mathrm{t}}$

From above

1.25

1.0

0.925

1.21

1.32

0.878

0.668

0.723

$0.88 \mathrm{~W}_{\mathrm{t}}$ response.
Can be used for design of HD bolts and foundation plus stability check on foundation.

Damping $=2 \%$ of critical

$\mathrm{C}\left(\mathrm{T}_{1}\right)=3.0 * 0.75 * 0.39 * 1.0$

$\mathrm{C}_{\mathrm{d}}\left(\mathrm{T}_{1}\right)=0.878 * 1.0 / 1.0$

$=\mathrm{C}_{\mathrm{d}}\left(\mathrm{T}_{1}\right) * \mathrm{C}_{\mathrm{f}}(2) * \mathrm{~W}_{\mathrm{t}}$

\section{$\underline{\text { O.K. AS/NZS } 1200 \text { Appendix I min. value }=0.60 .}$}

Used for stability check on foundation.

Used for design of HD bolts and foundation

Damping $=2 \%$ of critical as wanting maximum elastic

$\mathrm{C}\left(\mathrm{T}_{1}\right)=3.0 * 0.75 * 0.39 * 1.0$

$\mathrm{C}_{\mathrm{d}}\left(\mathrm{T}_{1}\right)^{\mathrm{o}}{ }_{\text {uls }}=0.878 * 0.925 / 1.21$

$\mathrm{C}_{\mathrm{d}}\left(\mathrm{T}_{1}\right)^{\mathrm{o}}{ }_{\text {ot }}=0.878 * 1.0 / 1.21$

$=\mathrm{C}_{\mathrm{d}}\left(\mathrm{T}_{1}\right)^{\mathrm{o}}{ }_{\mathrm{uls}} * \mathrm{C}_{\mathrm{f}}(2) * \mathrm{~W}_{\mathrm{t}}$

O.K. AS/NZS 1200 Appendix I min. value $=\mathbf{0 . 6 0}$.

\section{Limited ductily structure - foundation} stability check force model

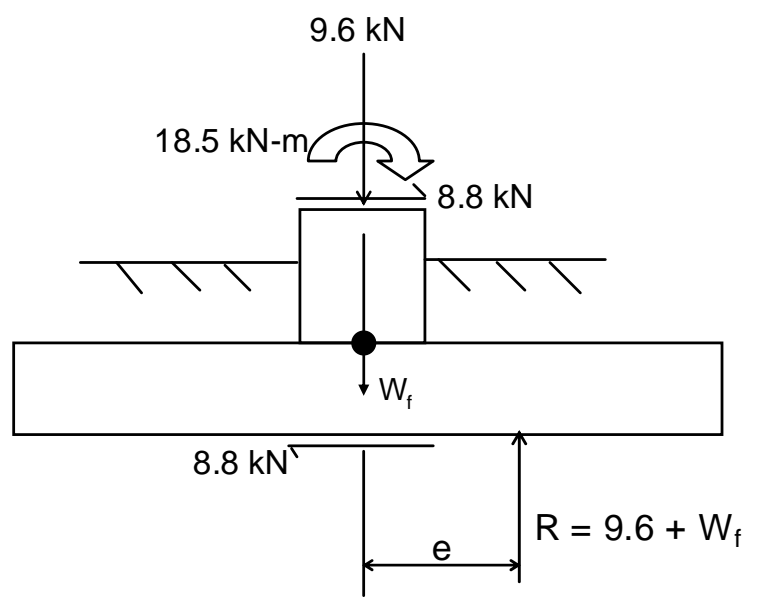


Table B5 -Equivalent Static Earthquake Coefficients Calculation for a Vertical Cantilever Pipe Support and Supported Piping

\section{Description}

\section{Determine inertia forces on}

\section{piping for pipe stress analysis:}

Level of allowable deformity

Weight of components:

$$
\begin{aligned}
& \text { Weight of structure } \\
& \text { Weight of piping }
\end{aligned}
$$

\section{Parameter}

\section{$\underline{\text { Value }}$}

Medium

$\mathrm{W}_{\mathrm{s}}$

$\mathrm{W}_{\mathrm{p}}$

$\mathrm{h}_{\mathrm{n}}$

Overall Height:

Horizontal Fundamental periods:

Support including piping

Piping $T_{\mathrm{p}}$

Vertical Fundamental periods:

$$
\text { Support } T_{\mathrm{v} 1}
$$

1.12

Table $3.1 \quad \mathrm{C}_{\mathrm{h}}(0)$

$\mathrm{C}_{\mathrm{h}}\left(\mathrm{T}_{\mathrm{v}}\right)$

1.31

Displacement Ductility Factors:

$$
\text { ULS } \mu_{\mathrm{p}}
$$$$
\text { SLS1 } \mu_{\mathrm{p}}
$$

Risk Factor for Parts:

ULS $R_{\mathrm{p}}$

SLS1 $R_{\mathrm{p}}$

Parts Response Factors:

$\begin{aligned} \text { ULS } & C_{\mathrm{ph}} \\ \text { SLS1 } & C_{\mathrm{ph}} \\ & \\ \text { ULS } & C_{\mathrm{pv}} \\ \text { SLS1 } & C_{\mathrm{pv}}\end{aligned}$

System Damping Factors:

ULS $\quad C_{\mathrm{f}}(3)$

SLS1 $\mathrm{C}_{\mathrm{f}}(1)$

1.18

1.53

Part Category:

\section{Table 8.1 ULS}

SLS1

Floor Spectral Shape Factor:

Clause $8.4 \quad C_{\mathrm{i}}\left(T_{\mathrm{p}}\right)$

Floor Height Coefficients:

$$
\text { Support } \mathrm{C}_{\mathrm{Hi}}
$$

\section{Horizontal Forces on Part:}

5\% Damped Elastic spectrum @ T $=0 \mathrm{sec}$ :

$$
\begin{array}{rr}
\text { ULS } & C(0) \\
\text { SLS1 } & C(0)
\end{array}
$$

Spectral Ordinate of the Part:

$$
\begin{aligned}
\text { ULS } & C_{\mathrm{p}}\left(T_{\mathrm{p}}\right) \\
\text { SLS1 } & C_{\mathrm{p}}\left(T_{\mathrm{p}}\right)
\end{aligned}
$$

$7 \mathrm{kN}$

\section{Consequence}

Flange jointed but with tolerance for leaks after an event, $\therefore \mu_{\mathrm{p}}=1.25$ for ULS

From above

$1.7 \mathrm{kN}<0.2 * 9.2 \mathrm{kN} \therefore$ can use Section 8

$0.25 \mathrm{secs}$

$0.20 \mathrm{secs}$

From above for ULS

From above for SLS1

From pipe stress engineer

From above for ULS and SLS1

Site Subsoil Class $=\mathrm{D} \& \mathrm{~T}=0.0$ secs

Site Subsoil Class $=D \& T_{v}=0.01$ secs

Clause 8.5

Table C8.2

Table 8.1

Table 8.2 and Clause 8.6

For horizontal forces

For vertical forces

Chosen values:

Damping $=3 \%$ of critical

Damping $=1 \%$ of critical

High pressure system representing danger to those working within plant. $R_{\mathrm{pu}}=1.0$

$R_{\mathrm{psls} 1}=1.0$

$T_{\mathrm{p}}<0.75 \mathrm{secs}$

Eqns 8.3(1), 8.3(2) and 8.3(3)

As $h_{n}<12$ m, Eqn 8.3(1) applies.

$\mathrm{C}(0)=\mathrm{C}_{\mathrm{h}}(0) \mathrm{R} Z \mathrm{Z}(0, \mathrm{D})$

$C(0)=1.12 * 0.75 * 0.39 * 1.0$

$C(0)=1.12 * 0.25 * 0.39 * 1.0$

$C_{\mathrm{p}}\left(T_{\mathrm{p}}\right)=C(0) * C_{\mathrm{Hi}} * C_{\mathrm{i}}\left(T_{\mathrm{p}}\right)-$ Eqn 8.2(1)

$C_{\mathrm{p}}\left(T_{\mathrm{p}}\right)=0.328 * 1.4 * 2.0$

$C_{\mathrm{p}}\left(T_{\mathrm{p}}\right)=0.109 * 1.4 * 2.0$ 


\section{Table B5 -Equivalent Static Earthquake Coefficients Calculation for a Vertical Cantilever Pipe Support and Supported Piping \\ Description \\ Value Consequence}

Horizontal Design EQ Actions:

ULS - No collapse

WSD - No loss of contents

$$
\mathrm{E}_{\mathrm{u}}=F_{\mathrm{ph}}
$$

$\mathrm{E}_{\mathrm{wsd}}=0.8 \mathrm{E}_{\mathrm{u}}$

$\therefore \quad \mathrm{E}_{\mathrm{wsd}}$

SLS1 - To sustain no damage

$\mathrm{E}_{\mathrm{s}}=F_{\mathrm{ph}}$

$0.74 \mathrm{~W}$

$0.47 \mathrm{~W}_{\mathrm{p}}$

WSD
$F_{\mathrm{ph}}=C_{\mathrm{p}}\left(T_{\mathrm{p}}\right) * C_{\mathrm{ph}} * R_{\mathrm{p}} * C_{\mathrm{f}}(\xi) * W_{\mathrm{p}}-$ Eqn $8.5(1)$

$F_{\mathrm{ph}}=0.92 * 0.85 * 1.0 * 1.18 * W_{\mathrm{p}}$

$=0.8 * 0.92+$ possible over-stress allowance of $1 / 3$

O.K. as AS/NZS 1200 Appendix I min. value $=0.60$.

Plus possible over-stress allowance $=1 / 3$

$F_{\mathrm{ph}}=0.306 * 1.0 * 1.0 * 1.53 * \mathrm{~W}_{\mathrm{p}}$

Piping system to be analysed for:

WSD case of $0.74 \mathrm{~g}$ in two principal directions being analysed separately.

Any over-stress allowance $(=1 / 3)$ may mean that the SLS1 case governs for horizontal loads.

Internal forces and moments $=\mathrm{M}_{\mathrm{iux}} \& \mathrm{M}_{\text {tuy }}$
SLS1 case of $0.47 \mathrm{~g}$ in two principal directions being analysed separately. Over-stress allowance $=1.0$. Internal forces and moments $=M_{\text {is } 1 x} \& M_{\text {isly }}$

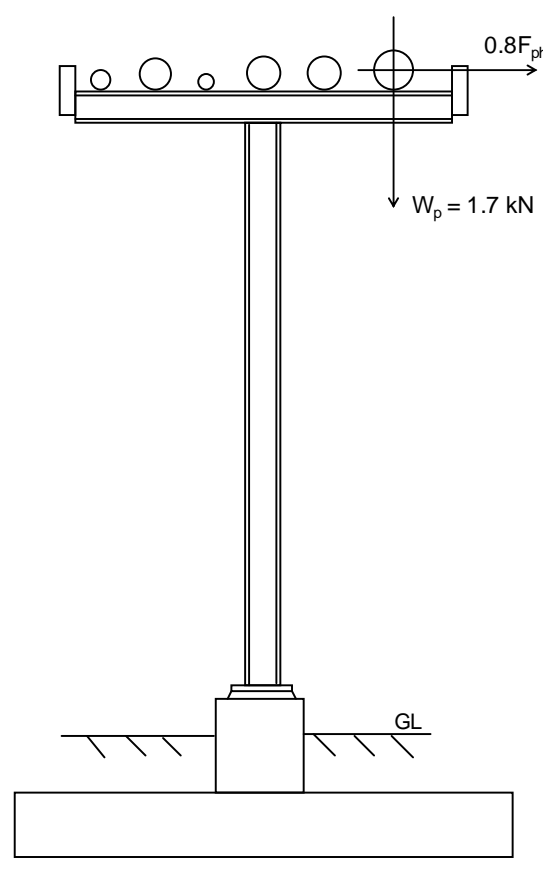

Horiz Design Actions due to EQ

\section{deflections:}

ULS deflections at pipe support $\quad \delta_{\text {i esa }}$

$1 \mathrm{~mm}$

Seismic deflections small and within tolerances for pipe guides. Likely displacement induced actions from this support are minimal.

Piping system analysed for ULS deflection case with the system's imposed deflections in two principal directions analysed separately.

Internal forces and moments $=\mathrm{M}_{\delta \mathrm{ux}} \& \mathrm{M}_{\delta \mathrm{uy}}$

SLS1 deflections at pipe support

$\delta_{\text {i esa }}$

$0 \mathrm{~mm}$

Minimal deflections for SLS1 case so ignore SAM actions for SLS1 case

Piping Design Horizontal Actions

due to EQ acting on piping

WSD:

X direction $\mathrm{M}_{\text {hux }}$

$\mathrm{Y}$ direction $\mathrm{M}_{\text {huy }}$
$\left(\mathrm{M}_{\mathrm{iux}}{ }^{2}+\mathrm{M}_{\delta \mathrm{ux}}{ }^{2}\right)^{0.5}$

$\left(\mathrm{M}_{\text {iuy }}{ }^{2}+\mathrm{M}_{\text {duy }}{ }^{2}\right)^{0.5}$ 
Table B5 -Equivalent Static Earthquake Coefficients Calculation for a Vertical Cantilever Pipe Support and Supported Piping

\section{Description}

\section{SLS1:}

$\begin{array}{lll}\text { X direction } & \mathrm{M}_{\mathrm{hslx}} & \mathrm{M}_{\text {islx }} \\ \mathrm{Y} \text { direction } & \mathrm{M}_{\mathrm{hs} 1 \mathrm{y}} & \mathrm{M}_{\text {isly }}\end{array}$

\section{Vertical Forces on Part:}

5\% Damped Elastic spectrum @ T

$=\mathrm{T}_{\mathrm{v} 1}$ sec:

$\begin{array}{rll}\text { ULS } & \mathrm{C}_{\mathrm{v}}\left(\mathrm{T}_{\mathrm{v}}\right) & 0.268 \\ \text { SLS1 } & \mathrm{C}_{\mathrm{v}}\left(\mathrm{T}_{\mathrm{v}}\right) & 0.089 \\ & & \\ \text { ULS } & \mathrm{C}_{\mathrm{vd}} & 0.268 \\ \text { SLS1 } & \mathrm{C}_{\mathrm{vd}} & 0.089\end{array}$

\section{Vertical Design EQ Forces:}

ULS - No collapse WSD - No loss of contents

SLS1 - To sustain no damage

$\mathrm{E}_{\mathrm{s}}=\mathrm{F}_{\mathrm{pv}}$

$\mathrm{E}_{\mathrm{u}}=\mathrm{F}_{\mathrm{pv}}$

$\mathrm{E}_{\mathrm{wsd}}=0.8 \mathrm{E}_{\mathrm{u}}$

$0.27 W_{\mathrm{p}}$

$0.21 W_{\mathrm{p}}$

$0.09 W_{\mathrm{p}}$

\section{Piping Total Design Actions due}

\section{to EQ \\ WSD:}

SLS1:

$\begin{array}{lll}\text { X direction } & \mathrm{M}_{\mathrm{xu}} & \mathrm{M}_{\mathrm{hux}}+\mathrm{M}_{\mathrm{uv}} \\ \text { Y direction } & \mathrm{M}_{\mathrm{yu}} & \mathrm{M}_{\mathrm{huy}}+\mathrm{M}_{\mathrm{uv}} \\ & & \\ \text { X direction } & \mathrm{M}_{\mathrm{x} 1} & \mathrm{M}_{\mathrm{hs} 1 \mathrm{x}}+\mathrm{M}_{\mathrm{s} 1 \mathrm{v}} \\ \text { Y direction } & \mathrm{M}_{\mathrm{ys} 1} & \mathrm{M}_{\mathrm{hs} 1 \mathrm{y}}+\mathrm{M}_{\mathrm{s} 1 \mathrm{v}}\end{array}$

$\mathrm{C}_{\mathrm{v}}\left(\mathrm{T}_{\mathrm{v} 1}\right)=0.7 \mathrm{C}_{\mathrm{h}}\left(\mathrm{T}_{\mathrm{v}}\right) \mathrm{R} \mathrm{Z} \mathrm{N}\left(\mathrm{T}_{\mathrm{v}}, \mathrm{D}\right)-$ Eqns 3.1(1) and $3.2(1)$

$\mathrm{C}_{\mathrm{v}}\left(\mathrm{T}_{\mathrm{v}}\right)=0.7 * 1.31 * 0.75 * 0.39 * 1.0$

$\mathrm{C}_{\mathrm{v}}\left(\mathrm{T}_{\mathrm{v}}\right)=0.7 * 1.31 * 0.25 * 0.39 * 1.0$

Eqn 5.4(2)

$\mathrm{F}_{\mathrm{pv}}=C_{\mathrm{vd}} * C_{\mathrm{pv}} * R_{\mathrm{p}} * W_{\mathrm{p}}-$ Eqn $8.5(2)$

$\mathrm{F}_{\mathrm{pv}}=0.268 * 1.0 * 1.0 * W_{\mathrm{p}}$

$=0.8 * 0.268+$ possible over-stress allowance of $1 / 3$ WSD case of $0.21 \mathrm{~g}$ in vertical direction. Possible overstress allowance $=1 / 3$.

Internal forces and moments $=\mathrm{M}_{\mathrm{uv}}$

$\mathrm{F}_{\mathrm{pv}}=0.089 * 1.0 * 1.0 * \mathrm{~W}_{\mathrm{p}}$

SLS1 case of $0.09 \mathrm{~g}$ in vertical direction. No over-stress allowance.

Internal forces and moments $=\mathrm{M}_{\mathrm{s} 1 \mathrm{v}}$

These earthquake actions need to be combined with normal operating pressure and temperature conditions for pipe stress checking. 